

UNIVERSIDAD AUTÓNOMA METROPOLITANA

Maestría en Estudios Organizacionales

División de Ciencias Sociales y Humanidades

Universidad Autónoma Metropolitana

Unidad Iztapalapa

\title{
AMBIGÜEDAD ORGANIZATIVA Y FLOJO ACOPLAMIENTO EN UNA ONG. EL CASO DE AIESEC COMITÉ UNAM
}

Tesis para obtener el grado de Maestra en Estudios Organizacionales

Presentada por: Areli Isabel Martínez Hernández

Director: Dr. Ayuzabet de la Rosa Alburquerque

2013 


\section{Índice}

Introducción

CAPITULO 1: La Organización No Gubernamental desde la perspectiva organizacional.

1. Las organizaciones como objeto de estudio en el contexto de los

Estudios Organizacionales.

1.2La organización no gubernamental: Algunas aproximaciones a su emergencia.

1.3 La sociedad y la Globalización como contexto de emergencia de la organización no gubernamental.

1.4 Sobre las nociones de Organización de la Sociedad Civil y Organización No Gubermanental.

1.5 La organización no gubernamental: una posible caracterización y su rol

1.6 La organización no gubernamental: una primera aproximación desde la perspectiva organizacional

Capítulo 2: Una aproximación a las Teorías de ambigüedad organizativa.

2.1 Antecedentes teóricos de la Teoría de la Ambigüedad Organizativa

2.2 Supuestos básicos de la Teoría de la Ambigüedad Organizativa e incertidumbre.

2.3 Supuestos básicos de Anarquías organizadas.

2.4 Sobre la noción de Sistemas Flojamente Acoplados.

2.5 Sobre la noción de Garbage Can Model. (Modelo de Cesto de Basura).

2.6 Aspectos metodológicos a considerar durante el análisis de las Teorias de Ambigüedad Organizativa.

Capitulo 3. Metodología de la Investigación. El acercamiento al estudio de caso.

3.1 ¿Que es investigar?

58

3.2 El Estudio de caso como estrategia en la investigación.

3.3 La metodología cualitativa como esquema de investigación.

3.4 De las herramientas de investigación.

3.5 El proceso de investigación. Mapeo de la organización-caso de estudio. 
Capitulo 4: Una ONG flojamente acoplada. El caso de AISEC Comité UNAM

4.1 ¿Que es AIESEC Internacional? $\quad 70$

4.2 Orígenes y desarrollo de AIESEC $\quad 74$

4.3 El desarrollo profesional de AIESEC $\quad 76$

4.4 AIESEC México 81

4.5 Estructura Organizacional de AIESEC México 82

4.6 Programas de AIESEC México 84

4.7 Eventos de AIESEC México 85

4.8 AIESEC México. El Comité UNAM 85

4.9 Comprendiendo la problemática del comité UNAM 95

4.10 Factores de la problemática 102

4.11 El flojo acoplamiento en comité UNAM. Una aproximación 112

4.12 La ambigüedad en comité UNAM 119

4.13 Conclusiones 121

Referencias bibliográficas 128

Anexo 1. Listado de preguntas 131

Anexo 2. Directorio AIESEC 132

Anexo 3. Recorrido histórico en imágenes 136

Anexo 4: Análisis estructural de Comité UNAM 139

Anexo 5. Graficas de resultados de Comité UNAM. 


\section{Agradecimientos.}

Reconocer que todo esto es el reflejo de mucho esfuerzo y dedicación es lo que se viene a la mente, agradecer la oportunidad que se me brindo para pertenecer a esta generación de maestría, por la confianza en mi de los profesores; ya que se me permitió vivir diversas experiencias en todos los sentidos. Quiero decir gracias a mi esposo Luis Felipe Tovar por sus palabras de aliento, su compresión por el tiempo que le robe, su paciencia, su amor por compartir cada una de mis felicidades y mis tristezas, ya que dicha estancia y paso por la maestría hubiera sido diferente sin su apoyo, se que el amor construye y nos motiva en muchos aspectos ya que es pilar de casi todo lo que hacemos, por que èl es parte de todo esto, fue y es mi inspiración en lo que hago.

Al mismo tiempo agradecer nuevamente a mis padres por apoyarme en cada paso que he dado en mi vida, y por motivarme a ser mejor persona cada dia, se que este paso que doy para ellos es un logro; a mi hermano que desde donde se encuentra, se que está muy orgulloso de mi, por que el compartía este sueño por mi y por el también, le comparto mi felicidad y la emoción de llegar hasta aquí y se que esta tan feliz como yo.

A mis compañeros de clase con los cuales también pude construir una amistad. Agradecer a Regina Guerrero de AIESEC México Comité UNAM por su apoyo invaluable, ya que sin ella esta tesis no hubiera sido posible y a todos aquellos que aparecen dentro de ella.

Por supuesto al Dr. Ayuzabet de la Rosa por su orientación y apoyo en la construcción de esta tesis, por ser eje en la creación y materialización de esta idea, al Dr.Oscar Lozano por su apoyo desde el comienzo de este camino y confiar en mi, a la Dra. Mazzoti por aceptar el compromiso y guiarme, a la Dra. Diana Caldera y al Dr. Germán Vargas y sobre todo a Conacyt por el apoyo institucional siempre oportuno. 


\section{Introducción.}

Irremediablemente en un constructo como la organización pasamos gran parte de nuestra vida, llámese escuela, trabajo, clubes, y como objeto de estudio resulta relevante a fin de comprender nuestra relación con las organizaciones de cualquier tipo. Debido a que las organizaciones se encuentran en la mayoría de las esferas de nuestra vida se hace necesario acercarnos al estudio de las mismas, ya que la sociedad moderna es modelada por organizaciones que generan tendencias que permean todos los grupos humanos.

Recordando el legado de Etzioni (1979), nacemos en organizaciones, nos educamos en ellas, nos desarrollamos en ellas e inevitablemente morimos en ellas. Las organizaciones son unidades sociales construidas y reconstruidas de forma deliberada para buscar metas específicas tales como corporaciones, ejércitos, iglesias, prisiones, lo que da cuenta de su diversidad pero simultáneamente de su complejidad por lo que es necesario reorientar nuestro pensamiento hacia su reflexión y comprensión y abordarlas desde un marco teórico que nos permita ver en realidad como funcionan. En lo que se refiere al marco teórico es preciso y pertinente abordarla desde un constructo que nos permita identificar su evolución, su importancia y su emergencia, pero sobre todo reconocer de antemano su complejidad.

La Teoría de la Organización se ha venido nutriendo apartir de lo que se conoce como Administración Científica, Relaciones Humanas, Burocracia, Comportamiento, Contingencia y Nuevas Relaciones Humanas, lo que ha pasado de una visión tradicional de las organizaciones hacia una visión más moderna de ellas en aras de seguir construyendo el conocimiento inacabado sobre la organización.

Al mismo tiempo es natural que el conocimiento se transforme; la evolución del marco teórico que explica las organizaciones refiriéndose a lo que conocemos como la Teoría de la Organización como marco de teórico esencial, sufre un cambio, una ruptura, y da paso a lo que hoy conocemos como Estudios Organizacionales (EO), donde las organizaciones como objeto de estudio por excelencia ya no se ven como un ente estable e inamovible. Dicho paradigma se refiere a un constructo organizacional en constante cambio para y con el ambiente que le rodea y su estudio se orienta a pensar a las 
organizaciones como imperfectas, complejas e inmersas en un ambiente turbulento y de incertidumbre.

Sin embargo el estudio de las organizaciones se ha orientado a estudiar aspectos específicos como la cultura, el poder, la estructura, la toma de decisiones, pero a su vez es necesario revolucionar dicho marco teórico y trasladarse a pensar en nuevas formas de organización que responden a otros fines por lo menos en su esencia, ya que hasta el momento la literatura sobre ese tipo de organizaciones es incipiente y es necesario nutrir la literatura y los marcos de estudio y orientarse a aspectos relacionados con la solidaridad, lo civil, lo no lucrativo, ya que la emergencia de formas de organización que responden a dichos aspectos son las llamadas Organizaciones de la Sociedad Civil (OSC). Es necesario reconocer su presencia en amplios terrenos de la vida social, política y económica de muchos países desarrollados y en vías de desarrollo, ya que se han desarrollado tanto en un ambiente local y a su vez global.

El estudio de la OSC es pertinente debido a que como una nueva forma de organización ha tenido y tiene un gran impacto en distintas esferas de la sociedad. Su emergencia ha tomado forma y fuerza, y a través del marco de los Estudios Organizacionales será posible avizorar aspectos fundamentales de su creación, y de su auge cada vez más presente y constante. La OSC puede ser visualizada como un instrumento de acción social, pero lo que atañe a nuestra disciplina es la relación bilateral entre la organización y la sociedad y como la organización marca pautas y patrones que resultan relevantes y pertinentes estudiar. Es bajo la mirada de los EO que se presume la posibilidad de identificar su operación, su estructura y su impacto en la sociedad.

Como forma de organización la OSC se engendra en distintos campos, ya sea el sector indígena, el popular, el campesino, entre otros, la cual cuenta con una capacidad de autogestión, marcos técnico-operativos propios, administración de recursos en la búsqueda de optimizar recursos ante necesidades ilimitadas.

En el seno de la sociedad la OSC ha adquirido en los últimos años mayor presencia e injerencia en la vida social, se han orientado hacia valores como la solidaridad, la cooperación, el beneficio mutuo, es entonces que a través de la mirada de los EO se pretende analizar sus formas y modelos de operación, para comprender su 
esencia en un entorno tan complejo, en el que han surgido y permanecido, ya que atendien a cuestiones que en su mayoría están fuera del interés de otras disciplinas o que como objeto de estudio no representa el interés que realmente tienen las OSC.

La OSC, como se delimitara posteriormente, se materializa en distintas formas de organización, en un primer acercamiento, el enfoque organizacional trasladado a una Organización No Gubernamental (ONG) como una forma que toma las Organizaciones de la Sociedad Civil, nos permitirá delinear nuestro objeto y marco de estudio; así mismo es una herramienta de detección de especificidades de operación, de la estructura y de problemáticas particulares.

Como objeto de estudio especifico se expone el caso de AIESEC la cual es una organización no gubernamental de presencia internacional encargada de la vinculación de estudiantes con otras universidades o empresas de presencia mundial a través del intercambio estudiantil entre México a otros países y viceversa, o mediante prácticas profesionales que permitan a los estudiantes un cambio de visión en el ámbito laboral y personal.

A partir de un diagnostico inicial como forma de mapeo se pretende conocer las principales actividades de la organización, la formas en como organiza sus actividades y como se coordinan, y a su vez estructuralmente cuál es su situación y problemáticas particulares. Todo ello permitirá orientar la comprensión y el saber inacabado sobre el mundo organizacional.

En un primer momento nos encontramos con delimitar y acercarnos a una definición del objeto de estudio o qué tipo de organización es decir, que define a una ONG, y posteriormente justificar por qué el estudio de este tipo de organizaciones. Lo anterior se resume en que la presencia y la importancia de la ONG, en la actualidad, como fenómeno social y organizacional, se encuentra en constante crecimiento por su relevancia social y por el papel que ha adquirido en la solución a problemas particulares que aquejan a la sociedad. Nos encontramos ante campo de definiciones sumamente variado que atribuye características particulares, las clasificaciones en la literatura van desde la noción de organización sin fines de lucro, del tercer sector, ONG, organización de la sociedad civil, por mencionar algunas. 
Sin embargo aunque el concepto de ONG pareciera que se refiere a un sector de organizaciones que se constituye entorno a problemáticas variadas, es preciso no atender a generalidades, ya que desde su constitución hasta su operación diaria es necesario retomar la noción de ONG para atender a un objeto de estudio que se encuentra en constante construcción.

Como un ejemplo de cómo una ONG se construye nos encontramos con AIESEC que por sus siglas en francés siginifica Association Internationale d’Étudiants en Sciences Économiques et Commerciales (AIESEC).

AIESEC México, una organización internacional no gubernamental que nace después de la Segunda Guerra Mundial en 1948 con la idea realizar proyectos de intercambios a través de prácticas profesionales durante verano entre universidades de Bergen, Noruega, Copenhague, Dinamarca, Helsinki, Turquía y Finlandia. Es así como surge la iniciativa de crear una organización encargada de realizar intercambios en toda Europa y para que su nombre llevara lo "clásico" y "diplomático" de Francia. AIESEC llega oficialmente a México en 1963. En 1965 se funda el comité AIESEC México, que abarca universidades como la Universidad Nacional Autónoma de México, la Universidad Iberoamericana, Universidad La Salle, Universidad Panamericana y el Instituto Politécnico Nacional que se dividen por comités, considerando que éstos están supervisados a su vez por un Comité Nacional el cual rinde cuentas directamente a AIESEC Internacional.

AIESEC México se conforma por 5 comités ubicados en universidades en la zona metropolitana de la Ciudad de México, lo interesante radica en que aunque dichos comités de acuerdo a lineamientos específicos deben de conformarse y operar de forma homogénea y dar resultados competitivos, durante la investigación se evidencio que un comité en particular, el Comité UNAM, opera de forma particular o de forma distinta a la visión de comité que en general tienen los otros comités ubicados en otras universidades, en el sentido de que en cuanto a espacio físico, materiales de oficina y equipo de computo están sumidos en la escasez; a pesar de ello una vez revisadas las estadísticas; dicho comité es de los mas productivos en cuanto a la realización de intercambios estudiantiles, que es la razón de ser de la organización, así mismo cuenta con finanzas mas sanas por que a pesar de ser una ONG, las finanzas es un tema que prevalece. Entonces es pertinente preguntarse ¿Por qué AIESEC-Comité UNAM, es un comité productivo, eficiente y eficaz a pesar de contar con recursos económicos, humanos y tecnológicos escasos, y desarrollar formas de trabajo y de organización distintas a los demás comités? 
La importancia de este estudio radica en lo particular e incipiente de la literatura organizacional sobre la OSC, lo que nos acerca a seguir construyendo un discurso y análisis que den lugar a nuevas investigaciones. En el caso de AIESEC, cabe decir lo interesante; por distintas aristas a través de las cuales podemos analizar la organización, el tema OSC debe seguir construyéndose y analizar nuevas formas de organización, por que bien es cierto, la presencia de la OSC es innegable y en forma particular la ONG sigue conformando pautas de comportamiento en la sociedad que coadyuvan al desarrollo de distintas actividades que cambian la vida de una y varias personas a la vez. 


\section{CAPITULO 1}

\section{La de Organización No Gubernamental desde la perspectiva organizacional}

\section{Introducción.}

Durante este capítulo nos acercaremos a comprender por que la importancia del estudio de las organizaciones actualmente y en futuras investigaciones, la importancia de su estudio como un constructo que día a día modifica y edifica las acciones de los individuos y la sociedad. La importancia de las Organizaciones No Gubernamentales (ONG) tiene un gran impacto hoy en día en amplios campos de la sociedad, ya que como actor social transforma el ámbito local y a su vez internacional dando lugar a nuevas condiciones de vida en pro de una sociedad más justa. Este capitulo tiene por objetivo mostrar la emergencia y desarrollo de la ONG y como a través de la perspectiva organizacional permitirá avizorar no sòlo razon de ser de dichas formas de organización sino sus formas de trabajo y organización de manera integral. 


\section{Las organizaciones como objeto de estudio en el contexto de los Estudios Organizacionales.}

Los Estudios Organizacionales dan pauta a una concepción multidisciplinaria que enriquece ampliamente el desarrollo de este campo de estudio.

Los estudios organizacionales, por lo menos en la construcción de una disciplina en México, ha dado cuenta fiel que en sus raíces están en diversas disciplinas de las ciencias sociales, sin embargo esa diversidad nos sitúa en una atmósfera amplia de perspectivas de estudio donde cada mirada nos ofrece distintas concepciones, alcances, planteamientos que nos dan la posibilidad de palpar o vislumbrar a las organizaciones de distinta forma.

En amplio sentido lo que ofrece a los estudiosos de las organizaciones ésta diversidad de perspectivas es la posibilidad de construir nuestra propia mirada, nuestra propia lente a través de la cual vamos a contribuir en mayor o menor medida al compresión de las organizaciones por lo menos en nuestra realidad mexicana.

La construcción de nuestro propio marco explicativo, a través del cual vislumbraremos las organizaciones es el ápice central, por que a través de el trataremos, guardando distancias, de comprender ese complejo constructo llamado organización. Sin embargo debemos ser cuidadosos por que podemos ver a través de una mirada que no es la nuestra. En este sentido vale la pena mencionar que la complejidad está presente también en la lente, (Naime, 2004: 42), los objetos pueden ser los mismos, pero las miradas diferentes, un cuerpo o un objeto puede tener entonces varias lecturas, algo similar ocurre con las organizaciones, "si quien las observa lo hace a través de otros ojos, la percepción será diferente a la que es en realidad; lo que nos puede encaminar a tener una concepción distinta a la que es realmente, sobre todo enfatizar el cuidado que debemos tener como investigadores al analizar la realidades de la organización a través de la cual se derivan principios y valores que luego se consideran con valor universal".(Naime, 2004: 12). 
Lo organizacional es una amplio espacio donde se interrelacionan distintos elementos que conforman una organización, pero dichos elementos no siempre fueron a primera vista reconocidos, todo parte de un proceso de construcción de un análisis organizacional y la forma de acercarse a las organizaciones ha sido una construcción constante en la búsqueda de respuestas que coadyuven en la compresión de las organizaciones.

El detalle central es ese, como entender mejor a nuestras organizaciones, siendo los estudios organizacionales una constructo de reciente creación en comparación a otros, en la búsqueda de significados, la realidad ha dado cuenta de que hemos sido solo observadores y ejecutantes de recetas, el reto radica en orientarse a una investigación más ambiciosa en términos de herramientas metodologías propias de realidades locales.

El reto en ampliar el marco conceptual y las herramientas metodológicas propias de los estudios organizacionales y abrir paso a una comprensión más certera del fenómeno organizacional.

Bien es cierto, nacemos y morimos dentro una organización, pero simultáneamente se puede cuestionar el hecho de por qué su estudio, que es lo que abre la mirada hacia su comprensión. Si damos por hecho que pasamos sino es que la mayoría de nuestra vida dentro de organizaciones, se hace imperante la necesidad de estudiarla y comprender su impacto en amplias esferas de la sociedad y conocer desde su funcionamiento hasta como se desenvuelven sus miembros.

Su naturaleza se ha estudiado desde otros espacios, en el caso de la sociedad occidental ha sido caracterizada como una sociedad organizacional y su población como hombres de organización. Las naciones modernas utilizan las organizaciones como un instrumento importante en el desarrollo de sus sistemas políticos, económicos, sociales y militares. Estas organizaciones adquieren diversas formas pues representan los sistemas de valores conflictivos y cruciales dentro de una sociedad (Hall, 1996:30).

Hacia una definición certera nos encontramos con una variedad de explicaciones, pero es preciso retomar los clásicos a fin de que se contribuya al conocimiento propio. Conocer el impacto de las organizaciones sobre sus medios y viceversa es crucial, retomemos la definición de Weber (en Hall 1996) a fin de conocer su esencia. Según Weber distingue el grupo corporado de otras formas de organización social. El grupo 
corporado es una relación social cerrada que limita por medio de normas la admisión de sus integrantes siempre y cuando su orden sea implantado por un jefe o cabeza. Esta definición tiene los siguientes puntos de discusión:

- Las organizaciones conllevan relaciones sociales, pues los individuos interactúan dentro de las mismas.

- La organización (grupo corporado) incluye unos sectores de la población y excluye otros (los individuos no están en simple contacto casual). Las organizaciones tienen sus límites.

- La idea de orden, los modelos de interacción no aparecen de manera simple, existe una estructuración de la interacción impuesta por la organización (las organizaciones poseen una jerarquía de autoridad y una repartición del trabajo en la realización de sus funciones). El orden se refuerza con el personal para realizar las tareas.

El concepto de grupo corporado agrega otras consideraciones. En las organizaciones, la interacción es asociativa más que comunal. Otro elemento importante que destaca Weber es que las organizaciones son planeadas para hacer algo, es decir, están encaminadas a un propósito de naturaleza específica (metas).

En el caso de Barnard (en Hall 1996) define a las organizaciones como un sistema de actividades o fuerzas conscientemente coordinadas de dos o más personas. Las organizaciones requieren comunicaciones, deseos de colaboración por parte de sus miembros y un propósito común. Enfatiza el papel del individuo, a diferencia de Weber (hizo énfasis en el sistema), Barnard se ocupa de los miembros del sistema.

A su vez Etzioni y Scott (en Hall, 1996:31) afirman que las organizaciones son unidades sociales deliberadamente construidas para lograr metas. Las organizaciones se caracterizan por división del trabajo, poder y comunicación, que se distribuyen con base a la planificación, presencia de líneas de autoridad para el cumplimiento de las metas y la sustitución del personal.

Ahora bien una vez retomado lo clásico es preciso conceptualizar que es la organización, el cual es nuestro objeto de estudio: "Se define como una colectividad con límites relativamente identificables, con un orden normativo, con escala de autoridad, con 
sistemas de comunicación y coordinación; esta colectividad existe sobre una base relativamente continua en un medio y se ocupa de actividades que se relacionan con una meta" (Hall, 1996:31).

Las organizaciones como actores han establecido un sistema de normas y expectativas para su publico el cual es en si misma la sociedad. Las organizaciones poseen características propias que afectan el comportamiento de los miembros, se puede decir que las características organizacionales deben ser comprendidas para entender el comportamiento humano general.

Considerando que las organizaciones son influidas por su medio ambiente pero ellas también lo influyen, hay un consenso en cuanto a definir que las relaciones entre organizaciones y medio ambiente son vitales, complejas e interdependientes (Barba y Solís, 1996:48).

En particular lo que será el objeto del estudio de esta tesis es pertinente retomar un tipo de clasificación que empate con el tipo de organización estudiada.

El criterio central que se propone para tipificar a las organizaciones de acuerdo a Blau y Scott (en Hall, 1996), es el beneficiario central de las acciones de la organización, es decir, la naturaleza del resultado no es lo que importa sino a quien se beneficia y según ese resultado se identifican ccuatro tipos de organización:

- Asociación de mutuo beneficio

- Organización mercantil

- Organización de servicio

- Organización para el bien común

Es preciso mencionar que la ONG se relaciona directamente con la "organización para el bien común, que es la razón de ser de dichas organizaciones.

\subsection{La organización no gubernamental: Algunas aproximaciones a su emergencia.}


En principio es importante considerar como se han constituido este tipo de organizaciones y cuál ha sido su finalidad, a su vez, reconocer como han evolucionado y cuáles han sido sus contribuciones en el ámbito social.

Hacia la compresión sobre la forma en la que estas organizaciones se conforman se podría considerar en una primera aproximación que para Habermas (en Calvillo et al, 2004) el núcleo de la sociedad civil se encuentra constituido por una trama asociativa que institucionaliza los discursos, dando solución a problemas relativos a cuestiones de interés general en el marco de espacios públicos más o menos organizados. La sociedad civil incluye, según él, una multiplicidad de espacios públicos distintos del sistema político, privado y potencialmente autónomo. La trama asociativa sólo puede conservar su autonomía y su espontaneidad en la medida en que se apoya en un sólido pluralismo de formas de vida, de subculturas y de orientaciones en lo concerniente a creencias.

La importancia radica en que es necesario avizorar las transformaciones que han dado lugar a procesos como la globalización, en un primer momento, sobre todo acercarnos las implicaciones sociales y políticas que implica la emergencia de nuevas condiciones, situaciones, movimientos y relaciones en tiempos de la globalización, que como parte del entramado social debe tener nuestra atención principalmente (Mazzotti y Solís, 2002: 48). Las organizaciones no gubernamentales son un elemento importante puesto que representan un tipo de organización que en ha generado estrategias de sobrevivencia alternas y constituyen una "tercera vía" para asegurar la sobrevivencia del individuo, además del hecho de que su orientación solidifica principios cuya intencionalidad está marcada por modos de desarrollo distintos del que ha marcado el crecimiento y el desarrollo del capitalismo ( Mazzotti y Solís, 2002: 48).

En la actualidad ha sido posible apreciar cierto fenómeno refiriéndose a la emergencia de nuevas forma de organización conformada apartir de la sociedad civil, lo anterior podría explicarse como resultado de la búsqueda de condiciones óptimas para el desarrollo de una sociedad más justa.

Los ejes que conducen las acciones de la sociedad civil, son vastos pero sobre todo heterogéneos, los temas van desde la lucha por una globalización con menos efectos colaterales hasta la protección de los derechos humanos; pero que al paso del tiempo se van conformando nuevos temas y nuevos ejes de acción tanto a un nivel local como internacional. 
Dichas forma de organización como actor social tiene un amplio espectro de acción y reformula en algunas ocasiones el statu quo, sin embargo desde la perspectiva organizacional, marcan un referente como organización misma. Identificar elementos que permitan su análisis no solo como actor, sino identificar elementos de tipo organizacional que conformen el saber inacabado sobre las organizaciones, pero en particular, las de las organizaciones de la sociedad civil (OSC) como una forma alternativa de organización, y la importancia de su estudio radica su impacto y el auge en diversos espacios de la sociedad y a través de la perspectiva organizacional acercarnos a su estudio y a sus saberes.

Han sido evidentes los cambios que consigo ha traído la globalización y su efecto es casi totalizador, distintas esferas son permeadas, desde la esfera cultural hasta la económica que es la que mas perece ante dicho proceso macroeconómico, lo que ha conducido a la participación de formas de organización provenientes de la sociedad civil como actor social en un ámbito local y a su vez internacional.

Los efectos de la globalización permean a distintas esferas del ámbito social, pero no es para todos igual, mientras que para unos representa el camino a la prosperidad, para otros ha encauzado a la pérdida paulatina de prosperidad y oportunidades, marcando desigualdad en varios sentidos.

Aunque uno de los efectos de la globalización sea la creciente interrelación e intercomunicación entre los distintos actores sociales, provocando que su actuar aparezca como una unidad en tiempo casi real a escala planetaria, la forma que adquiere la acción colectiva continúa dependiendo, en gran medida, de los distintos espacios sociales, económicos, culturales y políticos atendiendo que es preciso identificar nuestra propia realidad, la de otros espacios (Calvillo et al, 2004).

Conservando siempre la idea de que las problemáticas no son generales, sino de responden a un tiempo y espacio determinado para responder a problemáticas y saberes particulares. El carácter específico de las problemáticas nos abre la mirada a no generalizar, pero si identificar aspectos que nutran el conocimiento sobre este tipo de organizaciones y sus diferentes aristas atractivas desde la perspectiva organizacional.

Como un primer ejemplo, en México, las condiciones particulares que han propiciado la generación de estas nuevas formas de organización social han tenido que ver 
con factores como el desbordamiento de la pobreza, producto de las políticas económicas de las últimas décadas, y con el efecto derivado de la limitación de las tareas de atención social del Estado (Calvillo et al, 2004).

Ante la retirada del Estado en el desempeño y atención a las políticas sociales, la acción social se presentara como una reacción frente al creciente empobrecimiento y marginación de la población (Calvillo et al, 2004). Es entonces donde los actores sociales enfrentaron una pérdida de sentido de representación de las formas tradicionales de organización política y social, como los partidos políticos y los sindicatos, como otro elementos más que apoyaran la emergencia de nuevas formas de organización de la sociedad civil (Calvillo et al, 2004).

La Sociedad Civil de manera irremediable no queda al margen del fenómeno de la globalización, incluso esta introducida, sin embargo desde ese campo de acción, toma la palabra y se manifiesta en contra del fenómeno, con sus pronunciamientos y acciones organizadas como una forma de oposición a las consecuencias perversas de la globalización, tal como la brecha aun más marcada de entre ricos y pobres, incrementos de la pobreza, aumento de la deuda externa, falta de equidad en las naciones, los costos ambientales o el respeto a los derechos humanos (Charry y Montero, 2004).

Se van construyendo movimientos en pro de la lucha por cumplir las demandas de las sociedad civil, los movimientos tiene presencia mundial, alineándose en una gran cantidad de organizaciones civiles y sus redes, además se nutre de individuos reflexivos con la necesidad de sumarse ante las demandas de justicia social en respuesta a los efectos colaterales de la globalización.

Es importante señalar que la concepción que se refiere a sociedad civil es aun más amplia y las más difundida, existen otras que van acotando espacios e instituciones, y que responden a comportamientos y momentos específicos de la sociedad lo que da cuenta actualmente es que el concepto de sociedad civil está muy lejos de ser homogéneo y es polisémico (Charry y Montero, 2004).

Al margen de la discusión sobre innumerables formas de organización que resultan de procesos macroestructurales como la globalización, reconocer la especificidad y tipos de organización que surgen por esta razón, no es una tarea fácil, dando por hecho el carácter complejo del fenómeno organizacional, donde aparecen nuevas formas de 
organización diferenciándose de las tradicionales las cuales reflejan nuevos proyectos políticos y sociales capaces de enfrentar y resolver los graves problemas de nuestras sociedades en el nuevo milenio.

Dichas formaciones dan claro ejemplo de heterogeneidad en cuanto a objetivos, publico que atienden, tamaño, ubicación por mencionar algunas diferencias. Tal es caso la sociedad civil que se constituye en la esfera política determinante, que como esencia tiene la de valorar la pluralidad y el respeto a las diferencias, culturales, étnicas y religiosas. El caso de la Sociedad Civil representa entonces un modelo que aprecia y respeta la existencia de diferencias expresiones de acción colectiva, tendientes a la articulación y a la representación de los intereses y a su vez valora las agremiaciones, las cooperativas, la acción comunal, las organizaciones no gubernamentales, las fundaciones sin ánimo de lucro que representan apéndices de las empresas lucrativas con responsabilidad social y, en general, toda la gama de entes convergentes en el llamado sector solidario, el célebre tercer sector.

La particularidad de este modelo asociativo radica en que las personas que pertenecen a estos grupos por una parte efectúan el consumo solidario donde suelen manifestar un alto grado de satisfacción cuando participan en él, lo cual se traduce en una experiencia generalizada de gratificación y alegría que proporciona el consumo en tonos de amistad, en comunidad y en familia, explica que prácticamente no exista un agrupamiento humano de cualquier tipo donde no surjan constante o periódicamente iniciativas volcadas a organizar alguna forma de consumo solidario.

Lo cual en esencia configura un ambiente de reciprocidad, ayuda al prójimo, empatía, que equipara en alguna forma la desigualdad económica, política, social y cultural de procesos hegemónicos como la globalización traen como uno de muchos efectos colaterales.

La realidad actual o contemporánea ha dado cuenta que la sociedad civil se ha organizado en torno a la demanda de un cambio sustancial, un cambio que traspase las fronteras del Estado y del mercado. Entonces la sociedad civil de concebirse solo como una nueva forma de organización con demandas claras, se convierte en un nuevo actor que se desempeña tanto en el ámbito local o internacional con la firme idea que fenómenos como la globalización no han tenido el impacto positivo que en el discurso se habían planteado. 
La reflexión entorno a la sociedad civil y su relación con la globalización resulta entonces pertinente y sobre todo relevante, ya que las manifestaciones de la sociedad civil se han dejado ver, tanto en el ámbito local como en el internacional, en lugares como Seattle, Praga, Québec ó Davos; se ha sentido su presencia y se da cuenta que el Tercer Sector se organiza en torno a conjunto de demandas comunes, una de ellas es una pugna y una lucha constante por una globalización más justa, encontrar alternativas para los países en deuda, el deterioro ambiental, la pobreza entre otros.

La realidad de las pugnas muestra entonces una cuestión importante, es viable o posible que pueda coexistir el sistema que impera y una sociedad en busca de mejoras en vías de un desarrollo que le permita por lo menos tener acceso a mejores oportunidades. Una primer reflexión tiene una vía clara, la de fomentar la discusión y la reflexión sobre la forma en que la sociedad civil concibe las distintas problemáticas como las que anteriormente se mencionan y que mecanismo es capaz de crear para subsanar el deterioro de una sociedad claramente desigual.

Lo anterior es una de sus tantas manifestaciones, pero en vías de la comprensión de la configuración de la sociedad civil, es preciso mencionar que unos de los efectos de la globalización es el nacimiento de una sociedad civil globalizada, la cual se hace presente en diversos foros y escenarios internacionales para negociar asuntos como la condonación de la deuda en los países más pobres o la lucha por el respeto a los derechos humanos (Charry y Montero, 2004).

Entonces la sociedad civil emerge desde Canadá hasta otros territorios lejanos, sobre todo que no ha permanecido al margen del proceso y se organiza ante el mundo global de hoy en día, que se caracteriza entre otras cosas, por un dinámico flujo de comercio e inversión, la disminución de las actividades del Estado y las disparidades sociales que trae consigo la globalización misma (Charry y Montero, 2004).

El Estado entonces es afectado directamente, ya que se encuentra con una gran influencia de las políticas internacionales, y como consecuencia una menor participación, lo cual implica una nueva modalidad de funcionamiento del capital ${ }^{1}$ y una tendencia a la reducción de los presupuestos estatales y su impacto en las políticas sociales parece no detenerse; lo que se observa es que sociedad que habita este espacio global en el cual

\footnotetext{
${ }^{1}$ Refiriéndose a una creciente disparidad entre ricos y pobres y no sólo entre los países sino también al interior de las organizaciones.
} 
no tiene gran campo de acción para mejorar la situación prevaleciente (Charry y Montero, 2004).

\subsection{La sociedad civil y la globalización como contexto de emergencia de la ONG}

La emergencia de la ONG transita en distintas posibles explicaciones, por una parte nos podemos encontrar con que la conformación de dichas organizaciones se da en un contexto plagado de inequidad, incertidumbre, desempleo, ausencia de políticas sociales sólidas, falta de respuestas ante las demandas de una sociedad más justa o por lo menos con las mismas oportunidades; la sociedad civil toma el papel de actor y no el de espectador, aunado al adelgazamiento del Estado, es preciso entonces la reacción de la sociedad ante la "no" intervención y cumplimiento de las actividades estatales.

Entonces aristas distintas nos pueden orientar a distintas explicaciones, sin embargo la literatura nos abre aun más la mirada a otra vía, que como un fenómeno permea también otras esferas en la sociedad. La globalización aparece con mayor poder como un fenómeno totalizador que conduce a la homogeneidad, las diferencias y la imperante necesidad de sobrevivir en un ambiente de total turbulencia; su expansión en la cultura, en los patrones económicos, en lo social abre aun más la brecha de desigualdad e incertidumbre social, entonces a través de la conformación de nuevas dinámicas de acción como respuesta ante dicha inequidad se hace presente con la emergencia de la Sociedad Civil como un intermediario de la defensa de los derechos que como sociedad tenemos ante la indiferencia de políticas públicas claras y eficientes.

La globalización es el resultado de una interdependencia siempre más intensa a escala mundial (Segre, 2004:183), y prevalece esa forma ya que no se ha logrado integrar equitativamente en el Norte y en el Sur, en tanto esto es cierto la economía, la política y la cultura están permeadas por la globalización; dichos procesos abren nuevas dinámicas ya que la forma de Estado-nación continua siendo el pilar de la organización; pero al mismo tiempo recibe un ataque simultaneo ya sea por globalización política, económica o cultural.

Considerando que nos encontramos ante una sociedad post-industrial que entraña transformaciones no sólo a nivel individuo sino en sus relaciones con el entorno, se da cuenta que el entorno entonces también ejerce su influencia en el ámbito social que de 
forma simultánea está generando cambios, los cuáles parece ser, no se tiene opción de aceptar.

Globalidad significa:

"la totalidad de relaciones sociales que no están integradas al Estado nacional ni están determinadas ni son determinables a través de éste. Una sociedad mundial se puede comprender como una pluralidad sin unidad y la globalización significa los proceso mediante los cuales los Estados soberanos se imbrican mediante actores transnacionales y sus respectivas probabilidades de poder, orientaciones y entramados varios" (Beck et al, 2008: 65)

El termino Globalización es un término un tanto engañoso pues se refiere ante todo a un interconexión en el plano de la economía y las comunicaciones, mas no conlleva necesariamente en un sentido de comunidad (Lomnitz, 2004:90).

En la actualidad estamos tratando con sistemas complejos de los que los seres humanos y las sociedades somos una pequeña parte de ella, los sistemas simultáneamente se autoorganizan y nuevos sistemas pueden aparecer en cualquier momento, reivindicando sus elementos básicos y buscando mayor poder para sí mismos en el sistema estatal (Lomnitz, 2004:120).

En lo que corresponde al ámbito económico el significado de globalización es aun de mayor proporción, ya que la producción se elabora bajo relaciones de producción capitalistas, lo que aparece como una gran fiesta de diversidad que se desarrolla en el primer mundo integrando culturas, patrones dominantes de gusto, creando nuevas dinámicas que aumentan más aún la brecha entre los países pobre y los ricos (Lomnitz, 2004).

Entonces la sociedad se ve impulsada a generar nuevas formas de conciencia, actuar y de modos de vida (Mazzotti y Solís, 2002: 37); dichas transformaciones organizacionales traen consigo en términos globales y al mismo tiempo efectos negativos que se manifiestan en un creciente desempleo, una alta concentración de la riqueza, un aumento de la pobreza y un proceso de exclusión social y económica de grandes capas de la población, así como graves problemas ecológicos, considerados efectos 
secundarios del desarrollo y el crecimiento económico, que amenazan el equilibrio del ecosistema global y la erosión de los espacios naturales.

El papel del Estado es fundamental, su intervención se encuentra limitada a la ejecución de sus funciones esenciales traducido en un proceso de paulatino adelgazamiento y reducción de sus márgenes de intervención, entonces quedan acciones pendientes y queda un vacío sobre quien se encargará de garantizar condiciones sociales mínimas para la evolución de la sociedad (Mazzotti y Solís, 2002).

La búsqueda de condiciones de vida y un espacio social con igualdad de oportunidades es lo que la sociedad civil reclamará ante un escenario de incertidumbre e intervención estatal disminuida, la sociedad civil se conformará entonces antes ese escenario con estrategias de acción específicas. Se podría partir de una posible causa, si nos referimos a lo que corresponde a la globalización como un efecto totalizador el cual con su espectro, permea a varias esferas de la sociedad.

Como una forma de respuesta a muchos de los efectos negativos de un espacio donde el acceso a mejores oportunidades es limitado, la sociedad civil se ha constituido en un nuevo actor mundial que se la ha ingeniado para crear nuevos formas de organización que se configuran en redes mundiales, como una forma de hacer frente a las condiciones que resultan de las transformaciones que deja la globalización (Mazzotti y Solís, 2002: 38).

La forma de respuesta es creando sus propias organizaciones al margen de los estados nacionales y la empresa privada, lo cual implica la elaboración estrategias especificas como una forma de tener presencia ante organismos nacionales o internacionales, con el objetivo de formular de forma tentativa modelos alternativos de desarrollo ante la desigualdad de oportunidades para los miembros de la sociedad dentro del contexto de la globalización. (Mazzott y Solís, 2002: 39)

La materialización de las demandas se da a través de la conformación de la sociedad civil, la cual se configura en espacios sociales dispersos, con demandas variadas pero con una esencia que es homogénea, la de ser un mediador entre las demandas sociales y las instituciones.

Algunas condiciones como la evolución de las tecnologías de información, la reestructuración de los estados nacionales, tratados comerciales, expansión democrática, 
por mencionar algunos; cooperan con el surgimiento de un nuevo actor mundial: la sociedad civil que según sostiene el Grupo de Lisboa (1996) es portadora de tres funciones:

- Deviene poco a poco en portadora de la conciencia moral del planeta a partir de definirse como vector de ideas y prescripciones de orden moral contenidas en la Declaración de los Derechos Humanos. Aparece pues como reivindicatoria de las aspiraciones y objetivos que se han convertido en demandas universales como condición necesaria para el desarrollo humano, estas demandas sociales mundiales despegan de fuentes concretas de desigualdades e injusticia y adquieren fuerza política y viabilidad social que se consolida en la Conferencia de Río en 1992, en el contexto de la globalización

- También es un escenario diverso y heterogéneo de múltiples formas de soluciones locales y fragmentadas para resolver los problemas, es decir, vehicula las posibilidades reales de los individuos para responder de forma activa a los problemas provocados por el desarrollo.

- Una tercera función esencial que define a la sociedad civil mundial es que representa una oferta política mundial y porta la solución concreta a problemas mundiales (Mazzotti y Solís, 2002: 39).

Bajo ese contexto es donde se engendra un nuevo actor y se va consolidando lo que se denomina Sociedad Civil; justo ese contexto marca pautas de acción de las sociedades civiles nacionales donde las tendencias mundiales marcan las pautas organizacionales locales. (Mazzotti y Solís, 2002)

El término globalización tiene su propio discurso y desde su perspectiva puede abordarse desde 3 maneras:

- A partir de relaciones espaciales que incluyen distancia y tiempo, este entendimiento de la globalización se basa en las uniones o interconexiones entre Estados y sociedades, remarcando los impactos significativos de acciones en lugares diversos y gente lejana. Estas conexiones y acciones pueden incluir, por una parte, las actividades de criminales internacionales y terroristas y, por la otra, las campañas por Internet de Organismos no Gubernamentales (ONG) para prohibir minas terrestres y oponerse al Acuerdo Multilateral de Inversiones (AMI). 
- A partir del proceso mercantil sustentado en los movimientos de comercio y del capital, este proceso, orientado al mercado tiene una impacto global en la cultura, la política, la ideología y las relaciones sociales debido a la intensidad, crecimiento y rapidez de este proceso de integración económica en el mundo y una transferencia de responsabilidad y autoridad del Estado al mercado. Los objetivos son incrementar al máximo el crecimiento económico y las ganancias.

- A partir de un cambio consciente, de un cambio en nuestra percepción de cómo se ve al mundo, este conocimiento global permite una sola mirada mundial de responsabilidad ecológica, cuidado del medio ambiente, activismo en los derechos humanos, empuje para crear normas humanitarias a nivel mundial, creer en la "solidaridad" humana y la esperanza del desarrollo sostenido global, la paz universal y la libertad. (Charry y Montero, 2004)

Entonces haciendo referencia a la propuesta de Mazzotti y Solís (2002) respecto a las finalidades de este tipo de organizaciones que partiendo de que surgen en un contexto globalizado que permea sus acciones y sus fines se encuentran lo siguiente:

Figura 1: Efectos de la globalización en la sociedad.

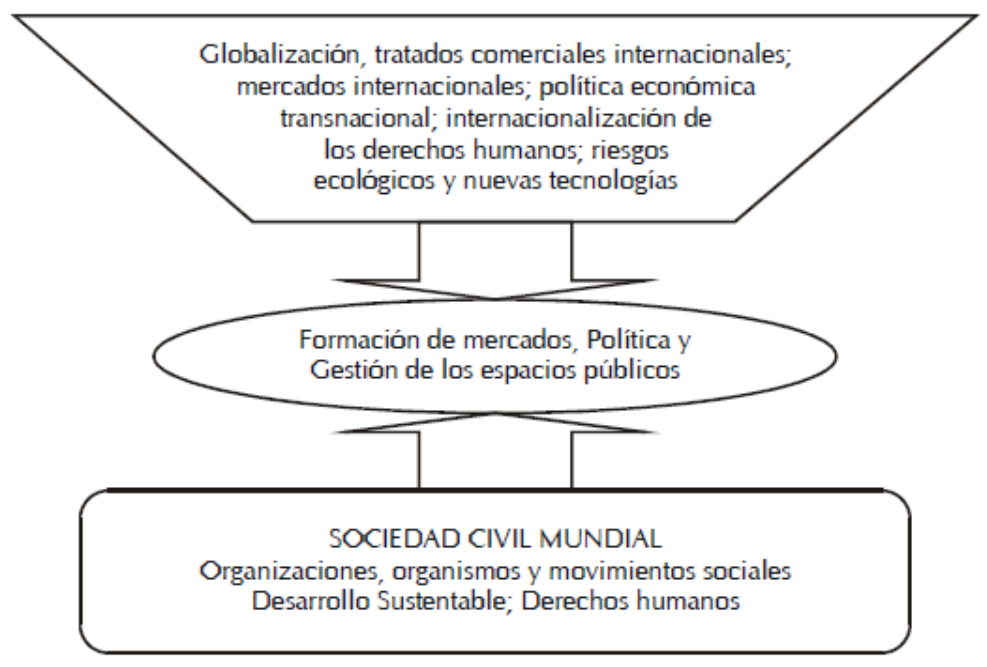

Fuente: Mazzotti y Solís (2002: 42). 
Lo anterior muestra una forma de explicación en la cual se determina la relación Globalización-Sociedad Civil, ya que a la globalización se le puede considerar como un proceso de cambio, pero también como un proceso de mercado orientado a las ganancias y a la sociedad civil como el espacio para la lucha contra procesos macroestructurales como el capitalismo.

El camino hacia la edificación de un espacio de pluralidad y diversidad donde pueda coexistir el sistema imperante y la sociedad civil con demandas claras, es un espacio donde puedan ser consideradas las voces de la sociedad civil donde entre otras muchas de sus demandas está la de adecuar la globalización en función de beneficios compartidos.

La respuesta se encuentra en las asociaciones, entre aquellos sectores de la sociedad civil involucrados en dirigir los problemas de la globalización y las personas en el gobierno encargadas de la política que tienen la obligación o la responsabilidad administrativa de la política pública, en este sentido tanto universidades como comunidades académicas tiene un papel fundamental en la reflexión en torno al tema (Charry y Montero, 2004). La sociedad civil apunta a retos y responsabilidades claras con beneficios compartidos, pero que a su vez necesitan reconfigurarse en torno a realidades y espacios distintos, por mencionar algunos (Charry y Montero, 2004):

- compartir información

- transparencia y dialogo

- inclusión

- representación y responsabilidad

- recursos

- coherencia

- reglas de compromiso

- vínculos y cooperación

- consecuencias para la gobernabilidad

Es importante resaltar que el paso de este fenómeno ha dejado disparidad y descontento en todas las esferas de la vida social, donde de forma muy marcada se 
traduce en una serie de disparidades y disturbios sociales, los cuales se pueden reconocer casi de manera inmediata en la sociedad que se encuentran al otro lado del mundo, gracias a la eficiencia de los medios de comunicación, lo que hace referencia a la connotación social de la globalización y no sólo al ámbito económico y político. (Charry y Montero, 2004)

Entonces el proceso de globalización entra en un nuevo debate, ya que lo que a primera vista aparece es su efecto negativo, por ejemplo la liberalización de los mercados financieros y de capital ha producido una situación de quiebra y crisis en muchos países como el caso de Corea, Rusia, Brasil, México, Argentina por mencionar algunos, aunados al problema de crecimiento mundial (Charry y Montero, 2004). El capitalismo como un proceso que se superpone ante cualquier otra doctrina económica, pasa a ser un capitalismo global que está mucho más atento a controlar las relaciones económicas mundiales, que apuntar a reformas democráticas en pro de mejorar la pobreza en el mundo.

\subsection{Sobre las nociones de Organización de la Sociedad Civil y Organización No Gubernamental.}

Como parte de la construcción del concepto se comenzará por hacer referencia a distintas concepciones sobre el concepto de OSC lo que abarca una amplia gama de organizaciones, tales como las no gubernamentales y sin fines de lucro, ciudadanas, campesinas, gremios, que en esencia expresan los intereses y valores de sus miembros, según consideraciones éticas, culturales, políticas, científicas y religiosas.

En la actualidad, donde conviven sociedades puramente capitalistas (economía privada), con su ánimo de lucro y enriquecimiento individual, la "economía estatal" con su orientación de servicio ciudadano, interés común y colectivo, con o sin ánimo de lucro, que para muchos continúa con una tendencia a disminuir su participación en el campo laboral con las correspondientes consecuencias, es importante considerar el surgimiento de la "economía solidaria" con compromiso, responsabilidad, vocación del bien común y servicio a la comunidad.

La idea de solidaridad, de defensa, emerge como la solución a los problemas asociados al desarrollo tecnológico, a la injusticia e inequidad social y a la sociedad de 
consumo imperante, vale la pena resaltar de la economía social como es llamada en Europa, su presencia en lo económico y social, su capacidad para penetrar, desarrollarse y mantenerse en sectores de menor rentabilidad como la actividad agropecuaria, la salud, el reciclaje, la ecología, la educación, entre otros, cobrando importancia como generadora de empleo y bienestar social. En ámbitos como la cultura y dinámica de las regiones no han permitido interiorizar la naturaleza y fundamentos de la ideología solidaria o cooperativa.

Hay una gran discusión en torno a la denominación de aquellos grupos organizados de la sociedad civil, uno de ellos, como señalamos, es el de organizaciones no gubernamentales (Calvillo et al, 2004); sin embargo, y a pesar de su uso corriente, este término no implica una teorización del fenómeno, se refiere más bien a su carácter de oposición al gobierno, las empresas, los partidos políticos pero como un contraste; existe una corriente bastante difundida que las caracteriza como el tercer sector. Esta perspectiva parte del entendido de la división de la realidad social en sectores diferenciados; en el origen están el mercado y el Estado.

Entonces la razón de ser de las OSC es la de visualizar los problemas contemporáneos en búsqueda de certidumbre social, que encuentren nuevas soluciones a estos problemas y conjuntamente con los sectores ya articulados planteen estrategias de desarrollo que permitan a través de ellas hacer frente a los cambios económicos, políticos, sociales y culturales que se presentan con las tendencias globales, y que como núcleo de operación sea el de articular esfuerzos entre sí, con las entidades gubernamentales que existan apostando por una convivencia conjunta.

Por su parte el término organización no gubernamental (ONG) se dio a conocer en las Naciones Unidas en los años de posguerra; el objetivo era identificar y catalogar a un grupo especial de participantes que no tenían representación oficial de sus países de origen, pero que actuaban en algún organismo social, aunque muy pronto dicho término fue adoptado por todas aquellas organizaciones emanadas de la sociedad civil (Calvillo et al, 2004).

Recientemente se ha dado cuenta del prevaleciente debate sobre la sociedad civil como sujeto, como organización, como actor, pero a su vez, dando cuenta de la polisemia que el mismo concepto de sociedad civil implica, actualmente se postula una nueva concepción de las ONG y las asociaciones u organizaciones ciudadanas que constituyen 
la sociedad civil; la sociedad civil en si misma es el discurso y se materializa en distintas maneras de forma circunstancial.

La concepción sobre el tema por una parte da cuenta de ser restrictiva por que excluye una gran cantidad de asociaciones (profesionales, religiosas, culturales y populares) que también forman parte de la sociedad civil (Charry y Montero, 2004). La importancia radica reconocer el papel relevante que las Organizaciones No Gubernamentales y las ciudadanas han cumplido en México y en otros países, sobre todo para no minimizar el concepto mismo y no pensar que al hablar de sociedad civil solo nos estamos refiriendo a estas organizaciones.

Nutriendo el constructo conceptual sobre organización de la sociedad civil, otro concepto importante es el que se refiere a Tercer Sector, el cual se usa como un mecanismo alternativo para hablar de la sociedad civil organizada (Charry y Montero, 2004). El pensamiento relacionado con el concepto de Tercer Sector responde a la percepción de que el Estado es un sector de la sociedad, otro es la economía, otro la sociedad civil; el tercer sector es diferente al poder político, al poder económico y a la actividad lucrativa, en este sector se agrupan todas las organizaciones no lucrativas dirigidas al bienestar social (Charry y Montero, 2004: 19).

Conformando el pensamiento sobre la sociedad civil organizada, es necesario mencionar los distintos conceptos que han dado lugar al debate y la estructuración de dicho pensamiento a través del cual se debe generar una propuesta propia que siga contribuyendo al saber de dichas organizaciones.

Nos encontramos en un contraste de ideas, por una parte el pensamiento sobre dichas organizaciones se encuentra permeado por el pensamiento organizacional:

"entidades privadas constituidas con o sin figura legal, que no tienen fines de lucro y están orientadas hacia el logro de beneficios sociales para la comunidad, carecen de intereses políticos de un grupo definido, aun cuando estimulan la participación ciudadana en áreas públicas como las políticas electorales, la vigilancia gubernamental, derechos humanos o conservación ambiental, la participación ciudadana se considera como la clave para la existencia de una mayor corresponsabilidad de los gobiernos y los ciudadanos." (Mazzotti y Solís, 2002: 39) 
En otro sentido:

"son asociaciones (o grupos o movimientos) constituidas por personas privadas cimentadas en lazos asociativos sobre una base puramente voluntaria sin fines de lucro, que no persiguen beneficios personales sino sociales comunitarios." (Mazzotti, Solís, 2002:39)

Por su parte, el Banco Mundial estipula lo siguiente:

"Organizaciones privadas que persiguen actividades para aliviar el sufrimiento, promover los intereses de los pobres, proteger el medio ambiente o generar el desarrollo de la comunidad" un año después incluyó entre sus fines el de "brindar servicios sociales"

Ahora bien, de forma general se puede ofrecer una caracterización que encamine la construcción de un concepto propio; la caracterización es fundamental para reconocer particularidades (Mazzotti y Solís, 2002: 40):

"como organizaciones independientes y no una parte orgánica de estructuras mayores como Iglesia, universidad o empresa; no representan un electorado más amplio. Su valor está dado por lo que hacen, no a quienes representan; los servicios sociales que prestan tienden a la auto sustentabilidad y no son agencias de financiamiento; están constituyéndose como canales no oficiales para el apoyo internacional de proyectos típicamente locales, lo cual los facilita como conexiones entre agencias internacionales y locales, sin limitaciones formales ni definiciones territoriales se desplazan de manera más o menos fluida" (Mazzotti, Solís, 2002: 40). 
Bien es cierto, la sociedad civil organizada actúa como un canal no oficial de apoyo o como mecanismo de mediación que no se ve limitado ante idioma, territorio, localidad o globalidad.

Se rescata en ese sentido la idea de que son organizaciones sin fines de lucro, por lo menos lo son discursivamente, que estimulan la participación de los individuos de la sociedad de forma proactiva con el fin de generar mayor responsabilidad o por lo menos mas conciencia. La sociedad civil no sólo surge como respuesta ante las inconsistencias políticas, económicas y sociales que la globalización ha impuesto a través de ideologías económicas como el neoliberalismo que se traduce en una doctrina de Estado (mínimo) mutilado y una sociedad dislocada por el agravamiento de las desigualdades.

En general los aspectos de las OSC más relevante podrían ser los siguientes (Caldera, 2008):

- Existe un predominio de los servicios de bienestar social

- Son un importante generador de empleo

- La mayoría de los ingresos proceden del sector público y de pagos por servicios

- Existen grandes variaciones en tamaño entre países y regiones

- Son una importante fuerza económica

La experiencia latinoamericana (Charry y Montero, 2004), y como un ejemplo el caso de Argentina, que bajo la presión de grandes instituciones en términos de dictar las reglas del juego bajo la presión de la deuda externa ha sido sometido a instrumentar reformas estructurales enérgicas dictadas por el Fondo Monetario Internacional (FMI) y el Banco Mundial (BM) sustentados en la idea de apertura sin límites de sus fronteras y menor participación del Estado como la manifestación por excelencia de este fenómeno.

Pero a su vez también es preciso reconocer una posible dualidad en términos organizacionales, ya que por un lado es sana y por el otro muestra patologías.

Dicha dualidad llama a ser analizada de forma integral a través de los estudios organizacionales; ya que existen organizaciones que se autonombran OSC pero en la realidad resulta que son todo lo contrario, por ejemplo, lucran con la "buena voluntad" de los ciudadanos al hacer campañas masivas para ayudar a una "buena causa" y recibir donativos millonarios, no dando recibos deducibles de impuestos a cambio, mostrando una actitud humanitaria y de preocupación pero los recursos con los que operan no son 
suyos con los cuales obtienen ganancias ante instituciones como la Secretaria de Hacienda y Crédito Publico, y dichos donativos los declaran como suyos, consiguiendo saldos a favor es decir, recibiendo dinero del erario público.

Además dichas organizaciones (Caldera, 2008: 46) se han ganado una fama no del todo saludable; se ha dicho que estas organizaciones son excelentes lavadoras de dinero, ya que como no se pide justificación de la procedencia de los recursos donados, se recibe dinero y al dar a cambio un recibo deducible de impuestos, este dinero se vuelve "limpio" (Caldera, 2008: 46).

Sin embargo, la esencia de este tipo de organizaciones podría decirse es similar en algún sentido, que es la de ser una vía para subsanar los rezagos en el ámbito social, aquello que adolece que le adolece, a través de la búsqueda de nuevas vías de acción social que conduzcan a mejoras que coadyuven al desarrollo de la sociedad.

Cuando se refiere al termino OSC se podría referir a las organizaciones no estatales, sin ánimo de lucro y de carácter voluntario integradas por miembros de la Sociedad Civil (SC) que se preocupan por los problemas sociales, el cual es un término referido principalmente a la idea sobre su origen asistencialista. Dichas organizaciones se nutren de las relaciones de carácter comunitario, barrial, laboral, social, político, cultural, nacional, internacional, entre otras; conformando un espacio a través del cual la sociedad civil trata de ejercer sus derechos ciudadanos y de contribuir al cambio, ya sea social, cultural, educativo, político o económico (Caldera, 2008: 23).

En México fue hasta el 4 de diciembre del 2002 cuando se aprobó la Ley Federal de Fomento a las Actividades Realizadas por las OSC, no obstante, entró en vigor hasta febrero del 2004, dicha ley tenía como objetivo principal el de poder registrar a las OSC de forma voluntaria y gratuita para que operaran de forma legal y que estuvieran legalmente constituidas y que se dedicaran a actividades contempladas en la Ley.

Los desafíos que plantea la sociedad civil en este siglo (Charry y Montero, 2004) es la construcción de una perspectiva analítica que ha dado paso a abrir el interés sobre la importancia del tema, y sobre todo, construir el saber inacabado sobre la sociedad civil, abordar desde el origen, la dinámica y los grandes temas que discute la sociedad civil a la luz del proceso de la globalización. Entonces: 
"la sociedad civil actualmente se organiza de frente al proceso de globalización, el cual implica relaciones espaciales que involucran distancia y tiempo, un proceso dominado por el mercado y una visión global del mundo, donde la interrogante es si existe una sociedad civil global y un gobierno global, pero lo que sí es claro es que la sociedad civil ha tenido un papel claro, que es el de tratar de reparar y redistribuir frente a un gobierno global dominado por las organizaciones internacionales" (Charry y Montero, 2004)

El camino es constituir un nuevo espacio que habitar (Mazzotti y Solís, 2002: 49) en el sentido de portar nuevos esquemas de relaciones sociales y políticas que condensen los principios morales que las estructuran y que permitan a los individuos constituir sus mundos de vida con relación a nuevos y distintos parámetros que se distingan de los esquemas organizacionales que se han mantenido como hegemónicos hasta ahora.

Durante este siglo el concepto de sociedad civil ha conservado su esencia, pero a su vez se ha sostenido en otras ideas propias de la sociedad actual, pero como una propuesta comprende tres características comunes (Charry y Montero, 2004):

- La sociedad en contraste con el Estado (generalmente en contraste con la elite económica, tanto del capitalismo como del comunismo).

- Una sociedad plural y diversa (intereses diversos, individuos, grupos e instituciones).

- Se considera que la sociedad civil posee un valor moral como algo "bueno".

\subsection{La organización no gubernamental: una posible caracterización y su rol.}

En el comienzo del siglo XXI, las organizaciones se transforman en cuanto a las relaciones tradicionales de poder entre el Estado y las organizaciones mediante estrategias de presión y concertación política donde sus acciones se perfilan como alternativas diferentes de las iniciativas del Estado, perfilándose hacia practicas comunitarias y culturales distintas al corporativismo gubernamental (Cortés, 2008). 
La ONG se manifiesta entonces ante la crisis y limites tanto materiales como culturales a través de estrategias como la manifestación de sus demandas a través de la movilización, la conformación de organizaciones sin fines de lucro, asociaciones civiles, sin embargo el fin que persiguen no dista del todo.

La sociedad civil gira entorno a demandas claras entorno a la mejora de las condiciones prevalecientes, la sociedad civil global tiende a movilizarse por demandas sin fronteras tales como la defensa de los derechos humanos, la búsqueda del equilibrio ecológico, la oposición a la política neoliberal por la secuela que sus dictados tiene sobre el incremento de la pobreza, particularmente en África y América Latina, contra la marginación y la desigualdad, un comercio justo y equitativo, una política económica coordinada, la defensa de los derechos de los pueblos indios, contra el capital especulativo, la búsqueda de soluciones y alternativas al problema de las deudas externas, contra el $\mathrm{ALCA}^{2}$, contra la circulación y expansión del capital trasnacional especulativo, el impulso a políticas sociales en los planes del Banco Mundial y el Fondo Monetario Internacional, la paz mundial, contra el desempleo, a favor de la salud y la educación, reformas a la seguridad social, la supresión de los paraísos fiscales, entre otras (Charry y Montero, 2004).

Lo anterior conforma el cúmulo de aspiraciones de los pueblos, que se ven materializados en movimientos sociales que traspasan las fronteras territoriales, que van transitando desde las calles, los foros, los medios de comunicación, encabezado por grupos de la sociedad civil en pro de la lucha por el cumplimiento mínimo de esas demandas.

Como movimiento, la sociedad civil tiene diferentes definiciones, existe una gran variedad de posibles explicaciones para tratar de definirlo, se podría aseverar a términos más usuales como (Charry y Montero, 2004) globalifóbicos, anarquistas, antineoliberalistas, antiglobalizadores, pero acercándose a un término mas propio, se podrían llamar sociedad civil organizada. Las manifestaciones están conformadas por estudiantes, obreros, campesinos, mujeres, productores, médicos, artesanos, maestros, periodistas y población general, entre ellos, se presenta una diversidad de posiciones políticas e ideológicas como podrirán ser marxistas, campesinistas, nacionalistas, radicales, liberales, etcétera (Charry y Montero, 2004).

\footnotetext{
${ }^{2}$ Por sus siglas en español Área de Libre Comercio de las Américas
} 
Haciendo referencia a las forma de organización y a su vez de coordinación de las acciones de organizaciones de la sociedad civil, se puede identificar que las acciones que en sus acciones no existe un movimiento unificado ni una instancia coordinadora, se trata más bien de una red de redes estructurales horizontalmente. La propuesta es buscar una cabeza o un centro de decisión del movimiento, es más una red de redes en que el movimiento encuentra su fuerza, su flexibilidad y su capacidad de convocatoria, sin uniformar, sino mas bien alimentándose de la diversidad.

Es importante recalcar que la organización es una dimensión de la acción colectiva aunque en muchas ocasiones se le quiera considerar como un espacio de campos distintos, uno correspondiente a las estructuras racionales que producen a la sociedad y el otro relativo a los movimientos de las fuerzas sociales que pretenden transformarla; organización y acción colectiva pueden verse como parte de un mismo fenómeno social. " No hay acción colectiva de cierta duración que no produzca un mínimo de organización y que no genere finalmente un núcleo organizacional mas o menos formalizado en torno al cual la movilización se organizará y los intereses podrán agregarse" (Friedberg,1997: 23).

En la misma línea de ideas Friedberg (1997) en su aporte sobre la organización como constructo social busca conformar un espacio de cooperación y coordinación de los actores sociales que a su vez lo anterior implica poner en juego estrategias, intereses, intenciones y relaciones de poder que producen interacción de carácter político.

Debido a las dimensiones que han alcanzado las sociedades modernas la representación social mediante partidos, sindicatos, órganos y poderes de gobierno se asume no sólo como necesaria sino como inevitable. Bajo esta lógica, existen funciones particulares del propio gobierno, para lo cual se requiere un margen de decisión individual y reacción rápida. En otras palabras, la representación se justifica sobre todo en términos de su relativa eficacia, donde las condiciones prácticas del ejercicio gubernamental necesitan la acción de expertos que obren en nombre de los demás (Calvillo et al, 2004).

Entonces desde la noción de acción colectiva es necesario recalcar que la institucionalización del movimiento no implica que el sujeto colectivo no cuente con capacidad de acción como motor de cambio, sino que como actor buscará dicho cambio y lo hará en el marco de las reglas institucionales, dentro de un sistema a través de la lucha como las protestas sociales, la cooperación, el no lucro, el beneficio mutuo o la solidaridad (Cortes, 2008: 228). 
Considerar simultáneamente según Cortes (2008) que los limites están marcados por los recursos disponibles en función del cumplimento de las demandas y el análisis del contexto donde se generan dichas demandas y los recursos disponibles de cada actor resulta crucial en el análisis de este tipo de organizaciones.

Las nuevas formas de organización no son sólo estructuras organizativas que trabajan en favor de los sectores sociales más marginados y vulnerables, ellas mismas nacieron y se desarrollaron en la propia marginalidad, la cual, por otra parte, ha sido un estado muchas veces buscado, y con frecuencia, política y éticamente reivindicado (Calvillo et al, 2004). Fue por ello que muy pronto adoptaron el término mundialmente generalizado de organizaciones no gubernamentales para referirse a las nuevas estrategias de organización y participación social que estaban emprendiendo (Calvillo et al, 2004).

Como un manera de materializarse, la sociedad civil adquiere forma a través de organizaciones no gubernamentales, los fines que persiguen son tan amplios y hasta hace pocos años a partir de la Cumbre de Río de Janeiro, han empezado a abandonar la definición fundada en la negación: no gubernamentales y no lucrativas a conformarse como organizaciones civiles (Mazzotti y Solís, 2002:41).

Estructuralmente la ONG han creado la capacidad de integrarse en redes mundiales lo cual proviene de sus características organizacionales tales como estructuras descentralizadas, horizontales, informales, flexibles y adaptables, así como de sus capacidades de comunicar, manejar información y conocimiento, de adaptación a condiciones locales y los mecanismos para integrarse desde la localidad con la globalidad mediante la forma red, en la ramificación, densidad y configuración de relaciones regionales y globales (Mazzotti y Solís, 2002).

A continuación de muestra una posible caracterización sobre como podemos definir a la sociedad civil y retomar puntos importante para construir nuestra propia explicación.

Dichos ejes (Mazzotti y Solís, 2002: 41) son: 
1) como primera variable para definir a las organizaciones civiles no gubernamentales como organizaciones globalizadas, el hecho de que sus finalidades y objetivos estén orientados a por lo menos uno de los elementos que constituyen la denominada "conciencia planetaria", es decir, la ONG tendencialmente globales se orientan hacia la ecología y/ o a la defensa de los derechos humanos y su estrategia está básicamente definida por su capacidad para crear y difundir información.

2) El segundo eje, se orienta hacia la comprensión de la globalidad inherente en las organizaciones civiles en cuanto a las variaciones ocurridas en la estructura organizacional. Las organizaciones civiles tienden a estructurarse en nodos dispersos e interconectados, con una estructura horizontal, con una forma de gobierno no centralizado, con jerarquías tendiente a cero, mucha iniciativa interna y local, que actúa siguiendo una idea central realizada a través de tácticas descentralizadas y que depende de una comunicación densa sobre intercambio de información.

3) El tercero es en relación a la borrosidad de las fronteras organizacionales con la densidad en las interacciones organizacionales, control articulado y propósito colectivo; necesarias para llevar a cabo sus objetivos, nos permite clasificar el grado de integración y definir el tipo de redes que se están constituyendo en el campo de las organizaciones civiles no gubernamentales.

Es interesante identificar elementos clave sobre las ONG a fin de reconocer elementos centrales que nos permitan reconocer en el universo de organizaciones existentes y distinguir cuales pertenecen al grupo estudiado, la sociedad civil que se materializa a través de la ONG como una forma de expresión de la sociedad que favorezcan el desarrollo, la armonía y mejores condiciones de vida para nuestra sociedad a través de expresiones locales vistas a mayor escala. El entorno global es un ambiente turbulento y contingente, que acumula necesidades que evidencian y alertan hacia una nueva forma de actuar en vías de configurar una ruta que ofrezca nuevas posibilidades; por supuesto reconocer lo complejo de la tarea es un primer acercamiento sin embargo las distintas aristas que ofrece el panorama a su vez permite construir un ambiente incluyente y de cooperación mutua-

Reconocer sus particularidades coadyuvará a tener una noción más certera de su definición y su campo de acción, por lo anterior de manera grafica se mostrara una forma de caracterizar a las OSC: 
Tabla 1: Características y elementos de la Sociedad Civil.

\begin{tabular}{|c|c|c|c|c|}
\hline $\begin{array}{l}\mathrm{S} \\
\mathrm{O}\end{array}$ & $\begin{array}{l}\text { RED } \\
\text { Global, nodos } \\
\text { interconectados }\end{array}$ & $\begin{array}{l}\text { ORGANIZACIÓN } \\
\text { Estrategias de financiamiento } \\
\text { inserción en el mercado. } \\
\text { Vínculos con organizaciones } \\
\text { Internacionales. }\end{array}$ & $\begin{array}{l}\text { MISIÓN } \\
\text { Sustentable } \\
\text { orientación } \\
\text { a largo } \\
\text { plazo, equidad, } \\
\text { democracia }\end{array}$ & $\begin{array}{l}\text { PROYECTOS } \\
\text { Perdurabilidad, } \\
\text { tecnologías de largo } \\
\text { plazo, relación con el riesgo } \\
\text { Empoderamiento, y } \\
\text { cualidades autogestivas }\end{array}$ \\
\hline $\begin{array}{l}\text { E } \\
\text { D } \\
\text { A } \\
\text { D }\end{array}$ & $\begin{array}{l}\text { ORGANIZACIÓN } \\
\text { Horizontal, fluida, } \\
\text { autonomía } \\
\text { individual, densidad } \\
\text { en los intercambios. }\end{array}$ & $\begin{array}{l}\text { Toma de decisiones } \\
\text { descentralizada, democrática, } \\
\text { consenso,flujo libre de } \\
\text { información, control } \\
\text { articulado, diseño colectivo, } \\
\text { coespecialización, } \\
\text { conocimiento implícitoexplícito. }\end{array}$ & $\begin{array}{l}\text { PROPÓSITO } \\
\text { COMÚN } \\
\text { Sentido de } \\
\text { identidad }\end{array}$ & $\begin{array}{l}\text { Innovación en todas las } \\
\text { direcciones, visión del } \\
\text { trabajo en equipo e } \\
\text { individual, tareas } \\
\text { múltiples, trabajo } \\
\text { integrado, division por } \\
\text { las cualidades de experto. }\end{array}$ \\
\hline $\begin{array}{l}\text { V } \\
\text { I } \\
\text { L }\end{array}$ & $\begin{array}{l}\text { ACTORES } \\
\text { (config.relacional) } \\
\text { Actor-Red } \\
\text { Interdependencias } \\
\text { estratégicas. } \\
\text { Con el cliente } \\
\text { Modelo de promoción }\end{array}$ & $\begin{array}{l}\text { Experto, formas de } \\
\text { regulación, compromiso } \\
\text { cooperación, } \\
\text { intercomunicación } \\
\text { Esquema de relación } \\
\text { incluyente, integrada, } \\
\text { coparticipativa }\end{array}$ & $\begin{array}{l}\text { EMPODERAMIENTO, } \\
\text { Equidad } \\
\text { Propósito común } \\
\text { Confianza } \\
\text { Comunicación, } \\
\text { alianzas. }\end{array}$ & $\begin{array}{l}\text { Acento en las capacidades } \\
\text { cualitativas, tareas y } \\
\text { conocimientos } \\
\text { multidisciplinarios } \\
\text { Modelo de promoción } \\
\text { social. }\end{array}$ \\
\hline
\end{tabular}

Fuente: Retomado de Mazzotti y Solís, 2002: 45.

El cuadro anterior muestra un acercamiento bastante certero sobre aspectos centrales que conforman a la sociedad civil como organización, que a su vez nos permite trasladar dichos criterios de definición a la realidad y poder identificar que tipo de organizaciones conforman la sociedad civil y que otras no lo son.

Según Olvera (en Caldera 2008) dicha clasificación es adecuada por que permite distinguir a las organizaciones que perdiguen el beneficio social y otras que tienen como esencia el beneficio propio. La sociedad civil se ve materializada en formas organizaciones determinadas, bajo el supuesto de asociación y se enuncian las siguientes:

- Asociaciones de carácter económico-gremial

- Asociaciones políticas formales

- Asociaciones de matriz religiosa

- OSC. Dentro de estas se encuentran: 
- Asociaciones y movimientos sociales para la defensa de los derechos ciudadanos

- Organizaciones de promoción, desarrollo y servicios a la comunidad

- Asociaciones de asistencia privada

- Asociaciones de tipo cultural

- Asociaciones privadas de tipo deportivo

- Asociaciones urbanas de tipo urbano-gremial

- Movimientos y asociaciones de comunidades indígenas

De acuerdo a Caldera (2008) el término de organizaciones no gubernamentales u ONG, también en nuestro país, se generalizó por los años 70’s y se adecuó a todas las organizaciones de este tipo. Las Naciones Unidas han enunciado su concepto de ONG como "toda organización sin ánimo de lucro que no sea gubernamental ni intergubernamental". En la actualidad el término ONG se refiere a las organizaciones formalmente constituidas, que a menudo que prestan servicios y movilizan a la opinión pública.

\subsection{La organización no gubernamental: una primera aproximación desde la perspectiva organizacional.}

En este apartado emplearemos una definición de organización para hacer el ejercicio de corroborar si las ONG cumplen con sus elementos formales desde la perspectiva organizacional como marco de estudio esencial, ya que le perspectiva organizacional implica al menos concebir al objeto de estudio como una organización en si misma de manera explicita. Si con este ejercicio encontramos que las ONG reúnen las características que la definición tomada postula como necesarias para identificar a una organización, entonces podremos decir con certeza que sí es tal. En caso contrario, el resultado obvio será que no es una organización, que no puede ser estudiado como tal y que, por lo tanto, no puede ser considerado como objeto de los estudios organizacionales.

Esta definición, tomada de Hall (1996: 33), es: 
"Una organización es una colectividad con una frontera relativamente identificable, un orden normativo, niveles de autoridad, sistemas de comunicaciones y sistemas de coordinación de membresías; esta colectividad existe de manera continua en un ambiente y se involucra en actividades que se relacionan por lo general con un conjunto de metas; las actividades tienen resultados para los miembros de la organización, la organización misma y la sociedad."

A través de la definición anteriormente expuesta, se abordara desde los supuestos de la organización de la sociedad civil en que medida empata con los elementos de una organización, para a su vez definir la factibilidad de su estudio como organización.

A continuación se abordarán cada uno de los elementos (análisis retomado de De la Rosa y Contreras, 2007)

- con una frontera relativamente identificable porque la idea misma de colectividad, tratada en la perspectiva cultural-cognitiva (Scott, 2003: 188), supone no sólo la identificación entre los miembros de la misma de acuerdo con valores, sino también la diferenciación de aquéllos respecto de los que se encuentran en el entorno y que por tanto no comparten tales valores.

Esta diferenciación representa las fronteras de la colectividad, es decir, de la organización. De lo contrario, la organización podría ser concebida como la extensión del ambiente o, a la inversa, el ambiente de la organización. En el caso de las ONG, los integrantes que los conforman se pueden identificar entre sí por su ideología, su proyecto entre otros factores; a la vez, estos elementos de identificación funcionan como elementos de diferenciación relativos a su entorno. Así, por ejemplo, las OSC marcan sus límites de acción con otras organizaciones y a su vez de su misma naturaleza, por la heterogeneidad de sus objetivos.

- Un orden normativo porque toda colectividad estructurada requiere de un mínimo de normas que permitan dirigir, coordinar y controlar la acción y recursos de sus integrantes, con lo que da certidumbre. Las ONG como acción colectiva se encuentran plagadas de movimientos controlados, bajo objetivos específicos, la acción debe regirse por reglas de 
operación que contribuyan al objetivo por el cual fueron creadas, y no optar por un accionar deliberado.

- niveles de autoridad, en el sentido de identificar algún tipo de autoridad e identificar quien rige la acción pues en vista de que la consecución de los objetivos requiere la creación de cargos que encaminen la acción de la organización, entonces la OSC cuenta con ello, existen líderes de los movimientos que se asignan de acuerdo a un tipo de dominación carismática que cuente con la capacidad formal y legítima de mandar y se refleje en obediencia; requiere un mínimo de estructura de dominación.

- sistemas de comunicaciones porque el proceso de comunicación es inherente a toda acción social materializada en movimientos de colectividades y como un enlace hacia su interior y exterior es preciso la existencia de circuitos de comunicación que permitan intercambiar y generar un mínimo de conocimiento y entendimiento mutuo sobre sus objetivos y valores que a su vez conformarán un espacio con símbolos y significados establecidos que permitirá a otras ONG conocer entre otras cosas sus objetivos y su funcionamiento hacia dentro y hacia el publico que atienden.

- sistemas de coordinación de membresías porque ya que las colectividades no existen sino a partir de seres humanos es necesario contar, además de la autoridad con mecanismos que coordinen las actividades en su conjunto de la manera que la acción sea coordinad; en el caso de las ONG es claro, sin un actuar coordinado la consecución de las metas por las que son creadas no tendrían el impacto que se puede dar cuenta han tenido y tienen en la actualidad.

- esta colectividad existe de manera continua porque su ciclo de vida trasciende al de los integrantes que la fundaron y ha contado con la capacidad de subsistir a través de largos periodos; en el caso de las OSC a pesar de que su estudio se remite a algunos años, la emergencia de otras OSC da cuenta de que este tipo de organizaciones algunas por una parte han crecido y por otra, se han creado nuevas con distintas metas, espacios, integrantes etc, sin embargo su aparición es cada vez mas constante y al día de hoy es posible darse cuenta de su presencia en distintos ámbitos.

- en un ambiente porque la interacción de los miembros es una factor constante hacia su interior como con otras organizaciones con el fin de intercambiar distintos elementos de operación, financieros, miembros; lo que las hace ser un sistema abierto que permita la interrelación con otras organizaciones en distintos espacios. En ese sentido, las OSC existen dentro de un ambiente del cual se deben buscar recursos, financiamiento, promoción y en general insumos con el ambiente. 
- Se involucra en actividades, es decir, su intercambio con el ambiente no solo se remite a la obtención de insumos, también debe interesarse e involucrarse en acciones que se consideran necesarias en vías del cumplimiento de las metas de la organización, lo que implica desde el funcionamiento de los circuitos de comunicación, hasta la búsqueda de otros medios para lograr una mayor presencia para el logro de las metas e ideales de la organización. La OSC implica una amplia gama de actividades que va desde la conformación misma, la organización, la movilización, todo aquello que le permita tener aun más relevancia en la sociedad algunas aseveraciones son las siguientes:

- que se relacionan por lo general con un conjunto de metas porque las concepciones de fines deseados (Scott, 2003) son el factor en torno al cual se construye la colectividad y a partir del cual se establece su coordinación y cooperación. Para el caso de las OSC la metas cohesionan a la organización y cada uno de los miembros coopera en el cumplimiento de las metas que se traduzcan en beneficios colectivos.

- las actividades tienen resultados para los miembros de la organización, la organización misma y la sociedad porque, por una parte, la incorporación y aceptación de colaboración de los miembros de la colectividad está mediada por el interés de obtener ciertos resultados, sean de estatus, materiales o simbólicos que corresponda a un objetivo común, todo en un pensamiento colectivo por que el objetivo es común, la perspectiva individual queda sesgada en las OSC.

En la ONG los objetivos y las metas son la columna vertebral de este tipo de organizaciones, es su razón de ser para lo cual emprenderá acciones encaminadas al cumplimiento de las metas ya establecidas. En torno a ellas se integran los potenciales miembros de la colectividad y aceptan contribuir con sus acciones para alcanzar las metas establecidas formalmente. En la ONG se puede apreciar claramente sus metas, atender problemas que aquejan a la sociedad, la igualdad, la contra la pobreza, etcétera.

Entonces una vez abordado lo anterior, es posible afirmar que las OSC sí son organizaciones, por lo que a través de la perspectiva organizacional puede brindarse un conocimiento multidisciplinario sobre ellas que permita la construcción de marcos teóricos y aportes para así de manera paulatina cimentar el estudio de este tipo de organizaciones. 
CAPÍTULO 2

\section{Una aproximación a las Teorías de ambigüedad organizativa.}




\section{Introducción}

La ambigüedad organizativa está mas presente en las organizaciones de lo que podemos llegar a pensar, ya que incluso la encontramos en el mismo funcionamientos de las organizaciones, debido a que las organizaciones han sido concebidas como constructos racionales y perfectos. Las teorías de la ambigüedad contribuyen a darnos explicación sobre la racionalidad no convencional e incertidumbre en las organizaciones. Dicho capitulo tiene por objetivo mostrar un recorrido por las teorías de ambigüedad organizativa para dar un panorama teórico que permita reconocer las particularidades de caso de estudio de esta tesis, de tal forma que como tal, no será un espejo de la teoría, sin embargo como marco de análisis toma un papel trascendental; en el sentido de comprender la realidad organizacional del caso de estudio para ofrecer una posible explicación de los fenómenos organizacionales.

\subsection{Antecedentes teóricos de las Teorías de la Ambigüedad Organizativa.}

Es importante comenzar por los antecedentes de la Teoría de la Ambigüedad Organizativa. En un primer plano a la organización se le ha pensado como racional, burocrática, lineal y en completo orden, se piensa que la organización opera en un ambiente de racionalidad, con estricto control orientando a la toma de decisiones a la permanencia de la organización a largo plazo, orientando la toma de decisiones a las mejores alternativas que le brinden a la organización los mejores márgenes de utilidad. Lo anterior se centra en lo que la Escuela del Comportamiento afirmaba, que el comportamiento organizacional estaba influenciado por la toma de decisiones en la búsqueda de soluciones a problemas específicos y en si misma la organización puede ser considerada como un sistema decisorio en una lógica de eficiencia reconociendo que a su vez es un sistema de comportamientos sociales interrelacionados considerando que la visión de los individuos se orienta a la racionalidad limitada con conocimientos de los medios y los fines y simultáneamente permite reducir la complejidad del espacio organizacional. 
En cuanto a la toma de decisiones en la organización, el supuesto es que el conocimiento perfecto de alternativas y consecuencias determina que entonces el proceso decisorio en las organizaciones sigue una lógica de la consecuencia donde las preferencias y consecuencias juegan constantemente en condiciones de incertidumbre, y sobre todo, las preferencias que se determinan en el proceso decisorio son ambiguas (March, 1972).

En conjunto March con la colaboración de Cohen, logran evolucionar el pensamiento y trasladarlo a otro plano, considerando que los objetivos, actores y procesos son difusos y contradictorios, dicha evolución del pensamiento se traduce en lo que se conoce como Anarquías organizadas, Garbage Can Model y Sistemas Flojamente Acoplados que dan cuenta de que la toma de decisiones es idóneo para diversas

interpretaciones y no existe claridad en la lógica de causa efecto entre decisiones y acciones, y simultáneamente las decisiones no se toman solo por el ápice y líder de la organización sino que ésta se construyen socialmente.

\subsection{Supuestos básicos de la Teoría de la Ambigüedad Organizativa e incertidumbre.}

Bien es cierto, la particularidad de las organizaciones nos hace pensarlas nuevamente como constructos inacabados que están simultáneamente integrados por miembros que se transforman y a su vez modifican su entorno.

La realidad reitera el hecho que no se puede atender a la generalización ante la realidad organizacional, nos enfrentamos ante características muy particulares, que es necesario comprender a través de una lente como los EO y comprender de forma integral que sucede con las organizaciones hoy en día y a su vez nutrir el conocimiento sobre las organizaciones de cualquier tipo y de las que en últimos tiempo han venido configurándose.

La realidad nos ubica en un espacio de organizaciones sumamente diversas, de alguna manera configuradas de forma distinta a lo que por lo menos se acostumbra a pensar y también aparecen organizaciones que sería pertinente y relevante estudiar a través de los EO, con el fin de seguir construyendo el conocimiento organizacional contemplando que es un constructo inacabado que es preciso también que pueda responder a lo que acontece en las organizaciones en la actualidad. 
En lo que se refiere a la decisión en algunas ocasiones si se relaciona directamente con el resultado obtenido o con las modificaciones que el medio o contexto experimentan, aunque dicha situación no sea la única que coexiste en las organizaciones, como el espacio de convergencia de los distintos; y afirmar que la toma de decisiones se reduce a búsqueda posibles alternativas de acción y a la selección de una de ellas, es una distorsión reduccionista (Del castillo, 2001:16).

De acuerdo a Del castillo (2001:16) se desarrollaron tres propuestas teóricas que se consideran extensiones naturales de los planteamientos de racionalidad limitada (Simon, 1947; March y Simon, 1958), conflicto (March y Simon, 1958) y negociación política en las organizaciones (Cyert y March, 1963).

Estas teorías han intentado generar algunas hipótesis explicativas de los procesos organizacionales y decisorios en forma de cestos de basura (Cohen et al., 1972), sistemas flojamente acoplados (Weick, 1969 y 1976) y anarquías organizadas (Cohen y March, 1974; March y Olsen, 1976).

Las teorías de la ambigüedad organizativa suponen (Del castillo, 2001: 20; De la Rosa, 2010):

- Es difícil establecer una relación causa efecto entre decisiones y acciones.

- Es difícil establecer una relación directa y clara entre alternativas y consecuencias

- Es difícil establecer una relación directa y clara entre problemas y soluciones.

- La toma de decisiones no sólo cumple un simple papel instrumental sino que es portadora de significados y susceptible de diversas interpretaciones.

- Las situaciones de decisión son ocasiones para cumplir lo relativo a lo formalmente establecido en la organización, definir el estado actual y futuro de la organización y sus suposiciones básicas, distribuir gloria y culpa sobre lo sucedido en la organización, definir situaciones de consenso, de conflicto y de status, disfrutar (o no) los placeres relativos a ser parte de las situaciones de elección.

- Las decisiones son construidas socialmente.

A manera de complementar el camino hacia la construcción del marco de análisis que dará forma a este trabajo y recordar las premisas que refieren a teorías de ambigüedad organizativa, aspectos como liderazgo, aprendizaje, cambio organizacional, cooperación aparece bajo condiciones de ambigüedad tal y como aparecen en cuadro siguiente: 
Tabla 2: Características generales de las Teorías de Ambigüedad Organizativa.

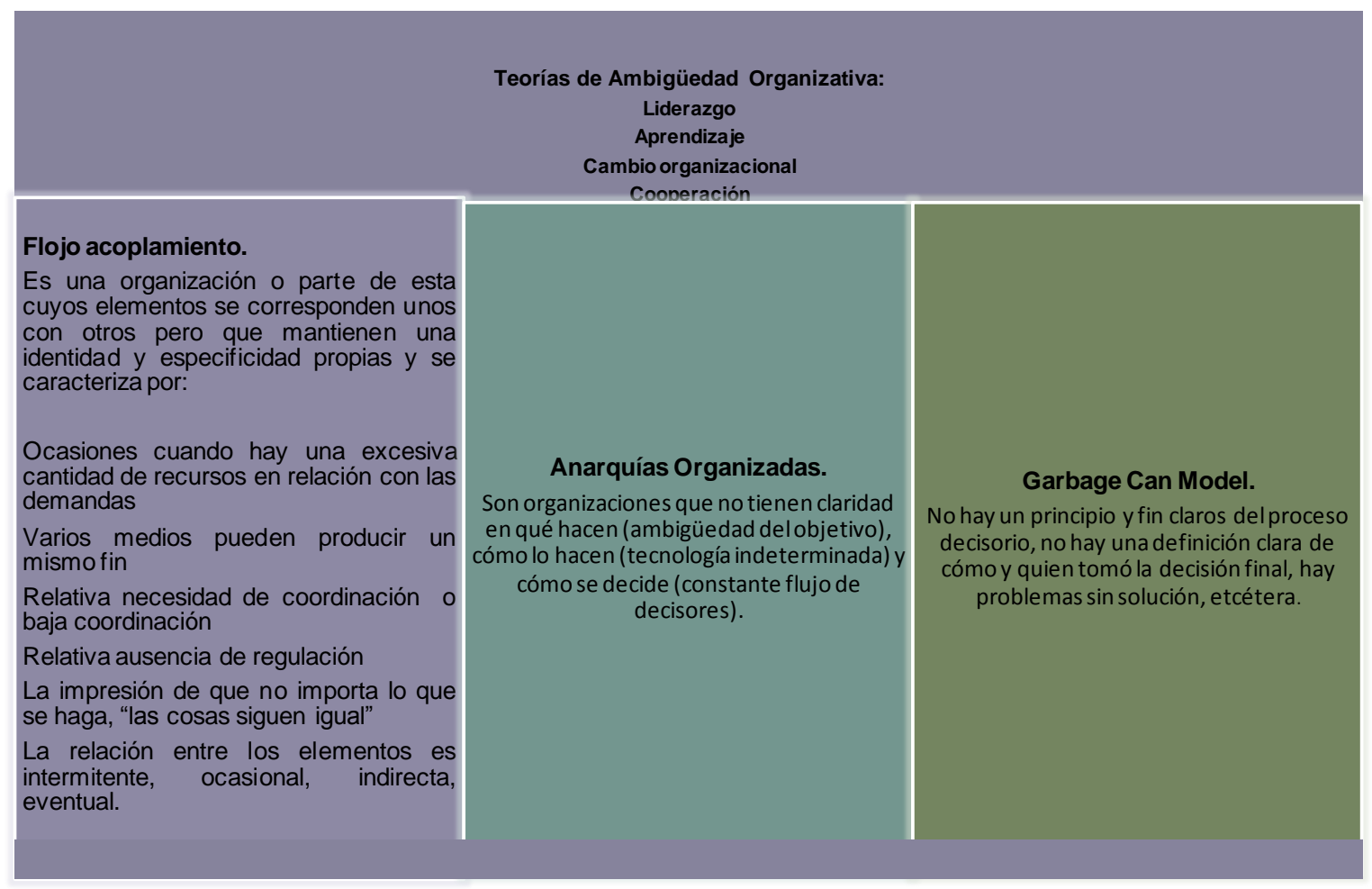

Fuente: Tabla de elaboración propia en base a Del Castillo (2001).

Ahora bien de manera puntual cada propuesta teórica será desarrollada a fin de reconocer las particularidades de cada una. 


\subsection{Supuestos básicos de Anarquías organizadas.}

Las anarquías organizadas refieren al concepto de ambigüedad el cuál se puede entender en varios sentidos March y Olsen (en De la Rosa, 2010) ya que dicho concepto hace referencia a la ausencia de claridad o a la necesidad de consistencia en la realidad, la causalidad o la intencionalidad. En la toma de decisiones, la ambigüedad hace referencia a los múltiples significados e interpretaciones que surgen al momento de decidir o a los múltiples significados e interpretaciones que se hacen de las decisiones tomadas por otros:

- Ambigüedad de intención: dificultad para establecer objetivos claros, consistentes y jerarquizados.

- Ambigüedad de entendimiento: poca claridad respecto de aspectos cotidianos como: tecnología es poco clara, el ambiente es difícil de interpretar, dificultad para establecer conexiones entre acciones y consecuencias.

- Ambigüedad de historia: dificultad para establecer qué sucedió, porqué sucedió y si tuvo que suceder cierto proceso organizativo.

- Ambigüedad de organización: dificultad para establecer un patrón de conducta y participación de los actores en los procesos decisorios.

- Ambigüedad de la experiencia: el hecho de que la experiencia resulta poco útil como recurso para la toma de decisiones.

- Ambigüedad del poder: dificultad para establecer los ámbitos de influencia de los actores organizacionales.

- Ambigüedad del éxito: dificultad para definir que significa el éxito en un contexto de diversidad de actividades.

Las anarquías organizadas (March, Olsen ,1975: 85-86) se caracterizan principalmente por que no tiene definidas con claridad y coherencia en que es lo que pretende, refiriéndose a la ambigüedad de objetivos, sin tecnología indeterminada y quien o quienes son los responsables de tomar las decisiones relacionado al concepto de constante flujos de participantes en el proceso decisorio y que a pesar de que existan objetivos tangibles o medibles, no siempre cuenta con el consenso de todos los participantes y en el caso de 
que se lograra integrarlos, resultan muy generales y tan ambiguos que su medición resulta difícil; en cuanto a la tecnología se refiere a la indeterminación en los procesos de trabajo además que el constante flujo de trabajo influye en la capacidad que los administradores tienen para influir en los procesos de toma de decisiones.

A su vez, March y Olsen (en Lopez y Solis, 2002: 38-39) plantean que el contexto de la toma de decisiones en las universidades está caracterizado por algunos aspectos.

Dichos aspectos se enuncian de la siguiente forma:

- Fuerte ambigüedad de preferencias: en este caso, los miembros de la organización no saben o no pueden establecer con claridad los objetivos y fines que desean, se tienen varios objetivos que resultan contradictorios o muy difícilmente conciliables, por lo que la acción precede a la formación de las preferencias.

- Tecnología indeterminada o poco dominada: en las organizaciones comúnmente es difícil establecer los inputs y los outputs de los procesos sustantivos de cada organización inclusive existe un escaso conocimiento del proceso de transformación (inmaterial e intelectual) que permita pasar de los inputs a los outputs; por lo tanto, se da una indeterminación en los procedimientos de trabajo con relación al impacto deseado sobre los problemas previamente identificados; la dificultad para evaluar los resultados hace que se pierda el papel regulador que juegan éstos en las relaciones entre actores.

- Fluida participación en los procesos de decisión: una característica de las organizaciones es el constante flujo de participantes en los procesos de decisión. Éstos pueden entrar o salir de dichos procesos o introducir nuevos problemas o retirar otros. A pesar de sus diferencias de poder, los actores tienen una gran capacidad para influir o modificar los procesos de decisión.

También es necesario reconocer que (Friedberg, 1997: 84-85) las anarquías organizadas son primordialmente una construcción que puede darse al interior de las 
organizaciones, lo cual hace evidente la ambigüedad presente en las situaciones en el contexto de la acción y la ambigüedad como condición de la acción humana.

Se pueden identificar 5 grandes propiedades de la toma de decisiones en las anarquías organizadas (Cohen y March, 1986: 206-207) que tienen gran importancia en las tácticas:

1. La mayoría de los temas cuenta con prominencia baja para la mayoría de las personas, las decisiones que se toman dentro de la organización aseguran sólo una atención parcial y errática de los participantes en la organización.

2. Todo el sistema tiene inercia alta, lo cual requiere un esfuerzo coordinado de la organización con el fin de empezar, lo que es poco probable que se suceda.

3. Cualquier decisión puede convertirse en un cesto de basura para casi cualquier problema.

4. Los procesos de elección son fácilmente sometidos a una sobrecarga.

5. La organización tiene una base de información débil.

Entonces la necesidad de abrir la mirada a concebir nuevas formas de concebir las organizaciones (López y Solís, 2000: 37) como espacios sociales en donde interactúan una gran variedad de racionalidades que se entretejen, donde tienen lugar las soluciones y decisiones que no corresponden a una finalidad que pareciera que prevalece un ambiente de incertidumbre donde las acciones de sus unidades y subnidades no están coordinadas, sino que por el contrario, existen flojos acoplamientos que permiten la segmentación y la desconexión de partes de las organizaciones.

Es pertinente mencionar que la diversidad organizacional nos conduce a concebir como un hecho inminente la emergencia de nuevos modelos organizacionales para lo que es necesario de marcos teóricos adhoc que expliquen mejor las complejas organizaciones que se desenvuelven en condiciones de alta incertidumbre y ambigüedad.

\subsection{Sobre la noción de Sistemas Flojamente Acoplados.}


Un sistema flojamente acoplado (Weick, 1976: 2) es una organización o parte de esta cuyos elementos se corresponden unos con otros pero que mantienen una identidad y especificidad propias y se caracteriza por:

- Ocasiones cuando hay una excesiva cantidad de recursos en relación con las demandas

- Varios medios pueden producir un mismo fin

- Relativa necesidad de coordinación o baja coordinación

- Relativa ausencia de regulación

- Casi independencia de las partes

- Infrecuente inspección de actividades dentro del sistema

- Delegación de discreción

- La observación de que la estructura de la organización no se corresponde con sus actividades

- La impresión de que no importa lo que se haga, "las cosas siguen igual"

- La relación entre los elementos es intermitente, ocasional, indirecta, eventual.

- La yuxtaposición de fuerzas contradictorias pertenecientes a un mismo sistema (diferenciación vs coordinación)

Abordar el concepto de flojo acoplamiento requiere de precisiones pertinentes, (Weick, 1976:3) la premisa básica es que el concepto de acoplamiento flojo puede servir como dispositivos de sensibilización, y que alertan al observador para advertir y cuestionar lo que anteriormente se había dado por sentado. Considerar la posibilidad que las organizaciones como sistemas flojamente acoplados no hayan sido vistas antes porque nadie creyó en ellas o no puede darse el lujo de creer en ellas es esencial y una posible respuesta es que sea debido a la preocupación por lo racional, lo ordenado, lo eficiente, las estructuras coordinadas, haya cegado a muchos profesionales, y aparece como una barrera para percatarse de las inesperadas propiedades menos racionales y menos estrechamente relacionadas.

Basta con detenerse en la palabra, (Weick, 1976:3) podría parecer que la palabra acoplamiento es sinónimo de conexión, enlace o interdependencia, sin embargo, con acoplamiento flojo se intenta transmitir la imagen de que los acontecimientos de acoplamiento dan respuestas, pero que cada hecho conserva también su propia identidad y alguna prueba de su separación física o lógica, adicionalmente, las imágenes del acoplamiento sugieren la idea de bloques de construcción que pueden ser insertados en 
una organización o cortados con relativamente poca perturbación, ya sea en los demás bloques o en la organización. La riqueza de esta propuesta radica en el acceso a una de las formas más poderosas de hablar de la complejidad en la realidad organizacional.

Es necesario enunciar los elementos que conforman un sistema flojamente acoplados (Weick, 1976:4) tal y como se menciona a continuación:

- Elementos acoplados: En principio, los dos mecanismos de acoplamiento que con más frecuencia se examinan son el núcleo técnico y la autoridad del cargo. La relevancia de estos dos mecanismos para cuestiones de identificación de los elementos es que, en el caso de acoplamientos técnicos, cada elemento es algún tipo de tecnología, tarea, subtarea, rol, territorio o persona; y los acoplamientos son inducidos por las labores. Otro caso es de la autoridad como mecanismo de acoplamiento, los elementos incluyen puestos, oficinas, responsabilidades, oportunidades, recompensas y sanciones; y es el acoplamiento entre estos elementos los que podrían pensarse mantienen unida la organización, lo anterior probablemente debido a que las organizaciones siguen pensando que la planeación es algo bueno y pasan mucho tiempo haciéndolo, y las acciones son evaluadas en términos de cómo se adecuan a los planes.

Es pertinente añadir que hay otro conjunto interesante de elementos que nos ofrece por sí mismo la imagen del acoplamiento flojo (Weick, 1976:3) es el de medios y fines ya que hay situaciones en las cuales diferentes medios llevan a obtener el mismo resultado por lo que se asevera que cualquier medio está acoplado flojamente con el fin reforzando la noción que hay varias vías para lograr ese mismo fin.

En la misma línea (Weick, 1976:5) los elementos pueden aparecer o desaparecer y fusionarse o devenir en separaciones como respuesta a las necesidades en lo individual, lo grupal o lo organizacional.

- Fuerza de acoplamiento: La idea del flojo acoplamiento refiere a una situación en donde la gente tiene diversas situaciones en la mente. Sin embargo hay aspectos que rodean dicho concepto como sigue a continuación (Weick, 1976:5): 
1) tiempos de holgura, cuando hay una cantidad excesiva de recursos en relación con las demandas; 2) ocasiones en las que cualquiera de varios medios produce el mismo fin 3) redes ricamente conectadas en las que la congruencia separatista es lenta o débil mientras se están separando; 4) una relativa falta de coordinación, coordinación lenta o coordinación que es desalentada cuando se mueve a través de un sistema; 5) una relativa ausencia de regulaciones; 6) falta de respuestas previstas; 7) causales reales de independencia; 8) escasa capacidad de observación por parte de un espectador; 9) inspección escasa de las actividades dentro del sistema; 10) descentralización; 11) la delegación de discrecionalidad; 12) la falta de vínculos que deben estar presentes con base en una teoría, por ejemplo, en las organizaciones educativas la retroalimentación de vínculos exteriores, a manera de insumos del sistema, frecuentemente es inexistente; 13) la observación de que la estructura de una organización no está vinculada para durar el mismo tiempo que la actividad; 14) aquellas ocasiones en que, sin importar lo que se haga, las cosas siempre resulta lo mismo.

En cuanto a las posibles funciones y disfunciones de acoplamiento flojo permite la permanencia de algunas partes de la organización, pues disminuye la probabilidad de que la organización pueda responder a los pequeños cambios producidos en el ambiente. Una segunda ventaja del acoplamiento flojo es que puede proporcionar un mecanismo de detección sensible y se podría argumentar que los sistemas flojamente acoplados preservan muchos elementos independientes de detección y permite conocer mejor su entorno respecto al de los sistemas más rígidos, los cuales tienen menos restricciones externas para los elementos independientes. Una tercera función es que un sistema flojamente acoplado puede ser pertinente para la adaptación localizada. Si todos los elementos en un gran sistema están flojamente acoplados entre sí, entonces cualquier elemento puede adaptarse y modificar una contingencia local única sin afectar a todo el sistema además que mantiene la identidad, la singularidad, y la diferenciación de los elementos, potencialmente puede retenerse un mayor número de mutaciones y soluciones novedosas; y por ultimo si hay una ruptura en alguna parte de un 
sistema flojamente acoplado, esta falla se cierra y no afecta a otras partes de la organización (Weick,1974: 6-7).

Ahora bien, es adecuado a fin de mostrar las dos caras de la moneda y mencionar las desventajas de este sistema. Un sistema flojamente acoplado (Weick, 1974: 7) aísla sus focos de conflicto y evita que el problema se propague, pero le es difícil reparar el elemento defectuoso, la influencia en el debilitamiento de las partes defectuosas se traslada hacia las partes en funcionamiento, entonces la influencia detrás de estos segmentos también será débil, adicionalmente que como la mayoría de las acciones tienen consecuencias ambiguas, siempre será posible justificar la acción como aprovisionamiento para las intenciones de aquellos que se quejan pero aunque este sistema es barato, lo flojamente acoplado es también un sistema no racional de asignación de recursos y, por lo tanto, imposible de precisar, inmodificable, e incapaz de ser utilizado como medio de cambio.

Por definición, si uno entra en una organización tal y como un reloj una parte afecta a otras, él o ella verá las partes estrechamente vinculadas y las partes que varían más (Weick, 1976: 9). Las partes que pueden variar ligeramente, con poca frecuencia y periódicamente menos visibles.

Weick ha argumentado que los elementos pueden aparecer o desaparecer y pueden fusionarse 0 se separan en respuesta a las necesidades en lo individual y grupal. Esto significa que la especificación de los elementos no es un paso a paso a la actividad. Teniendo en cuenta el contexto de la mayoría de las organizaciones, los elementos de ambas aparecen y desaparecen con el tiempo. Por esta razón una teoría de cómo los elementos se aflojen o juntan también tendrá que tener en cuenta la naturaleza y la intensidad del acoplamiento en cuestión para crear o disolver a los elementos (Weick 1976: 12).

De la misma forma (López y Solís, 2000: 39) este tipo de sistema tiene entre otras características que la fuerza y el éxito del diseño organizacional existe gracias a que a través de la descentralización y la delegación se ha podido proporcionar a las organizaciones un espacio para conciliar, tolerar y estimular de manera útil la inconsistencia y la incoherencia. Esto es así porque la descentralización y la delegación generan una dinámica de largo plazo de diferenciación que acentúa el nivel 
organizacional de flojo acoplamiento: cada subunidad, de manera relativamente desconectada, puede recrear sus propios objetivos, información, clientes, creencias e identidades, distintos de otras subunidades no olvidando las ciertas consideraciones en particular a que los investigadores estén conscientes de que en las organizaciones existe un número finito de "relaciones estrechas" que ocurren en cualquier momento, pero que estas "relaciones estrechas" en un lugar implican "relaciones flojas" en otro lugar y que, por lo tanto, lo importante es estudiar los patrones de "acoplamiento" que producen los resultados observados.

Del mismo modo otra premisa que coadyuva en la comprensión sobre la observación de flojo acoplamiento es que se utilizan los elementos de la intención y la acción donde hay una posición en desarrollo de la psicología que sostiene que las intenciones son una mala guía para la acción, las intenciones a menudo puede seguir en lugar de preceder a la acción, y que las intenciones y la acción están débilmente acoplados (March y Olsen,1975: 56-57). Desafortunadamente, las organizaciones continúan pensando que la planificación es algo correcto y como la forma por excelencia de predecir el futuro es la planificación, por lo tanto pasan mucho tiempo en la planificación y las acciones son evaluadas en términos de su alineación con los planes. Dado un acoplamiento potencial entre las intenciones y acciones de los miembros de la organización, entonces no debe de extrañar que los administradores están desconcertados y enfurecidos cuando las cosas no suceden de la forma en que se suponía ocurrían.

Si bien todos estos elementos son evidentes no es trivial especificar qué elementos se juntan. Como el concepto de acoplamiento es crucial debido a su capacidad para resaltar la identidad y separación de elementos que están momentáneamente unidos, el marco conceptual ejerce presión sobre el investigador para especificar claramente la identidad, la separación, y los límites de los elementos acoplados (March y Olsen, 1975: 58).

En cuanto a la búsqueda de sentido en un espacio flojamente acoplado (Weick, 1976: 13) ¿Qué tipo de información dentro del sistema se hace imprecisa y que proporcionan los miembros en torno a como se puede dar significado a las actividades, es decir, lo que se puede utilizar para dar sentido a tales estructuras efímeras?; por definición los elementos débilmente acoplados son modestamente predecibles en el mejor de los casos y no hay una estructura bastante estéril que se pueda observar dada la 
ambigüedad de las estructuras flojamente acopladas, esto sugiere que puede haber aumentado la presión sobre los afiliados para construir o negociar algún tipo de la realidad social donde se pueda vivir. Por lo tanto, en condiciones de un acoplamiento flexible debe haber un considerable esfuerzo dedicado a la construcción de la realidad social y a su vez poder conectar de alguna manera algún punto donde sea sensible y encontrar sentido en dicho espacio.

Los espacios de flojo acoplamiento (Weick, 1976: 13) no se ven como si fueran los responsables de dar a una persona muchos recursos para dar sentido, sin embargo la actividad predominante debe implicar la construcción de la realidad social como un espacio de interacción por excelencia.

\subsection{Sobre la noción de Garbage Can Model (Modelo de Cesto de Basura).}

En cuanto a los proceso decisorios Johan Olsen, James March, Michael Cohen (1972) proponen un modelo a través del cual podrían explicarse los procesos decisorios relacionados con el comportamiento individual, las acción organizada, y las reacciones del medio ambiente, a forma de metáfora toman el proceso decisorio como un cesto de basura (garbage can model) ${ }^{3}$ donde se explica lo relacionado a las acciones y acontecimientos del contexto, se mezclan con otros participantes, problemas, soluciones y situaciones de decisión.

Con lo anterior se refiere a analizar las situaciones de decisión, es decir cuando se espera que la organización tenga un comportamiento denominado decisión tipo cesto de basura en donde los participantes arrojan problemas y soluciones en función de la existencia de cestos, donde se mezclan los problemas que contengan y el tiempo que se disponga y como resultado optan por un cesto o lo dejan por otro. En dicho modelo, los participantes vienen y van entre las distintas situaciones de decisión, al actuar de los participantes es incierto, azaroso e indeterminado. Lo relacionado a los problemas es posible separarlos de quienes los originan y transformarse de tal forma que pueden convertirse en un problema muy diferente y con respecto a las soluciones no pueden considerarse como el resultado de alguien ya que se producen en su mayoría por un complejo proceso de interrelaciones entre los participantes los cuales diluyen la acción

\footnotetext{
${ }^{3}$ Por sus siglas en ingles.
} 
individual, para lo cual es preciso recalcar que el proceso de toma de decisiones se refiere a decisiones estratégicas o no programadas (March et al.,1972).

La organización cuenta con una amplia gama preferencias que son inconsistentes y mal definidas. Esto se puede describir de mejor manera como una colección dispersa de ideas antes que como una estructura coherente; la organización revela las preferencias a través de las acciones, antes que las acciones a través de las preferencias (March et al., 1972).

En el sentido de comprender el proceso decisorio dentro de las organizaciones, se puede realizar una analogía tal como ver la oportunidad de elección como un bote de basura, donde varios tipos de problemas y soluciones son desechadas por los participantes en cuanto son elaborados, "la mezcla de la basura en un solo bote depende de la mezcla de botes disponibles, de las etiquetas pegadas a los botes alternativos y del tipo de basura que se esté produciendo en el momento, así como de la velocidad con la cual la basura es recogida y retirada de la escena" pero es necesario reconocer que existen factores en la estructura organizacional que afectan o influyen en las decisiones en un proceso de decisión de bote de basura (March et al.,1972)

En el caso de las anarquías organizadas los procesos decisorios se entienden mejor si se enmarcan en su contexto, reconocer la interdependencia que tienen como sistema social donde la naturaleza de la elección, el tiempo que toma, y los problemas que resuelven dependen de un complicado entremezclado de estos elementos, lo que incluye una mezcla de elecciones disponibles a un cierto tiempo, una mezcla de problemas que tienen lugar en la organización, una mezcla de soluciones en busca de problemas, y las demandas externas sobre las que toman la decisión.

Así mismo en las anarquías organizadas, la inclusión de estructuras de poder en la toma decisiones supone procesos en los que intereses diversos se sobreponen y contraponen con lo que se origina un flujo sin orden o coherencia.

La imagen de la organización se encuentra plagada de fines ambiguos y conflictivos, con una baja comprensión de los problemas que deambulan tanto al interior como al exterior del sistema, con un medio ambiente variable, y tomadores de decisión con percepciones distintas en mente por lo que dicha imagen se contrapone a la concebida por el modelo racional (López y Solís, 2000: 39). 
El modelo de cesto de basura considera cuatro variables básicas (March et al.,1972):

Flujo de elecciones: Donde cierto número de elecciones se caracteriza por una entrada de tiempo y una estructura de decisión.

Flujo de problemas: Un número de problemas es considerado y se caracteriza por una entrada de tiempo, un requerimiento de energía, y una estructura de acceso refiriéndose a una lista de elecciones a las cuales el problema tiene acceso.

Flujo de las soluciones: es un conjunto más simple de supuestos que pone la atención en la tasa a la cual las soluciones fluyen o se incorporan al sistema.

Flujo de energía de los participantes: cosiste en un número determinado de participantes donde cada participante puede proveer alguna cantidad específica de energía potencial a la organización.

Supuesto de la aditividad de la energía: donde cada elección requiere tanta energía efectiva como la suma de todos los requisitos de los varios problemas a los cuales está añadida.

Supuesto de la localización de la energía: la energía de cada participante está asignada a no más de una elección durante cada periodo y cada participante asigna su energía de entre las elecciones para las cuales él es elegible.

El supuesto de la asignación de los problemas: cada problema está añadido a no más de una elección en cada periodo, eligiendo de entre las que son accesibles.

Es pertinente enmarcar que las anarquías organizadas pueden creerse sistemas flojamente acoplados cuando se dice que los procesos de una parte de la organización no afectan a otras partes de la organización para lo cual el modelos de cesto de basura concuerda con esta idea, ya que la organización es imaginada no solamente como un solo cesto sino coexisten distintos cestos donde la multiplicidad de participantes, problemas, soluciones, situaciones de decisión y contexto no impactan en la existencia de otros ( March, Olsen, 1975: 25).

\subsection{Aspectos metodológicos de las teorías de ambigüedad organizativa.}


Es muy importante referirse a aspectos que se deben considerar a fin de ofrecer una explicación pertinente y relevante en cuanto a la compresión sobre los sistemas flojamente acoplados, por una parte (Weick, 1976:9-11) dice que las actitudes están flojamente acopladas con el comportamiento, pero puede ser que esta conclusión sea un artefacto producido, ya que las actitudes evaluadas con independencia del tiempo y del contexto, se utilizan para predecir conductas dependientes de los mismos. Si tanto actitudes como conductas fueran evaluadas con medidas equivalentes, el fuerte acoplamiento sería la regla.

En el caso de la metodología si lo que se pretende es observar el acoplamiento flojo, entonces se tiene que ver tanto lo que hace como lo que no. La regla general sería que un fuerte acoplamiento en una parte del sistema sólo ocurre si el acoplamiento es flojo en otra parte del sistema.

Por último el investigador debe darse cuenta de que probablemente hay un número infinito de fuertes acoplamientos que puede ocurrir en cualquier momento, que dichos acoplamientos en un lugar implican flojos acoplamientos en otros lugares, que ése puede ser el patrón de acoplamientos que produce los resultados observados.

Un punto esencial en el estudio de los sistemas flojamente acoplados (Weick, 1976:11) es la importancia de descubrir la distribución de los sistemas fuerte y flojamente acoplados dentro de cualquier organización y a su vez reconocer que el problema sugiere la importancia de descubrir la distribución de los sistemas fuerte y flojamente acoplados dentro de cualquier organización.

\section{CAPITULO 3}




\section{Metodología de la Investigación. EI acercamiento al estudio de caso.}

\section{Introducción}

La investigación como tal, requiere de una metodología para acceder al conocimiento, analizarlo y configurarlo de tal manera que pueda hablarse de ciencia, es dentro de ésta, el instrumento más confiable y apropiado para llegar a la verdad, que tiene por fin ampliar el conocimiento científico, sin perseguir, en principio, ninguna aplicación práctica.

Durante el trabajo de campo se da cuenta de la realidad organizativa ofreciendo múltiples aristas para su estudio, bien es cierto los estudios de Ciencias Sociales en su mayoría esencialmente se nutren de investigaciones cualitativas que nos permiten ven el interior de las organizaciones, a través del contacto con el quehacer diario de la organización, sus miembros y como todo ello se encamina al cumplimiento de las metas.

El estudio de caso como herramienta de investigación es esencial por que permite al investigador recabar material descriptivo además de no ser intervencionista de tal forma que el quehacer cotidiano de la organización a estudiar no se vea modificado.

\section{1 ¿Que es investigar?}

La investigación es un proceso formal, sistemático, estructurado e interdisciplinario que va encaminado al descubrimiento de nuevos conocimientos en el campo de las ciencias, las artes o las letras, basado en hechos verificables conectados de manera lógica con el fin de concluir en conocimiento científico no conocido o comprobado, es decir, nuevo conocimiento (Sampieri, 1998). 
La investigación es un proceso sistemático, que nace de la necesidad de descubrir nuevo conocimiento o dar pauta a nuevas líneas de conocimiento que abordaran temas de interés individual o colectivo que beneficien el desarrollo y con éste, el nivel de vida de un país.

Es también la actividad de descubrir alguna cosa (objeto, problema, historia), y en una definición informal investigar sería "estudiar sobre un tema que no sé y no sabré cual es la respuesta que voy a encontrar", se puede partir de esta definición y ver que no todos los problemas de investigación planteados llevan a una solución, pero en realidad investigar es intentar descubrir o conocer alguna cosa, estudiando o examinando atentamente cualquier indicio o realizando las diligencias para averiguar o aclarar un hecho ( Sabino,1996:23).

La investigación como tal, requiere de una metodología para acceder al conocimiento, analizarlo y configurarlo de tal manera que pueda hablarse de ciencia, es dentro de ésta, el instrumento más confiable y apropiado para llegar a la verdad, que tiene por fin ampliar el conocimiento científico, sin perseguir, en principio, ninguna aplicación práctica.

Un punto central y lo que se puede denominar como el hilo conductor de cualquier trabajo de investigación es la identificación del problema para obtener los resultados buscados (Galindo,1998: 42); dicho proceso debe partir de una definición clara de la cual es el objetivo, el cual debe construirse a través del trabajo organizado; al definir un problema se formula un camino que habrá de tomar el proyecto, las circunstancias que lo anteceden y acotan, así como las implicaciones relacionadas, ya que mediante la definición del problema también se determina el qué y cómo lo vamos a medir la problemática de interés para a su vez comprobar la factibilidad.

Es preciso partir que no solo es el simple hecho de investigar, y no solo seleccionar un tema de interés (Sabino 1996: 25), es necesario saber cuál es el problema a resolver y tener en cuenta que se debe partir de un contexto globalizado, es decir, saber cómo está el mundo y las soluciones mundiales alrededor del problema a investigar, posteriormente dependiendo de la investigación a realizar ir centrando o localizando el problema investigativo, una vez se tenga muy claro el problema a resolver, se debe formular una gran pregunta que será resuelta al final con la respuesta dada a muchas 
otras preguntas que fueron surgiendo a través del proceso investigativo, siendo este uno de los primeros pasos para realizar una buena investigación.

La investigación puede asumirse como una forma de encontrar soluciones a "grandes preguntas" o a un problema en particular, en un carácter multidisciplinario se encamina hacia el descubrimiento de nuevos conocimientos en el campo de las ciencias $u$ otro campo, basado en hechos verificables conectados de manera lógica con el fin de concluir en conocimiento científico no conocido o comprobado, es decir, nuevo conocimiento.

Resulta evidente que no hay modo de crear nuevo conocimientos sobre un tema a resolver, o los pequeños y grandes enigmas de nuestro mundo, (Sabino 1996:25) sino se tiene intuición e imaginación, sino se exploran, con mente abierta, los diversos caminos que pueden llegar a la respuesta, pero la disposición creativa es verdaderamente indispensable, de nada sirve sino se encauza por medio de un riguroso proceso de análisis, de una organización de material disponible, de ordenamiento y de critica a las ideas pues, de otro modo, no obtendríamos un conocimiento científico sino simples opiniones, de similar valor a las que cualquiera puede expresar sin mayor reflexión sobre determinado tema.

Es necesario considerar que hay un modo de hacer cosas, de plantearse preguntas y de formular las respuestas que permite al investigador desarrollar su trabajo con orden y racionalidad, y a su vez ir desarrollando una libertad de pensamiento; mediante la crítica, el análisis riguroso, la superación de los errores y la discusión. No basta solo con la creatividad ni con el rigor analítico, la investigación requiere de una sólida disciplina de trabajo; el trabajo de investigación cobra entonces un carácter inevitable de labor artesanal y echar mano de destrezas, conocimientos y aptitudes particulares y que solo investigando se aprende a investigar.

Como se abordo anteriormente, se describió brevemente lo que conlleva el proceso de la investigación, pero el termino metodología nos hace referencia a "método" por lo que es conveniente empezar por definirlo.

No es posible obtener un conocimiento racional, sistemático y organizado actuando de cualquier modo (Sabino, 1996:12); es necesario seguir un método, un camino que nos aproxime a esa determinada meta. 
El autor señala que el estudio del método o de los métodos, si se quiere dar al concepto un alcance más general, se denomina metodología y abarca la justificación y la discusión de su lógica anterior, el análisis de los diversos procedimientos concretos que se emplean en las investigaciones y la discusión acerca de sus características, cualidades y debilidades.

Se hace referencia a "metodología de la investigación" cuando se habla de los pasos y procedimientos que se han seguido en una indagación determinada para designar modelos concretos de trabajo que se aplican en una disciplina o especialidad.

La ciencia no avanza por medio de un proceso mecánico, no solo se trata de formular un problema, aplicar un método y obtener el resultado que esperamos, va mas allá; la investigación es un proceso creativo, que está plagado de dificultades imprevisibles, prejuicios y obstáculos.

\subsection{El Estudio de caso como estrategia en la investigación.}

En el mundo contemporáneo el abanico de escenarios que se aparecen es rico en posibilidades, entorno a ser sujeto de investigación hacia distintas formas de compresión de la realidad. Es importante en cualquier investigación hacer una revisión teórica sobre temas en particular pero también es imperante la necesidad de mostrar que ocurre en la realidad, el estudio de caso (Ander-Egg, 1995:64) se refiere a un fenómeno y a un contexto en particular y a la influencia del estudio de casos en la literatura de la organización que se refleja en algunos de los trabajos empíricos más citados en los textos entre los que destacan los de Mayo (1946), Lawrence y Lorsch (1973), Mintzberg (1990). El estudio de caso como metodología que permite trabajar distintos temas desde una realidad inmediata, tiene como finalidad enseñar a elaborar una explicación histórica, geográfica o social del tema de estudio que sea coherente con el análisis general de la temática en la que se enmarca.

El estudio de caso (Stake,1995: 20) puede modificar también las generalizaciones mayores, ya que el cometido real del estudio de caso es la particularización, no la generalización, entonces se toma un caso particular y se llega a conocerlos bien, en el sentido de poder saber que es y que hace, destacando la unicidad, lo cual implica el 
conocimiento de otros casos de los que el caso en cuestión se diferencia pero sin olvidar que el fin esencial es la compresión.

Se debe considerar primeramente la complejidad de los fenómenos organizativos, lo que requiere de una investigación de carácter exploratorio y comprensivo más que de búsqueda de explicaciones causales, entonces a fin de encaminarse a un tipo de comprensión integral tal y como se orienta la investigación en los estudios de caso como una forma de investigación mas adecuada.

En este sentido, Mintzberg (1990:109) propone que "No importa cuál sea el estado del campo, si es nuevo o maduro, toda investigación interesante explora"; cuando se investiga más profundamente nos encontramos con que son más complejas y por eso se necesita de herramientas y metodologías de investigación más exploratorias.

En esta tesis recurrirá a dicha estrategia de investigación como forma de contrastar lo que se ha encontrado en el discurso y como se mencionó anteriormente, considerar que durante el transcurso de la investigación se podrá encontrar más complejidad y aun mas vetas de investigación que enriquezcan este trabajo.

En una disciplina como las ciencias sociales (Gundermann: 2004: 253) la noción de caso es un componente básico en dicha disciplina, considerando al caso con algo especifico, con un funcionamiento especifico, es como un sistema integrado. Dicha estrategia puede proveer simultáneamente información sobre las características individuales de los miembros de una colectividad; en el extremo, toda investigación social puede ser considerada un estudio de caso, puesto que dirige su atención a un fenómeno provisto de especificidad y limites espacio temporales definidos.

Según Gundermann (2004) la finalidad de investigar casos puede ser de manera intrínseca o instrumental, el caso aparece como el foco final de interés, bajo una óptica instrumental los estudios de caso aspiran a ser un medio de descubrimiento y desarrollo de proposiciones empíricas de carácter mas general que el mismo caso.

La utilidad es amplia de acuerdo al tema que se abordará en este trabajo ya que como una estrategia de investigación se considera una estrategia privilegiada para la elaboración teórica que arroja información relevante en cuanto a la construcción de material descriptivo y nos proporciona un mapeo importante sobre la organización que se estudia. 
Entonces es importante considerar que el buen estudio de caso es paciente, reflexivo, dispuesto a considerar otras versiones; el estudio de caso es empático y no intervencionista, es decir no estorbar en la actividad cotidiana del caso conservando las realidades múltiples que pueden coexistir en las organizaciones (Stake, 1995:23).

\subsection{La metodología cualitativa como esquema de investigación.}

En este apartado abordaremos el tópico referido a la manera de obtener y analizar la información; de manera precisa para este trabajo se refiere solo a la investigación cualitativa por sus particularidades y pertinencia.

Investigación cualitativa: hacia su objeto de estudio sucede sin interrogantes o hipótesis preconcebidas (Sampieri 1998:60) ya que esto implicará contaminar la realidad que se pretende conocer, el investigador en este tipo de estudios, debe estar consciente de la influencia que el mismo puede ejercer sobre su objeto de estudio, porque la recopilación y el análisis de la información que se lleva a cabo a través de procedimientos sistemáticos que se basan en la estadística, no pretende la generalización de sus resultados.

Por lo anterior, debido al objeto de estudio y a fin de tener información de viva voz, este trabajo se orientara a una investigación de tipo cualitativa y se recurrirá a las herramientas de investigación que este tipo de investigación propone, tal como podría ser la elaboración de entrevistas a los actores más importantes que participan activamente en el Comité UNAM que es el foco de este trabajo.

De tal forma que como se comentó anteriormente es necesario obtener información de viva voz y conocer las percepciones, experiencias, vivencias y prospectiva del objeto de estudio de este trabajo y a su vez mostrar imparcialidad ante la información que se brinda en el transcurso de la elaboración de las entrevistas.

Para lo anterior, es preciso la creación de un guion de entrevista para encauzar de forma objetiva la entrevista, posteriormente se dará evidencia del guion de entrevista.

Para explicar brevemente las principales características de estos tipos de investigación se muestra el cuadro siguiente a fin de justificar la elección. La tabla siguiente muestra las particularidades de cada tipo de investigación y as $u$ vez como 
síntesis de información, permite adecuar el estudio de caso para efectos de la investigación que se desarrollará en este trabajo.

Tabla 3: Características de la investigación cualitativa y cuantitativa.

\begin{tabular}{|l|l|}
\hline INVESTIGACION CUALITATIVA & INVESTIGACION CUANTITATIVA \\
\hline Datos cualitativos & Datos cuantitativos \\
\hline Investigación en contexto naturales & En contextos artificiales \\
\hline Preferencia por los significados & Preferencia por las conductas \\
\hline modelo & $\begin{array}{l}\text { Adopción de las ciencias naturales como } \\
\text { modelo }\end{array}$ \\
\hline Enfoque inductivo & Enfoque deductivo \\
\hline Búsqueda de patrones culturales & Identificación de leyes científicas \\
\hline
\end{tabular}

Fuente: Elaboración propia en base a Sabino (1996).

El método cualitativo es más comprensivo, y por ello puede aplicarse a análisis globales de casos específicos, en tanto que el método cuantitativo es más parcial pues estudia aspectos particulares o generaliza pero desde una sola perspectiva, por otra parte hay que recordar que un problema es siempre cualitativo.

Es importante considerar que un problema se puede definir como la diferencia entre una situación que existe en la realidad de una persona o de un grupo y una situación deseada (ideal); en realidad la formulación del problema es el elemento central en la investigación social y la guía para la formulación de hipótesis eventuales (Sabino, 1996:70) no obstante, la demostración o la refutación de las hipótesis depende en muchos casos del análisis de los datos cuantitativos. Lo que se puede observar en la investigación tradicional es el movimiento del inicio cualitativo (del problema) a la conjugación de los datos en las hipótesis, que es principalmente cuantitativo y su interpretación que es otra vez cualitativa. 


\subsection{De las herramientas de investigación.}

La manera más formal de proceder a la búsqueda de información (Ander-Egg, 1995:54) es seguir los lineamientos del método científico. El proceso consiste en:

- Recoger la información.

- Tabularla.

- Presentarla.

- Analizarla.

El aspecto medular del manejo de información es la recolección, ya que el procesamiento de datos depende de la confiabilidad que aquélla pueda tener.

Los métodos de recolección de datos (Ander-Egg, 1995: 54) aparecen como una constante en investigaciones de tipos social, con las cuales se llegerá de primera estancia al primer acercamiento con las organizaciones y de manera constante las herramientas empleadas, de las cuales solo de emplearan algunas con fin de una recoleccion de información optima.

- Encuestas: se levanta por muestras, por lo que no se aplica a la población total.

- Entrevista ( esta herramienta es la que se utilizará en este trabajo)

Por lo anterior a fin de realizar la investigación de forma óptima recurrimos a la herramienta de investigación (Ander-Egg, 1995: 54) que es la entrevista con el fin de que se nos brinde información de viva voz en el proceso de recolección de información, para lo cual es preciso la elaboración de un listado de preguntas (Anexo 1) con el cual se posible apoyarse en la recolección de información precisa para la investigación que nos atañe en este trabajo, mas adelante se mostrará como y a quienes se realizaran las entrevistas, el cuestionario (Galindo, 1998:67) cuenta con los criterios de focalización, brevedad, y claridad, además debe mostrar simplicidad, relevancia y no denotar algún tipo de dirección. Para dicho proceso se tomaran en cuenta a las personas que han sido 
elementos importantes en la creación de nuestro objeto de estudio. Más adelante mostraremos el orden de las entrevistas.

La que es de relevancia en nuestra investigación, es la entrevista, es por eso que se precisa más en ese punto la entrevista (Ander-Egg, 1995:25) y la encuesta es una averiguación en la que se emplean cuestionarios para conocer la opinión pública. Consiste en el acopio de testimonios orales y escritos de personas vivas. En la investigación de campo, para la recopilación de información pueden utilizarse las entrevistas, los cuestionarios y el muestreo, entre otros. La entrevista es una de las técnicas más usuales en ciencias sociales. Puede definirse como la relación que se establece entre el investigador y los sujetos de estudio. Puede ser individual o grupal, libre o dirigida. En cuanto a la entrevista es un proceso ordenado que va desde los objetivos hasta el cierre de la entrevista; a fin de que una entrevista sea mas productiva en su elaboración, como a continuación se explica:

Objetivos de la entrevista:

1. Obtener información sobre el objeto de estudio.

2. Describir con objetividad situaciones o fenómenos.

3. Interpretar hallazgos.

4. Plantear soluciones.

Por otra parte la investigación se tornara también de tipo documental, refiriéndose, a la revisión de documentos que den hecho de la creación de AIESEC-Comité UNAM, sus proyectos, historia, estructura, reglamentos y en general su acervo documental para que nos brinde información necesaria para la realización de nuestra investigación.

Con "estudio de caso" no referimos a nuestro objeto de estudio que es AIESECComité UNAM. A fin de brindar un antecedente breve, AIESEC en México cuenta con 47 años de experiencia desarrollando jóvenes con alto potencial en líderes responsables con mentalidades globales.

Presente en más de 107 países y territorios y con más de 45.000 miembros, AIESEC es la más grande organización en el mundo dirigida por jóvenes. Enfocados en brindar una plataforma para el desarrollo del liderazgo juvenil, AIESEC le ofrece a los jóvenes la oportunidad de participar en intercambios internacionales, experiencias de liderazgo y participar en un entorno global de aprendizaje. 
La identificación mediante la revisión documental permitirá evaluar si la organización cuenta con manual de procedimientos, organigramas, estructura documental, seguimiento de proyectos, y sobre todo, cuales han sido los resultados desde su creación, verificar si las actividades sustantivas de esta organización se cumplen o no, o si por el contrario, se han superado las expectativas.

Posteriormente, y no por ser de menor importancia, una vez reconocidos los participantes de dicho proyecto, responsables y creadores a fin de conocer cual es su función anterior y actual en el comité, se dará paso a realizar entrevistas a dichas personas con el objetivo de conocer sus impresiones, proyectos, expectativas y conocer de viva voz lo obtenido por este proyecto y sobretodo si hay planes a largo plazo a fin de dar seguimiento y consolidación del comité y su devenir, dichas entrevistas nutrirán la comprensión de la organización y la detección de la posible problemática que la aqueja.

\subsection{El proceso de investigación. Mapeo de la organización-caso de estudio.}

En un primer momento se determinó a manera de un primer acercamiento entrevistas a fin de tener información de viva voz de los integrantes de la organización como se muestra a continuación:

Flujo de entrevistas.

Como un proceso con el cual se pretende recabar toda la información posible, el flujo de entrevistas se dirige en un primer momento al comité UNAM por ser el objeto de estudio, y el contacto inicial para el estudio de la organización, posteriormente las condiciones favorecieron para expandir el estudio hacia otras partes de la organización, situación que favoreció la integración de la información de manera integral y nutrió la investigación con distintos puntos de vista lo que permitió contar con un panorama mas amplio de la situación actual de cada comité ubicado en cada unas de las universidades, encontrando en su mayoría heterogeneidad en los procesos y las formas de organizar el trabajo.

Principalmente las entrevistas se realizaron en el siguiente orden y sucesivamente se llevó acabo de la misma manera. 


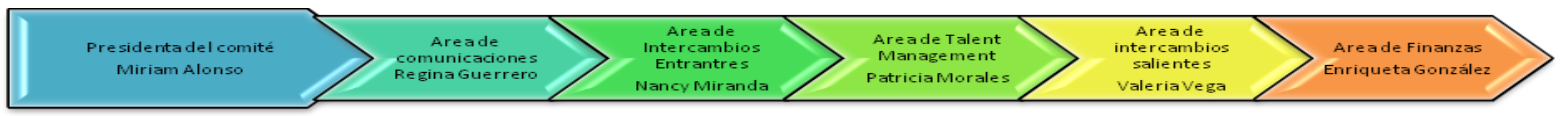

Figura 2: Orden de entrevistas.

Fuente: creación propia

Particularmente para este trabajo de investigación se realizaron entrevistas al presidente del comité nacional y los distintos comités de AIESEC México respectivamente, de tal forma que la información fuera abundante y permitiera reconocer las particularidades, disfunciones y características del comité UNAM como caso de estudio específico para determinar que le permite ser uno de los comités más productivos en cuanto a intercambios estudiantiles se refiere.

Es preciso decir que el flujo de entrevistas fue el mismo en el caso se Comité Nacional y de los otros comités, el cual se englobó en entrevistar al presidente, vicepresidente y staff, dichas entrevistas se realizaron de acuerdo al directorio de los comités que se proporcionó, formando una especie de paneles con los miembros de cada comité a nivel presidente, vicepresidentes y staff dadas las condiciones en que se prestaran las entrevistas. Por cuestiones de tiempo y espacio se determinó hacerlo de esa forma a fin de obtener información generalizada y de fuentes primarias a los miembros que ocuparan los comités. ${ }^{4}$

Con las entrevistas se pretendió recabar información de viva voz de las personas que dieron pauta a la creación del comité, mostrando imparcialidad, respeto, tacto y empatía, para así poder conocer los puntos más importantes en el proceso de creación y consolidación del proyecto.

Es necesario recalcar que el primer acercamiento se tuvo con comité UNAM por que fue la organización que mostró apertura dado el interés por estudiarla, la presidenta de comité UNAM siempre se mostró abierta y cada unos de los presidentes de las demás áreas que conforman comité UNAM de igual forma cooperaron con la investigación, sin

\footnotetext{
${ }^{4}$ Ver anexo 2, directorio AIESEC.
} 
embargo un momento crucial se dio al tener la posibilidad y apertura de estudiar los demás comités que conforman AIESEC México, Regina Guerrero presidenta de comité UNAM hizo el contacto posible y realice la investigación hacia todos los demás comités comenzando por comité nacional que es el comité regulador por excelencia, posteriormente al Institutito Politécnico Nacional hasta terminar con el de la Universidad Iberoamericana, lo cual nutrió e hizo de la investigación un trabajo mas integral.

Las entrevistas fueron de forma individual para estudiar una a una; cada una de las entrevistas, se orientó de tal forma que las entrevistas que se realizaron fueron de lo más productivas y significativas para que se efectuara un intercambio de información sobre nuestro objeto de estudio, y pudiera proporcionar la mayor parte de la información útil para la investigación y darnos un panorama más amplio.

La información que se recabo estuvo relacionada con opiniones, expectativas, necesidades, consejos y los planes a largo plazo del comité; las opiniones, comentarios, ideas o sugerencia en relación a como se podría mejorar su actividad diaria etcétera; de esa forma nos acercamos a la organización y a conocerla como una forma de mapeo, lo anterior por medio de la entrevista. 


\section{CAPITULO 4}

\section{Una ONG flojamente acoplada. EI caso de AISEC Comité UNAM}

\section{Introducción}

Este apartado tiene por objetivo mostrar en extenso el trabajo de investigación llevado acabo en la organización y dar un recorrido por toda la información recabada que en un primer momento nos acerca a posibles problemáticas que son intermitentes en la organización; se transita desde su configuración hasta el mismo contacto con los miembros de la organización de tal forma que el recorrido toma forma y a través de la lente de los estudios organizacionales permite avizorar aspectos mas profundos que la estructura misma.

\section{1 ¿Que es AIESEC Internacional?}

Presente en más de 107 países y territorios y con más de 50.000 miembros, AIESEC es la mayor organización mundial dirigida por estudiantes. Enfocada en proveer una plataforma para el desarrollo de liderazgo juvenil, AIESEC ofrece a los jóvenes la 
oportunidad de ser ciudadanos del mundo, para cambiar el mundo, y para adquirir experiencia y habilidades que importa hoy en día.

La definición y la imagen sobre la organización a nivel mundial se definen como una plataforma internacional por la cual los jóvenes descubran y desarrollen su potencial con el objetivo de tener un impacto positivo en la sociedad.

AIESEC es una organización no gubernamental de talla internacional que funciona por estudiantes y recién graduados de instituciones de educación superior que crean un impacto positivo en la sociedad a través de experiencias de intercambio que permita una difusión cultural llevando la paz a nivel mundial, sin discriminar razas, religiones, sexo, culturas u orígenes.

La historia ${ }^{5}$ de AIESEC a su fundación en 1948 para establecer y promover relaciones amistosas entre países de tal forma que se convirtiera en una organización internacional que se conforma actualmente por más de 80 países a nivel mundial.

En sus 55 años de historia AIESEC ha cambiado a la par de los cambios mundiales, las tendencias y los eventos en el ámbito global han cambiado simultáneamente la misión y filosofía de AIESEC, la tabla siguiente recorre las modificaciones a su visión hasta la última en 2010:

\footnotetext{
${ }^{5}$ Consultado en documentos internos y a su vez la información se encuentra en la página de internet, el documento se encuentra en ingles, la traducción es propia

.http://www.aiesec.org/cms/export/sites/default/Al/60/files/All_60Book_08_LR.pdf
} 
Tabla 4: Cambios en misión y definición de AIESEC a través del tiempo

\begin{tabular}{|c|c|c|c|}
\hline \multicolumn{4}{|c|}{ Modificaciones la misión y objetivos de AIESEC } \\
\hline Año & Misión & Actividades principales & Definición \\
\hline 1948 & $\begin{array}{l}\text { Establecer y } \\
\text { promover relaciones } \\
\text { fraternales entre los } \\
\text { miembros }\end{array}$ & $\begin{array}{l}\text { Intercambios de estudio e } \\
\text { intercambios culturales. }\end{array}$ & $\begin{array}{l}\text { AIESEC es una asociación internacional independiente, sin afiliación } \\
\text { política, la cual tiene el propósito de establecer y promover relaciones } \\
\text { fraternales entre los miembros. }\end{array}$ \\
\hline 1964 & $\begin{array}{l}\text { Disminuir las } \\
\text { diferencias y } \\
\text { mejorar la } \\
\text { comprensión } \\
\text { internacional. }\end{array}$ & $\begin{array}{l}\text { Comenzar el intercambio en } \\
\text { forma de prácticas } \\
\text { profesionales. } \\
\text { Viajes de estudio. }\end{array}$ & $\begin{array}{l}\text { El objetivo de la asociación se llevará a cabo por los miembros de la } \\
\text { organización y sus aprendices, brindar el suministro de contactos y otras } \\
\text { instalaciones para los estudiantes de visita, y llevar a cabo intercambios con } \\
\text { estudiantes }\end{array}$ \\
\hline 1978 & $\begin{array}{l}\text { Desarrollar una } \\
\text { nueva generación } \\
\text { de managers con } \\
\text { una compresión } \\
\text { internacional }\end{array}$ & $\begin{array}{l}\text { Intercambios en forma de } \\
\text { prácticas profesionales. } \\
\text { Actividades administrativas. }\end{array}$ & $\begin{array}{l}\text { AIESEC será una organización independiente, no político, una asociación } \\
\text { internacional sin fines de lucro de carácter científico, cuya finalidad será el } \\
\text { desarrollo internacional de la educación que puede afectar a diversos } \\
\text { entornos económicos } \\
\text { con este fin se AIESEC construirá puentes entre la dirección, académicos, } \\
\text { estudiantes y las comunidades para favorecer la comprensión, la buena } \\
\text { voluntad y empatía por las actitudes de gestión diferentes }\end{array}$ \\
\hline 1989 & $\begin{array}{l}\text { La comprensión } \\
\text { internacional y la } \\
\text { cooperación de los } \\
\text { países y las } \\
\text { comunidades }\end{array}$ & Proyectos de base social & $\begin{array}{l}\text { Plantea una visión: la paz y el cumplimiento de de objetivos encaminados a } \\
\text { explorar el potencial de la humanidad. } \\
\text { Objetivo: contribuir al desarrollo de nuestros países y sus pueblos y } \\
\text { compromiso primordial de la comprensión internacional y la cooperación }\end{array}$ \\
\hline 2010 & $\begin{array}{l}\text { Búsqueda de una } \\
\text { red mundial de } \\
\text { personas y } \\
\text { perspectivas }\end{array}$ & $\begin{array}{l}\text { Ser un puente de talla } \\
\text { internacional para la profesión } \\
\text { que los jóvenes desean }\end{array}$ & $\begin{array}{l}\text { Ser una plataforma para el cambio que los jóvenes desean ver. } \\
\text { Ser un mundo de oportunidades. }\end{array}$ \\
\hline
\end{tabular}


Fuente: elaboración propia de acuerdo a la consulta de documentos internos. 
Para lo cual es también importante hacer mención de su acta constitutiva emitida el 19 de julio de 1963 refiere que su objetivo es "Permitir a sus miembros conocer y familiarizarse con las organizaciones, sistemas y técnicas económicas y comerciales de los países miembros de AIESEC Internacional por todos los medios posibles, especialmente por el intercambio de puntos de vista y opiniones entre sus asociados a través de conferencias, publicaciones, películas, visitas, seminarios, entrenamientos y firmas comerciales, intercambios, becas y demás que le corresponde de acuerdo con estos estatutos y la ley". (Entrevista Presidenta comité UNAM 2010)

En cuanto a valores ${ }^{6}$ se refiere se encuentra lo siguiente:

- Activar el liderazgo: Predicamos con el ejemplo e inspiramos el liderazgo a partir de nuestras actividades. Tenemos completa responsabilidad en nuestro rol de desarrollar el potencial de la gente.

- Demostrar integridad: Somos consistentes y transparentes en nuestras decisiones y acciones. Nos regimos y comprometemos con nuestra conducta y actuamos de acuerdo a nuestros ideales.

- Vivir la diversidad: Buscamos aprender de diferentes maneras de vivir y opiniones representadas en un ambiente multicultural. Respetamos y fomentamos la contribución de cada persona.

- Disfrutar la participación: Creamos un ambiente dinámico a través de entusiastas y activos individuos. Disfrutamos vernos involucrados con AIESEC.

- Luchar por la excelencia: Clamamos por obtener el más alto desempeño de calidad en todo lo que hacemos. A través de creatividad e innovación buscamos mejorar continuamente.

- Actuar sosteniblemente: Actuamos de una manera sostenible para nuestra organización y sociedad. Nuestras decisiones toman en consideración las necesidades de futuras generaciones.

\footnotetext{
${ }^{6}$ Consulta en documentos internos de AIESEC.
} 


\subsection{Orígenes y desarrollo de AIESEC}

Durante 1948 Europa se encontraba en caos y en ruinas después de la segunda guerra mundial por la cual millones de personas murieron y el resto despojadas de todo sus bienes y devastadas por la situación de su país.

Fue entonces cuando en 1948 un grupo de estudiantes de 9 universidades y 6 países diferentes, se reunieron para debatir y crear nuevas alianzas que permitieran la creación de una organización.

En los primeros años de la Association Internationale des Etudiants en Sciences Economiques et Commerciales $^{7}$ (AIESEC), las actividades en materia de intercambio consistieron en prácticas, viajes de estudio y el intercambio de información sobre los estudios; los períodos de prácticas se organizaban durante los meses de noviembre o diciembre a través una cuidadosa selección de los "comités locales" (grupos de miembros de AIESEC) y se formalizaron como tal sus actividades y la formación de comités en el verano siguiente. Sus esfuerzos se vieron materializados después del congreso de Copenhague (1952) frente a procedimientos uniformes y contratos de trabajo bien establecidos para el intercambio lo cual formalizo sus actividades. Ver anexo 3 recorrido histórico en imágenes.

En ese entonces los esfuerzos por llevar acabo y promover los intercambios se comportaban de forma positiva y en crecimiento constante a pesar de las condiciones políticas,

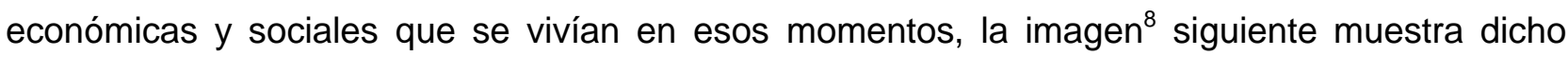
comportamiento:

\footnotetext{
${ }^{7}$ En la actualidad, el acrónimo francés de AIESEC ha dejado de ser utilizado por la organización ya que en la historia AIESEC se ha ampliado a otros fondos diferentes de Ciencias Económicas y Comerciales. Entonces se pide usar AIESEC simplemente como es.

${ }^{8}$ Dicha imagen fue consultada en documentos internos del comité, relacionados con la historia de AIESEC.
} 
Figura 3: Proporción de intercambios realizados entre el periodo 1949-1953.
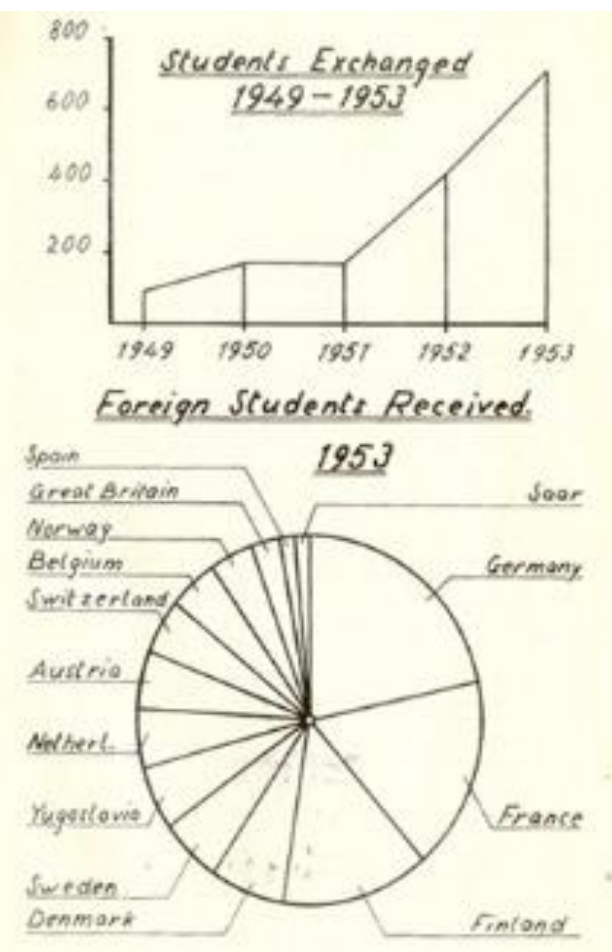

Fuente: Documentos internos.

Como se puede observar el mayor número de jóvenes en intercambio recibidos en otros países pertenecían a Alemania, como una forma de salir de las condiciones propias de su país en búsqueda de mejores condiciones de vida además de observar un proceso de intercambio claramente en aumento en ese entonces.

El desarrollo de la organización orientado al intercambio estaba progresando bien con un crecimiento anual de $22 \%$, pero hubo una creciente preocupación por la calidad de los intercambios y por lo tanto durante el verano se conforma AIESEC Escuela de Formación de Programas (SSTP) que se introdujeron en 1966. 
Era un movimiento de expansión de la "tradicional" forma de programas de prácticas de intercambio para brindar más experiencias significativas para el participante de intercambio. SSTPs contrató a un número limitado de alumnos seleccionados no solo en formación única sino en un campo o tema común en un proyecto. Cada semana se tomó un tiempo libre de sus empresas para satisfacer conferencias y debates en grupo y al final de su periodo de prácticas, los informes individuales se produjeron. A finales de 1969, SSTPs se llevaron a cabo en once países diferentes.

La presencia de AIESEC cada vez fue expandiéndose a nivel mundial, haciendo a más países miembros entorno a un ambiente de cooperación.

En 1967 se empezó a trabajar en un programa denominado Sistema de Intercambio de Estudiantes de Prácticas (Stres) con enfoque eficaz para facilitar el flujo y la normalización de la información y los números de intercambios, que para ese entonces ya habían alcanzado la marca de 4500 lo que extendía la capacidad de AIESEC.

En 1970 a nivel global ocurrían cambios importantes, Vietnam estaba en guerra, la economía global crecía y muchas de las compañías multinacionales que existen en la actualidad aparecían, tales como IBM, Mc Donalds, etcétera.

\subsection{El desarrollo profesional de AIESEC.}

Desde sus inicios en 1948 y hasta antes del desarrollo tecnológico de sistemas, la compartición de documentos y archivos se hacía vía correo postal, tardando de un mes hasta seis meses en el envío y recepción de material.

Los intercambios se hacían posibles sólo durante conferencias internacionales, donde se reunían líderes de AIESEC de diferentes países con la información necesaria sobre prácticas vacantes y perfiles disponibles que pudieran coincidir con los requisitos de las prácticas.

La comunicación intercomites a nivel local y mundial era una tarea imprescindible para lograr un flujo de información adecuado a pesar de la distancia, es hacia 1990 donde derivado de las necesidades de comunicación expedita y tiempo real a pesar de las barreras de tiempo espacio, se implementa la vía de comunicación "WISIQ" la cual facilita a los miembros de todos los comité locales e internacionales tener conversaciones en tiempo real, lo cual hasta hoy en día permite a los comité una comunicación expedita así como una supervisión continua hacia el 
interior de cada comité y con miembros de comités internacionales; es preciso mencionar que "Entre ellos compartían información indispensable a fin de poder continuar el proceso desde sus países de origen". (Entrevista con presidenta del comité UNAM, 2012)

Pero es hasta 1990 que el desarrollo tecnológico permite crear más programas especiales para el desarrollo de los intercambios en AIESEC. En 1992, AIESEC crea su primer plan organizacional a largo plazo para intercambios, llamado DIRECTION 96' y este plan concluyó en 1996 cuando, en Polonia, se decidió enfocar los esfuerzos de la organización totalmente en intercambios.

Esa década el desarrollo tecnológico contribuyó en gran medida para la adopción de computadoras personales y el comienzo del uso de Internet. El desarrollo de estos sistemas hizo que el proceso de intercambios fuera más rápido y sencillo.

A partir de 2006 comienza el uso de la plataforma www.myaiesec.net, base de datos internacional donde se guarda la información de los entrenados y las prácticas disponibles, apartadas y realizadas en AIESEC a lo largo de los últimos cinco años. Esta plataforma facilita la comunicación entre comités de todo el mundo, agilizando procesos de contacto y hasta migratorios.

Los avances en tecnologías información (TIC's) en la década de 1990 vivieron un desarrollo continuo en cuanto a comunicación e intercambio se refiere. La aparición de AIESEC Mundial de Sistemas de Información (AGIS) esencialmente adoptó la tecnología de Internet para conectar nuevas operaciones en todo el mundo para poder ejecutar las reuniones en línea en tiempo real, lo que se denomino "Insigth" a través de WISIQ; lo que fomento el libre acceso a la web lo que derivó en cambios al Programa de Intercambio Internacional de Prácticas (PIEE); ya que era posible administrarlo en línea y gran parte de los presupuestos de los comités locales fueron liberados para expandir dicha forma de comunicación.

Dicha visión tenía la ventaja de usar el Internet para enviar datos y la promoción continua lo cuál fue posible llevarse a cabo en momentos determinados. "Lamentablemente los éxitos de Insight fueron superados en número por problemas con el sistema, por lo que quedó claro que se requería una nueva versión sin embargo terminó siendo utilizada por varios años hasta el inicio de la perspicacia del XP en el 2004". (Entrevista Presidenta comité UNAM, 2011)

La introducción de las cuestiones basadas en experiencias (IBXPs) comenzó como una forma de garantizar que los jóvenes que han identificado una pasión por un tema en particular 
tengan la oportunidad de vivir una experiencia que no sólo les permite adquirir conocimientos generales de liderazgo, sino también conocimientos sobre un tema en particular. Este proceso complementa lo que AIESEC ofrece a sus miembros; experiencias para apoyarlos en el desarrollo de competencias necesarias para liderar el cambio positivo personal y dentro de una organización en vías del liderazgo positivo que necesita el mundo.

Los miembros de AIESEC tienen la oportunidad de dirigir equipos y ser acreedores a las prácticas internacionales, mientras que las organizaciones se benefician del acceso a la base de miembros de AIESEC.

Desde el 2000, la organización experimentó un aumento constante en lo que se refiere a intercambios estudiantiles con más de 5000 estudiantes enviados en prácticas en 2008. La introducción de prácticas de desarrollo, como un grupo distinto de intercambios, agregó diversidad en las experiencias que ofrece.

En 1998, AIESEC Internacional decidió traer a Diana Old, fundadora del Grupo RAE, firma de consultoría profesional, para que la organización tuviera un cambio importante. AIESEC ya no sólo buscaba crecer a través de intercambios, sino que se constituyó como una verdadera organización que permitía mejor entendimiento entre sus miembros. Se crearon una misión, visión, valores, estructura e iniciativas.

En el congreso internacional de presidentes de 1999 en Taiwan fue que se introdujo la propuesta del grupo RAE, y ayudó a conformar la visión 2005 de AIESEC. Se propuso el AIESEC WAY que engloba: WHAT WE ENVISION como su visión, OUR IMPACT como sus objetivos y THE WAY WE DO IT que es la manera en que la organización hace las cosas. "Te lo digo esta forma por que s la forma en la que la manejamos, así tal cual, en ingles (Entrevista presidenta comité UNAM, 2011).

A continuación a manera de ilustración se expone los que se planta como metas y objetivos organizacionales tal y como se muestra en sus documentos internos:

\section{AIESEC WAY:}

- Our impact: A través del desarrollo de los individuos, se contribuye al desarrollo de comunidades locales e internacionales a través del compromiso primordial de cooperación internacional y entendimiento. 
- $\quad$ The way we do it: AIESEC facilita intercambios internacionales y el soporte de actividades que proporcionen experiencias de aprendizaje práctico para los entrenados y facilita el aprendizaje de los miembros y otros aliados.

Para 2005, se redefinieron los objetivos de la organización para que el AIESEC WAY quedara de la siguiente manera:

- Facilitar la comunicación interna y externa para crear una sola imagen y mensaje alrededor del mundo sobre la organización.

- Reforzar la descripción y los ideales de AIESEC.

En ese entonces, el slogan de AIESEC fue: "la plataforma internacional para gente joven para descubrir y desarrollar su potencial". Para 2007 el slogan cambió a: "la plataforma internacional para gente joven que explora y desarrolla su potencial de liderazgo".

En 2008, AIESEC celebró 60 años de activar el liderazgo y fue en ese año que, Martti Ahtisaari, un miembro de la organización, obtuvo el premio Nobel de la Paz. A la fecha se ha buscado que los miembros de AIESEC tengan un rol proactivo en su sociedad, desarrollando una conciencia de sí mismos y una visión personal, así como la construcción de redes y desarrollo de su capacidad de impulsar el cambio y ofrecer oportunidades a los (as) estudiantes de vivir una experiencia que cambiara su visón de trabajo en cualquier organización.

Hoy en día presente en más de 107 países y territorios y con más de 50.000 miembros, AIESEC es la mayor organización mundial dirigida por estudiantes enfocada en proveer una plataforma para el desarrollo de liderazgo juvenil, AIESEC ofrece a los jóvenes la oportunidad de ser ciudadanos del mundo, para cambiar el mundo, y para adquirir experiencia y habilidades que importa hoy en día. AIESEC actualmente ha brindado más de 5,000 oportunidades de liderazgo, más de 3,500 oportunidades de intercambios internacionales, más de 350 conferencias alrededor del mundo y herramientas virtuales para la construcción de redes.

Las estadísticas muestran lo siguiente ${ }^{9}$ :

- 107 países y territorios

- $\quad 1,700$ universidades

- $\quad 45,000$ miembros

- $\quad$ Trabajo en el extranjero 8,500 a través de experiencias

${ }^{9}$ www.aiesec.org fecha de consulta febrero 2013. 
- 4,000 Socios / patrocinadores

- $\quad 470$ conferencias al año

- 60 años de experiencia

La organización AIESEC sigue en aumento, la organización se consolida y crece aun más con el interés de sus miembros por ofrecer más oportunidades a los jóvenes y brindar una forma de cambio en su ámbito de acción ${ }^{10}$ :

Figura 4 : Red mundial de AIESEC

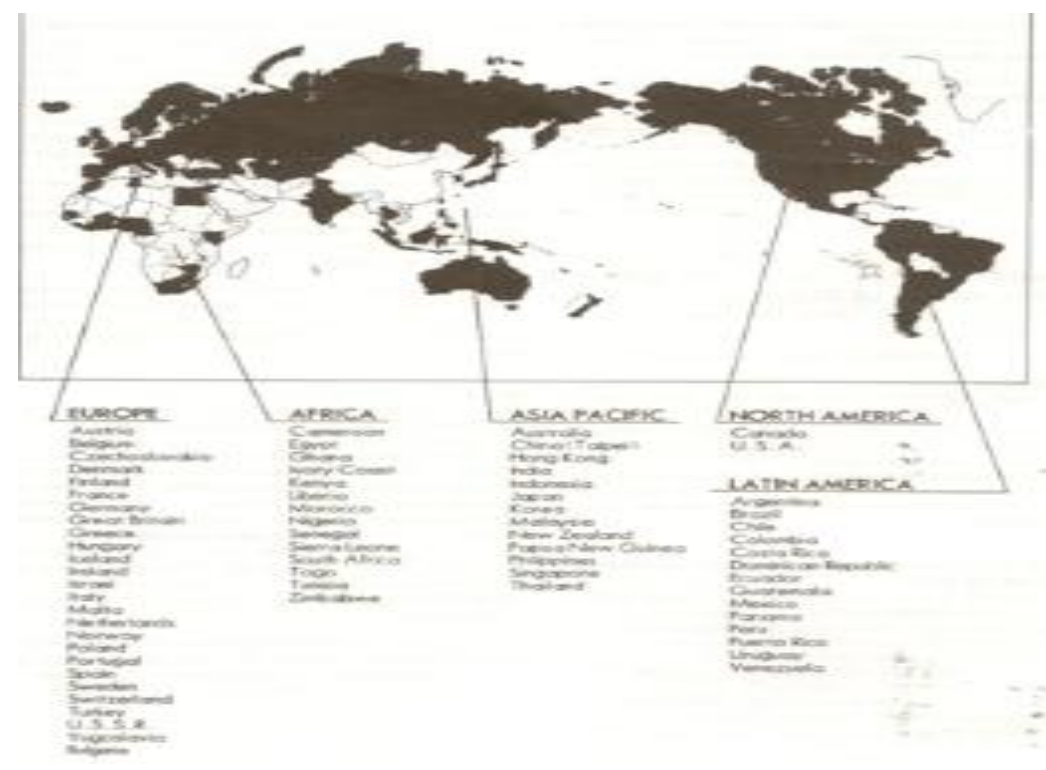

Fuente: Documentos internos.

AIESEC esta conformada por personas y perspectivas están en 110 países, bien es cierto su presencia también ha llegado a México, y como tal ese será el núcleo de dicho trabajo.

La Visión 2015 es: "Involucrar y desarrollar a cada persona en el mundo. Nuestro crecimiento físico y alcance virtual nos hace la voz juvenil más creíble y diversa a nivel global.

${ }^{10}$ Consulta de documentos internos y la imagen también proviene de dicha consulta. 
Somos reconocidos a través de diferentes sectores como la opción número uno por nuestra habilidad para desarrollar liderazgo responsable y emprendedor. Nuestro ambiente de colaboración invita a cada miembro a tener una experiencia AIESEC de alta calidad, creando un impacto positivo a través de generaciones en la sociedad"11.

\subsection{AIESEC México ${ }^{12}$}

AIESEC en México cuenta con 47 años de experiencia desarrollando jóvenes con alto potencial y formando líderes responsables con mentalidades globales.

En México participa activamente con los estudiantes en más de 60 universidades y 20 entidades locales ubicadas dentro de estas universidades en México. Durante los últimos 47 años en México han sido capaces de proporcionar 5640 Experiencias de Liderazgo, y más de 10.340 experiencias trabajando en el extranjero a través de los programas de intercambio que han ofrecido.

AIESEC México utiliza un enfoque innovador para atraer y desarrollar a los jóvenes de hoy. Al ofrecer oportunidades para construir extensas redes personales a nivel internacional y explorar las oportunidades de liderazgo, proporciona una plataforma para que los jóvenes descubran la dirección y la ambición de su futuro.

En México, todo esto es dirigido por los jóvenes y para los jóvenes, permitiendo una experiencia sólida para todos los interesados.

Los miembros son parte de una red mundial. Son capaces de contribuir al cambio social, mientras exploran su propia visión para un impacto positivo en la sociedad. Están apoyados por cientos de organizaciones asociadas en México y miles de organizaciones asociadas en todo el mundo que miran a AIESEC para apoyar el desarrollo de la juventud y para acceder a los mejores talentos a través del programa de intercambios globales.

Los egresados son líderes dentro de sus organizaciones y comunidades. Utilizan la experiencia, las habilidades y la inspiración que AIESEC les ha proporcionado para ser agentes de cambio positivo dentro de México y la sociedad actual.

\footnotetext{
${ }^{11}$ Consulta de documentos internos.

${ }^{12}$ Consulta de documentos internos.
} 
AIESEC en México se relaciona con miles de empresas y organizaciones para lograr que les sea posible la adquisición de talento altamente competitivo internacional y un posicionamiento global constante a través de programas personalizados y flexibles para ofrecer el talento que encaja con la cultura de las empresas y procesos. Como socio nacional de AIESEC en México la fuerza de trabajo se enriquece con una mente global en jóvenes profesionales que buscan hacer una diferencia en las organizaciones.

\subsection{Estructura Organizacional de AIESEC México.}

Sobre la estructura del comité casi siempre ha sido la que se tiene actualmente: Presidente de comité local, Director de Gestión de Talento, Director de Comunicaciones y Gestión de la Información, Director de Finanzas, Director de Intercambios Salientes, Director de Intercambios Entrantes, Director de Relaciones Externas, Coordinación de exmiembros de la asociación (Alumni).

En 2009 la estructura se modificó un poco pues además de las diferentes direcciones había una que se llamaba: Dirección de Relaciones de Soporte, que realizaba lo que hoy realiza (y siempre ha hecho) la Dirección de Relaciones Externas, que es establecer relaciones con facultades y apoyos externos como alianzas pero, no de intercambios. Por otro lado, el área de Relaciones Externas era la que vendía los servicios de AIESEC a empresas con el fin de abrir nuevas plazas para entrenados; por su parte el área de Intercambios Entrantes lo único que hacía era recibir a esos entrenados extranjeros realizando los procesos necesarios. (Entrevista con presidenta del comité UNAM, 2011). Sin embargo "al no obtener los resultados esperados, para el segundo semestre de 2010 se decidió que la estructura debía cambiar a la usual, es decir, la que se tiene ahora". (Entrevista con la Presidenta del Comité, 2010).

El organigrama siempre es sugerido por el Comité Nacional, quien tiene a la cabeza al Presidente de AIESEC México en este caso, Director Nacional de Finanzas, Director Nacional de Comunicaciones, Director Nacional de Gestión de la Información, Director Nacional de Gestión de Talento, Director Nacional de Intercambios Salientes, Director Nacional de Intercambios Entrantes, Director Nacional de Desarrollo de Comités Locales. Ellos deciden qué puestos debe abrir cada comité local para su correcto seguimiento. El Comité Nacional tiene su oficina en Álvaro Obregón 124 en la colonia Roma, El Presidente de AIESEC México (Comité Nacional) se llama José Luis Arévalo Aguilar. Él es egresado de AIESEC ULSA. 
Comité Nacional se integra de 7 áreas:

- Director de intercambios salientes

- Director de intercambios entrantes

- Director de finanzas

- Director de gestión de talento

- Director de gestión de la información y comunicación

- Director de Relaciones externas

- Director de desarrollo de comités locales

Todas bajo la coordinación del presidente de AIESEC México, a su vez los comités locales deben tener un área que corresponda a las que tiene el comité nacional. En el caso del comité IPN, ellos tienen un director para gestión de la información y uno para comunicaciones (aparte de los demás directores). Todos coordinados por el presidente de comité local. Además tienen otros directores que se enfocan a proyectos y otras actividades. Todos ellos forman la mesa directiva.

Ahora bien AIESEC México se conforma de la siguiente manera:

Comités locales oficiales

- Chihuahua

- Veracruz

- Ciudad Juárez

- Monterrey

- Culiacán

- Guanajuato

- Guadalajara

- Puebla

- IPN (Distrito Federal)

- UNAM (Distrito Federal)

- ITAM (Distrito Federal)

- ULSA (Distrito Federal) 
- UP (Distrito Federal)

Extensiones:

- Querétaro

- Aguascalientes

- Santa Fe

Al respecto la presidenta comenta lo siguiente:

"Uno de los comités mas motivados es Culiacán y Ciudad Juárez. Nadie nos explicamos por qué (risas). Son muy buenos motivando a sus miembros actuales y nuevos pero no hemos descubierto cuál es su secreto. Los comités con menos productividad son Veracruz y Puebla, aunque esperamos que ahora que la mesa directiva cambia todo mejore. De lo contrario corren el riesgo de desaparecer" (Entrevista con la presidenta del Comité UNAM, 2010)

\subsection{Programas de AIESEC México ${ }^{13}$}

Soluciones de Talento en $\mathrm{RH}$ Globales - Acceder a un talentoso grupo de estudiantes o recién graduados internacionales y adquirirlos como entrenados (Programa Global de Intercambio de AIESEC México) para apoyar a las necesidades organizacionales e iniciativas.

- Los entrenados trabajan tiempo completo en cualquier lugar de 2-18 meses.

- Los entrenados demuestran una serie de habilidades e impacto realizando proyectos específicos a corto plazo o trabajando en equipo en estrategias a largo plazo.

- Solución a cuentas restrictivas construyendo fuentes internacionales de información de gestión, y percepción de proyectos o estrategias.

- Los candidatos son actuales estudiantes y recién graduados de licenciatura, maestría y programas de MBA en 1.700 universidades a nivel mundial.

- Atraer a candidatos de 111 países con experiencias previas de liderazgo a través de un proceso centralizado y eficiente.

- Sin complicaciones para la adquisición de Visa y Permiso de trabajo, AIESEC se encarga de esas cuestiones.

${ }^{13}$ Documentos internos 
Programa de Reclutamiento para Graduados (Desarrollo de recursos humanos internacionales)

- Apoyar iniciativas para atraer, contratar y retener a los talentos locales e internacionales.

- Construir su fuente de información de gestión con talento con experiencia y mentalidad internacional.

- Los graduados tienen la combinación correcta de habilidades de liderazgo y experiencia de trabajo internacional para llevar su negocio a la escena mundial.

- Promoción orientada y candidatos de preselección para posiciones del programa que enriquezcan su grupo de candidatos.

\subsection{Eventos de AIESEC México}

Anualmente en México, las empresas y organizaciones los miembros de los comités asisten a los siguientes eventos los cuales se dirigen a los miembros de los comités y a su vez a los líderes de organizaciones como una manera de reclutamiento de personal:

Cumbre de Líderes: Evento exclusivo para los líderes mundiales con más experiencia de los miembros de AIESEC estará sucediendo en México año 2013.

Congreso Nacional de Planeación: El mayor evento anual con más de 200 delegados en representación de más de 20 Universidades y líderes corporativos. Se lleva a cabo en junio de cada año en diferentes sedes en México.

A las organizaciones se les ofrecen beneficios importantes como:

- Posicionar la empresa en la red de AIESEC para lograr lo mejor con contrataciones potenciales.

- Mostrar los valores de la empresa para conectarse y atraer a los mejores talentos del liderazgo de AIESEC México.

Juventud a las empresas: Foro Nacional captura opiniones de jóvenes acerca de asuntos nacionales relevantes.

Congresos Regionales de Liderazgo: Cinco eventos nacionales paralelos que involucran a líderes frescos de AIESEC de una región particular dentro de México. Ocurre en octubre de cada año en lugares diversos. 


\subsection{AIESEC México. El Comité UNAM.}

AIESEC-Comité UNAM es una ONG sin afiliación y ningún partido político, sin fines de lucro; es la mayor organización mundial dirigida por estudiantes. En México, están enfocados en proporcionar una plataforma para el desarrollo de liderazgo juvenil.

AIESEC-Comité UNAM tiene por objeto ofrecer a los jóvenes la oportunidad de ser ciudadanos globales para cambiar el mundo y para adquirir experiencia y habilidades que hoy en día son muy importantes.

Los medios por los cuáles se ofrecen dichas oportunidades es por medio de tomar un programa de intercambio cultural o un programa de trabajo en el extranjero es la experiencia más intensa de aprendizaje que AIESEC ofrece y la cual permite unir a dicha red global.

Cada año ofrecen la oportunidad de vivir un reto y trabajar en un país extranjero en áreas de gestión, tecnología, educación y desarrollo en el extranjero cultural o profesional a través de AIESEC.

En particular como un primer acercamiento nos encontramos con el Comité UNAM, ubicado en la Universidad Nacional Autónoma de México el cual se integra por 7 miembros que desempeñan un cargo distinto de acuerdo a su formación académica como sigue continuación:

Tabla 5: Formación del personal de AIESEC-Comité UNAM.

\begin{tabular}{|l|l|l|}
\hline Cargo & Nombre & Perfil Profesional \\
\hline Presidenta & $\begin{array}{l}\text { Miriam } \\
\text { Alonso }\end{array}$ & $\begin{array}{l}\text { Licenciada en Ciencia de la } \\
\text { Comunicación }\end{array}$ \\
\hline $\begin{array}{l}\text { Vicepresidenta Talent } \\
\text { Management }\end{array}$ & $\begin{array}{l}\text { Patricia } \\
\text { Morales }\end{array}$ & Estudiante de Lic. En Psicología \\
\hline $\begin{array}{l}\text { Vicepresidenta Inconming } \\
\text { Exchanges }\end{array}$ & $\begin{array}{l}\text { Nancy } \\
\text { Morales }\end{array}$ & Estudiante de Lic.en Psicología \\
\hline
\end{tabular}




\begin{tabular}{|c|c|c|}
\hline $\begin{array}{l}\text { Vicepresidenta Outgoing } \\
\text { Exchanges }\end{array}$ & Valeria Vega & $\begin{array}{llll}\text { Estudiante de } & \text { Lic. en } \\
\text { Administración. } & & \\
\end{array}$ \\
\hline $\begin{array}{l}\text { Vicepresidenta } \\
\text { Comunicaciones }\end{array}$ & $\begin{array}{l}\text { Regina } \\
\text { Guerrero }\end{array}$ & $\begin{array}{l}\text { Estudiante de Lic en Ciencias de la } \\
\text { Comunicación }\end{array}$ \\
\hline Vicepresidenta de Finanzas & $\begin{array}{l}\text { Enriqueta } \\
\text { González }\end{array}$ & $\begin{array}{l}\text { Estudiante de Lic. en Contaduría y } \\
\text { Administración }\end{array}$ \\
\hline $\begin{array}{l}\text { Vicepresidenta External } \\
\text { Relations }\end{array}$ & \multicolumn{2}{|c|}{$\begin{array}{l}\text { Fernando Rosique. Estudiante de la Lic. En } \\
\text { Administración. }\end{array}$} \\
\hline
\end{tabular}

Fuente: propia en base a documentos internos.

Como ya se ha mencionado anteriormente AIESEC es una ONG de presencia mundial con grandes resultados siempre en la búsqueda de mejores oportunidades que brinden a estudiantes de todo el mundo experiencias que nutran su vida profesional y su visión de vida a corto y largo plazo.

De manera simultánea tiene presencia en México a través de un Comité Nacional que a su vez se subdivide en 5 comités locales en distintas universidades:

Figura 5: Conformación de AIESEC México. 


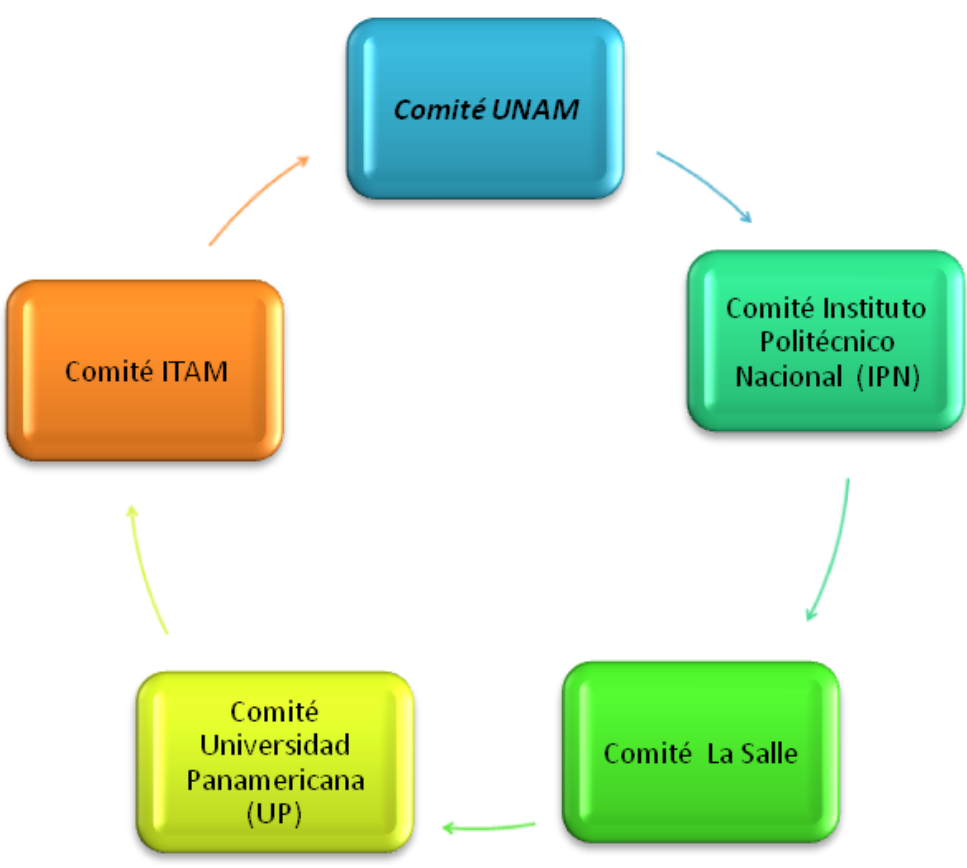

Fuente: Elaboracion propia.

Los comités tienen como atribuciones y funciones las mismas aunque no por eso se afirma que no haya competencia entre ellos.

En el caso de otros comités, las áreas de gestión de la información y comunicación se encuentran fusionadas, como en nuestro caso. $\mathrm{Y}$ algunos fusionan el área de Intercambios salientes y de Intercambios entrantes en una sola. Depende de las necesidades y la realidad local del comité. (Entrevista presidenta del comité, 2010)

Sobre el desempeño de los comités, los miembros tienen acceso a dos plataformas, una global y la otra local donde se registran los números. Sin embargo son plataformas privadas para miembros de AIESEC ${ }^{14}$.

En una de esas plataformas se evalúa nuestra "salud" como comité y nuestros resultados.

Estos son los resultados el máximo puntaje es 10; en ellos se evalúa el número de intercambios entrantes y salientes realizados, si todo se ha hecho conforme a los valores de

${ }^{14}$ Dicha plataforma es a través de MyAIESEC.net y solo miembros de mesas directivas ingresan. 
marca, si nuestro control financiero es adecuado, si nuestra relación con empresas y medios está teniendo resultados, etc. Todo lo manejamos con base a un balanced score card ${ }^{15}$ :

- Monterrey. Salud 3.62, Resultados 4.38

- Veracruz. Salud 7.03, Resultados 5.39

- Guanajuato. Salud 7.74, Resultados 5.71

- Chihuahua. Salud 7.94, Resultados 6.18

- Culiacán. Salud 8.96, Resultados 7.10

- Guadalajara. Salud 8.10, Resultados 7.42

- UNAM. Salud 8.12, Resultados 7.44

- Ciudad Juárez. Salud 7.57, Resultados 7.76

- IPN. Salud 7.49, Resultados 7.52

- ITAM. Salud 7.76, Resultados 7.02

- Puebla. salud 7.16, Resultados 7.54

- La Salle. Salud 6.63, Resultados 7.66

- UP. Salud 7.87, Resultados 9.54

Sin embargo la presidenta comenta que los resultados son muy subjetivos porque cada comité sube sus números de acuerdo a lo que considera.

Funciones del comité:

- Difusión de información relacionada con intercambios

- Vinculación con empresas

- Búsqueda de talentos

- Promoción de cursos y talleres

- Gestión de trámites para postulantes para intercambio

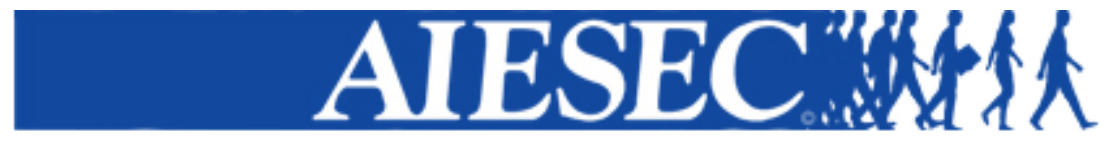

Comité UNAM se estructura de la siguiente manera:

\footnotetext{
${ }^{15}$ Dichos datos fueron proporcionados y vistos por la presidenta del comité de acuerdo a la última evaluación realizada a principios del 2011.
} 


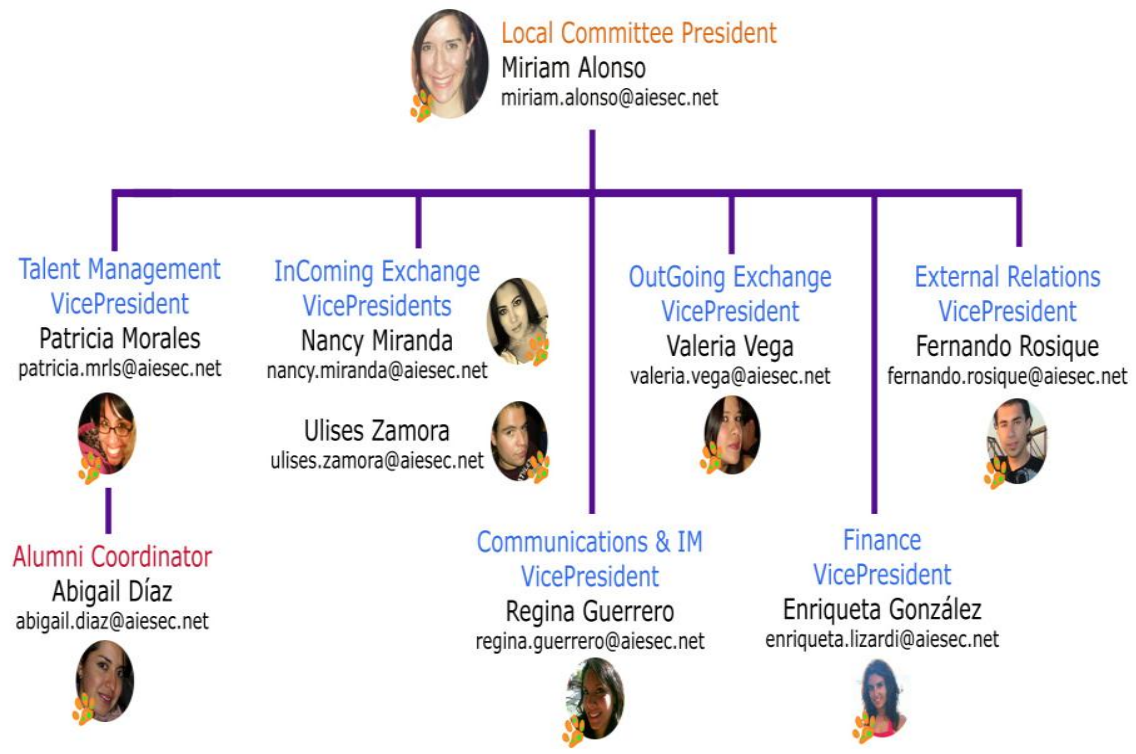

Dicho organigrama representa como el comité orgánicamente se conforma, sin embargo cada una de las 6 aéreas cuenta con un organigrama propio como se muestra a continuación:

- Outgoing Exchange. Intercambios salientes

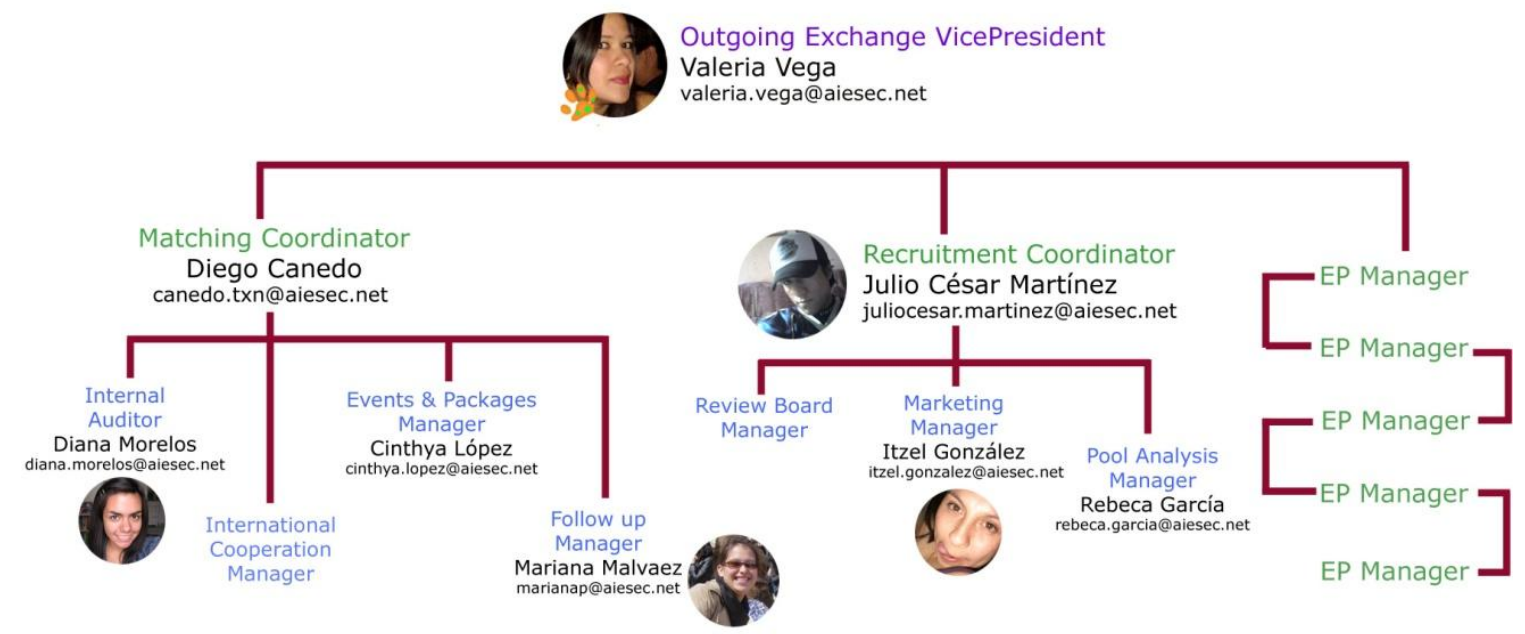

- Talent Management. (área de recursos humanos) 


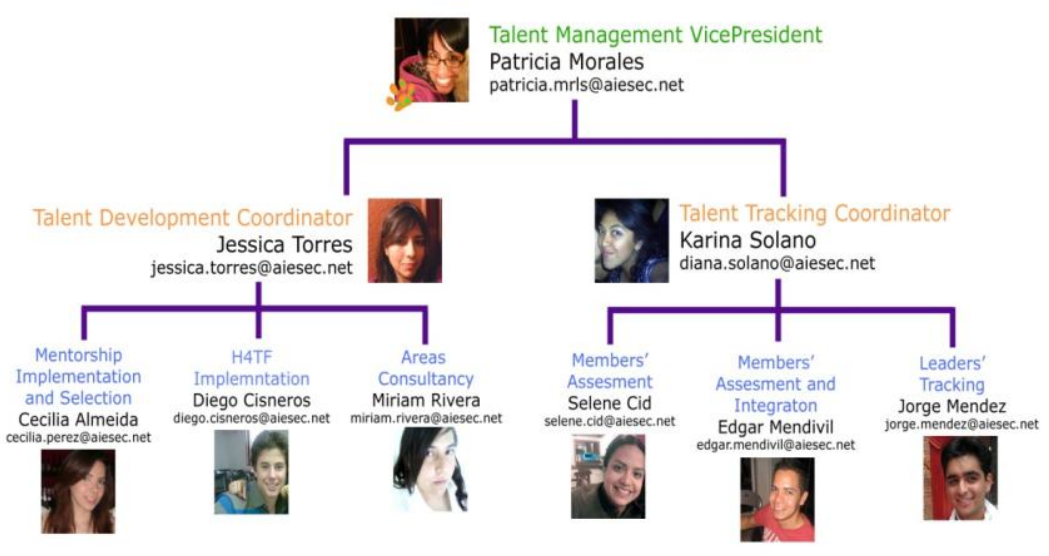

- Comunications. Comunicaciones

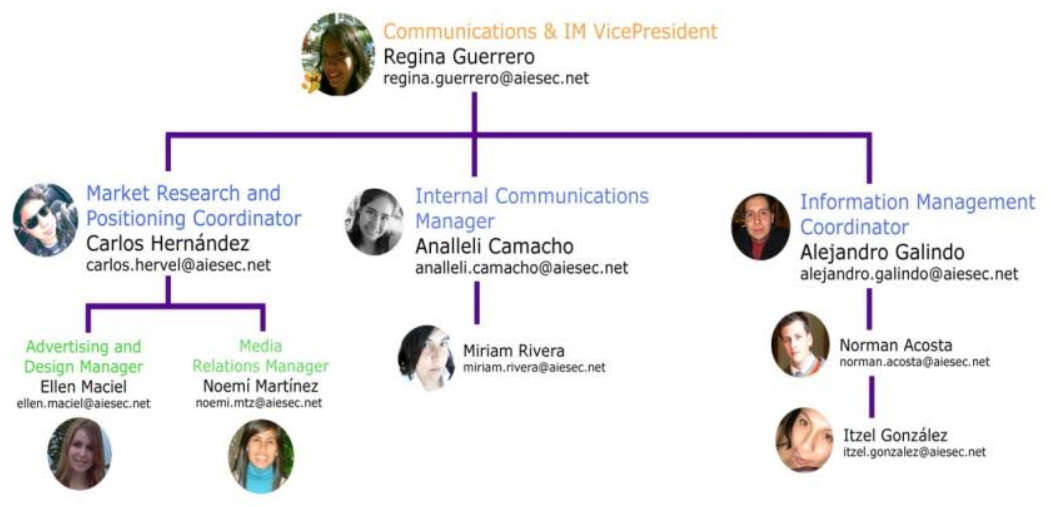

- External Relations. Relaciones publicas 


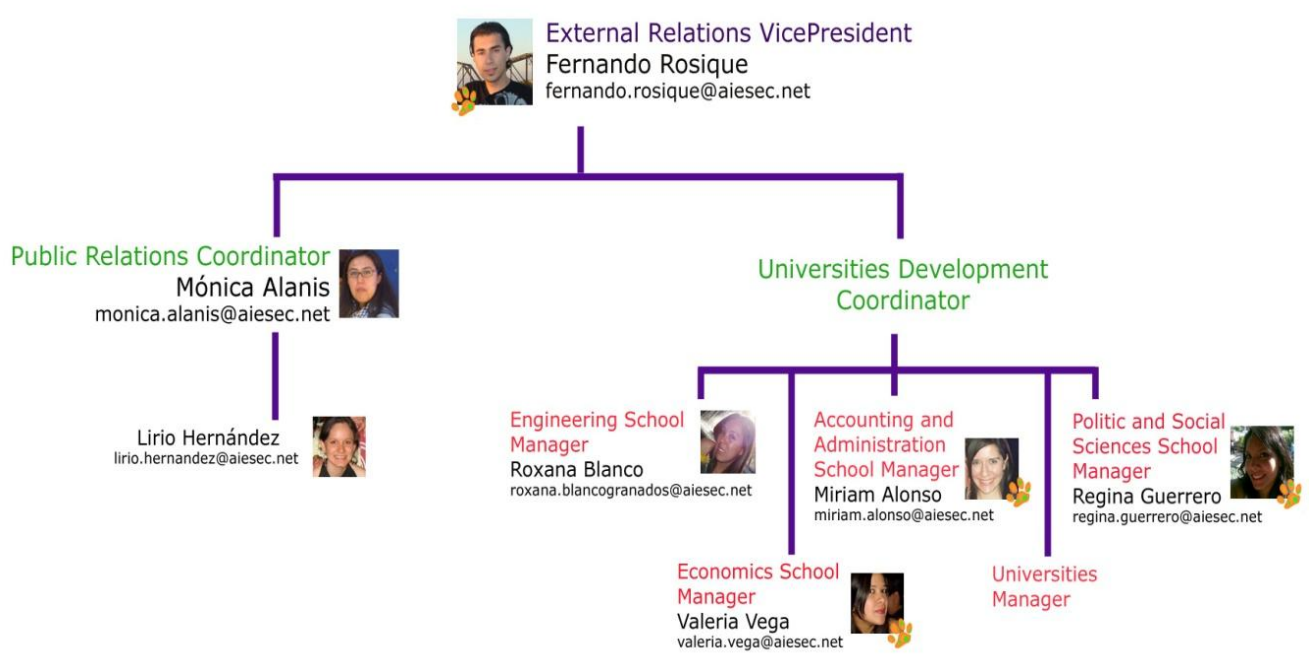

- Incoming Exchange. Intercambios entrantes.

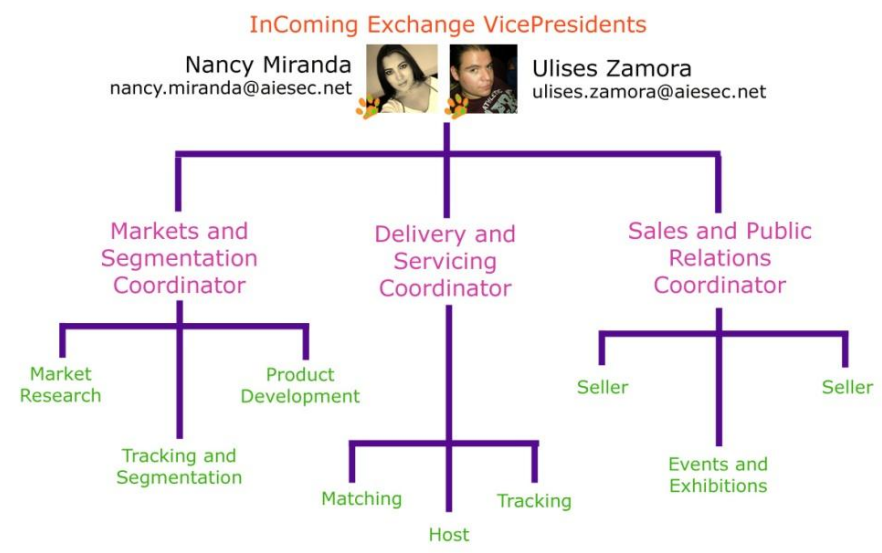

\section{Funciones y atribuciones}

- Talent management: se denomina de esa forma por las nomenclaturas que utiliza el comité nacional, se encarga de funciones relacionadas con el reclutamiento y selección de nuevos miembros del comité y posibles problemas entre miembros del comité.

- Incoming exchange: en español intercambios entrantes se encarga de apoyara alumnos de otras universidades en cualquier parte del mundo en cuanto a trámites para ingresar a México y su estancia en la UNAM. 
- Outgoing exchange: se refiere a intercambios salientes, su función es reclutar a candidatos para intercambios en otros países ya sea a universidades o empresas por medio de prácticas profesionales.

- Comunications: comunicaciones se encarga de todo lo relacionado con la imagen del comité, desde la publicidad, comunicación interna, creación de campañas y recabar información para todo el comité para enviarla al comité nacional.

- Finances: El área de finanzas resguarda los recursos con los cuales cuenta que comité las cuales principalmente provienen del pago que hacen postulantes para intercambios y prácticas profesionales proporcionadas a empresas.

- External relations: mantener estrecha relación con universidades fuera de México, supervisión de alumnos en intercambio, otros comités locales.

Las especificaciones, el rol, las responsabilidades que desempeña cada área de manera genérica como se muestra a continuación: 
Tabla 6: Tabla de descripción de actividades del presidente por área.

\begin{tabular}{|c|c|c|c|}
\hline Área & Rol & $\begin{array}{l}\text { Perfil y/o competencias } \\
\text { técnicas }\end{array}$ & Responsabilidades \\
\hline Presidente Comité local & $\begin{array}{l}\text { Facilitar la } \\
\text { consecución de las } \\
\text { actividades en vías } \\
\text { de lograr la visión de } \\
\text { AIESEC }\end{array}$ & $\begin{array}{l}\text { Gestión de proyectos, gestión } \\
\text { de conferencias, asociación } \\
\text { para el desarrollo, gestión del } \\
\text { proceso de cambio, evaluación } \\
\text { y sistemas de evaluación. }\end{array}$ & $\begin{array}{l}\text { Participación en reuniones de equipo, obtener y compartir conocimientos a nive } \\
\text { local, trasmisión de las estrategias a nivel nacional, planificación y seguimiento, } \\
\text { Coaching, Gobernanza y rendición de cuentas. }\end{array}$ \\
\hline $\begin{array}{l}\text { Relación con egresados } \\
\text { (Alumni relations) }\end{array}$ & $\begin{array}{l}\text { Capitalizar a los } \\
\text { antiguos alumnos } \\
\text { que han de } \\
\text { satisfacer sus } \\
\text { necesidades de } \\
\text { trabajo con las } \\
\text { necesidades del } \\
\text { comité local }\end{array}$ & $\begin{array}{l}\text { Entrenamiento en habilidades, } \\
\text { la habilidad de escuchar, toma } \\
\text { de decisiones, gestión de } \\
\text { proyectos, gestión del tiempo. }\end{array}$ & $\begin{array}{l}\text { Facilitar Congresos Locales, Obtener y compartir conocimientos a nivel local, } \\
\text { Transmisión de las estrategias del nivel nacional, Gestión de la información } \\
\text { relacionados con los proyectos, Recursos, materiales y conocimientos, Gestión } \\
\text { de la base de datos aprovechando la red, Relaciones con Alumni (eventos, } \\
\text { invitaciones, boletínes) }\end{array}$ \\
\hline $\begin{array}{l}\text { Comunicaciones } \\
\text { (communications) }\end{array}$ & $\begin{array}{l}\text { Desarrollar una } \\
\text { estrategia de } \\
\text { comunicaciones en } \\
\text { el comité } \\
\text { (comunicación } \\
\text { interna y externa y } \\
\text { posicionamiento), } \\
\text { asegurar su } \\
\text { educación y el } \\
\text { crecimiento del } \\
\text { comité local. }\end{array}$ & $\begin{array}{l}\text { Gestión de Conferencias. } \\
\text { Asociación para el Desarrollo } \\
\text { Sistemas de Información. } \\
\text { Planificación Estratégica y } \\
\text { Gestión del cambio. } \\
\text { Evaluación y Sistemas de } \\
\text { Medición. } \\
\text { Liderazgo. } \\
\text { Maketing. } \\
\text { Ventas y de posicionamiento. }\end{array}$ & $\begin{array}{l}\text {. Creación e implementación del plan de medios de comunicación y del plan } \\
\text { local. } \\
\text {. Directrices visuales } \\
\text {. Las emisiones y la comunicación externa } \\
\text { (Medios de comunicación) } \\
\text {. Coordinación de la aplicación de la marca } \\
\text {. Local Website (contenido) } \\
\text {. La comunicación interna (boletines, canales de comunicación), diseño de } \\
\text { plantillas (hojas de producto, salidas, etc) } \\
\text {. La gestión de marcas para asegurar un buen posicionamiento de AIESEC al } \\
\text { exterior y en la red } \\
\text {. Desarrollo de asociaciones con los medios }\end{array}$ \\
\hline $\begin{array}{l}\text { Relaciones al exterior } \\
\text { (external relations) }\end{array}$ & $\begin{array}{l}\text { Garantizar la } \\
\text { sostenibilidad } \\
\text { financiera del comité. } \\
\text { Desarrollo de } \\
\text { Productos Básicos } \\
\text { de trabajo que } \\
\text { generan } \\
\text { recursos financieros } \\
\text { de corto y largo }\end{array}$ & $\begin{array}{l}\text { Asociación para el Desarrollo. } \\
\text { Desarrollo de Personas. } \\
\text { Planificación Estratégica y } \\
\text { Gestión del cambio. } \\
\text { Evaluación y Sistemas de } \\
\text { Medición. } \\
\text { Liderazgo. } \\
\text { Gestión a través de grupos de } \\
\text { trabajo. }\end{array}$ & $\begin{array}{l}\text { La capacitación de todos los comités sobre ventas; Ingresos de dinero, } \\
\text { - Responsable final de atraer a nuevas asociaciones } \\
\text { - Responsable de los ingresos generados e intercambiar productos } \\
\text { - Responsable para cubrir el presupuesto del comité. } \\
\text { - Descubrir nuevas oportunidades para atraer ingresos procedentes de la área } \\
\text { empresarial y no empresarial - nuevos contactos, nuevas } \\
\text { estrategias en contacto con las organizaciones, nuevas actividades que puedan } \\
\text { desarrollarse. }\end{array}$ \\
\hline
\end{tabular}




\begin{tabular}{|c|c|c|c|}
\hline & $\begin{array}{l}\text { plazo. Buscar } \\
\text { diversificación de la } \\
\text { cartera de clientes y } \\
\text { los ingresos de } \\
\text { dinero. }\end{array}$ & | Gestión Organizacional. & \\
\hline Área & Rol & $\begin{array}{c}\text { Perfil y/o competencias } \\
\text { técnicas }\end{array}$ & Responsabilidades \\
\hline $\begin{array}{c}\text { Incoming Exchange } \\
\text { (Intercambios entrantes) }\end{array}$ & $\begin{array}{l}\text { Garantizar el } \\
\text { desarrollo y } \\
\text { mantenimiento } \\
\text { (legalidad) de } \\
\text { AIESEC en términos } \\
\text { de Intercambio, } \\
\text { mediante la } \\
\text { elaboración, venta y } \\
\text { entrega de productos } \\
\text { a los que entran en } \\
\text { intercambio. }\end{array}$ & $\begin{array}{l}\text { Capacidad para gestionar en } \\
\text { línea trabajo y equipos } \\
\text { Capacidad para aprender } \\
\text { rápido. } \\
\text { Experiencia en la gestión de } \\
\text { procesos de intercambio } \\
\text { Efectividad Personal y } \\
\text { Pensamiento estratégico } \\
\text { planificación. } \\
\text { Experiencia en la gestión } \\
\text { relaciones externas. }\end{array}$ & $\begin{array}{l}\text { Elevar a través del análisis interno. } \\
\text { - Entrada de productos de intercambio basado en el desarrollo. } \\
\text { Cooperaciones Internacionales } \\
\text { - Alineación y ejecución de estrategias globales y nacionales a nivel local. } \\
\text { - Cambio de la Gestión Local de canalización. }\end{array}$ \\
\hline $\begin{array}{l}\text { Information Management } \\
\text { (Administración de la } \\
\text { Información) }\end{array}$ & $\begin{array}{l}\text { Gestión del } \\
\text { conocimiento para } \\
\text { garantizar su } \\
\text { educación y } \\
\text { crecimiento de } \\
\text { comité. }\end{array}$ & $\begin{array}{l}\text { Experiencia en la gestión } \\
\text { los sistemas y desarrollo de } \\
\text { liderazgo. } \\
\text { Efectividad Personal y } \\
\text { Pensamiento estratégico. } \\
\text { Planificación. } \\
\text { Experiencia en Sistemas de } \\
\text { Información. }\end{array}$ & $\begin{array}{l}\text { Gestión de Proyectos } \\
\text { Gestión de Conferencias } \\
\text { Asociación para el Desarrollo } \\
\text { Sistemas de Información } \\
\text { Planificación Estratégica y Gestión del cambio } \\
\text { Evaluación y Sistemas de Medición } \\
\text { Facilitar y Formación } \\
\text { Liderazgo } \\
\text { Maketing } \\
\text { Ventas y de posicionamiento }\end{array}$ \\
\hline
\end{tabular}




\begin{tabular}{|c|c|c|c|}
\hline $\begin{array}{c}\text { Outgoing Exchange } \\
\text { (Intercambios entrantes) }\end{array}$ & $\begin{array}{l}\text { Asegurar el } \\
\text { crecimiento y la } \\
\text { estratégica } \\
\text { el desarrollo del } \\
\text { Programa de } \\
\text { Intercambio de } \\
\text { AIESEC }\end{array}$ & $\begin{array}{l}\text { Auto-conciencia Capacidad } \\
\text { para gestionar en línea trabajo } \\
\text { y equipos. } \\
\text { Capacidad para aprender } \\
\text { rápido. } \\
\text { Experiencia en la gestión } \\
\text { procesos de intercambio. }\end{array}$ & $\begin{array}{l}\text { Gestión de la información relacionada con } \\
\text { Intercambio de recursos, materiales y } \\
\text { conocimiento } \\
\text {. Para el desarrollo de estrategias locales para } \\
\text { aumento de miembros Intercambio de experiencias } \\
\text {. Liderar el proceso de intercambio de salida } \\
\text { planificación y ejecución }\end{array}$ \\
\hline $\begin{array}{l}\text { Talent Management } \\
\text { (Recursos Humanos) }\end{array}$ & $\begin{array}{l}\text { Garantizar la } \\
\text { cantidad y la calidad } \\
\text { de Experiencias } \\
\text { AIESEC a nuestros } \\
\text { miembros y entregar } \\
\text { herramientas } \\
\text { adecuadas para el } \\
\text { aprendizaje y el } \\
\text { desarrollo, } \\
\text { Retención de los } \\
\text { miembros }\end{array}$ & $\begin{array}{l}\text { Experiencia en la gestión } \\
\text { los sistemas y de desarrollo de } \\
\text { liderazgo. } \\
\text { Efectividad Personal y } \\
\text { Pensamiento estratégico } \\
\text { planificación } \\
\text { Experiencia en la gestión } \\
\text { relaciones externa e internas } \\
\text { dentro de una organización. }\end{array}$ & $\begin{array}{c}\text { Asociación para el Desarrollo } \\
\text { Desarrollo de Personas } \\
\text { Planificación Estratégica y Gestión del cambio. }\end{array}$ \\
\hline
\end{tabular}

Una vez presentada su conformación nos adentraremos a la organización a fin de avizorar particularidades. A fin de tener una visón mas integral sobre la estructura del Comité UNAM (ver Anexo 4) sobre la configuración estructural de comité UNAM según la propuesta de Mintzberg. 


\subsection{Comprendiendo la problemática del comité UNAM.}

Nos encontramos ante el paso mas complicado, el ingreso a la organización, ya que por una parte nuestro interés como investigador es indagar y dar respuesta a un fenómeno en particular, y por le otro, la organización guarda celosamente su espacio, el cual es sumamente difícil de invadir.

De forma sistemática se dará cuenta del ingreso a la organización, de tal manera que se de cuenta de cada paso por la organización y lo que se encontró en base a las entrevistas que se realizaron.

Lo difícil es el ingreso pero también seguir adentrándose aun mas en la organización es una tarea muy complicada, y la búsqueda se complica mas cuando se menciona que es una investigación, y al parecer la mayoría de las organizaciones suelen guardar muchos secretos y poca disponibilidad para sacarlos al aire, y aunado a ello, que ingrese un desconocido a la organización y modifique el ambiente, tampoco es de todo su agrado, pero conservar al máximo el ambiente que se tiene en el día a día es lo mejor que le puede ocurrir al investigador.

La tarea era también conocer la organización por parte del investigador, para que en el caso de cualquier duda, durante los encuentros se obtuviera toda la información posible, se descubrió que desde su nacimiento, esta organización surge en un momento de desequilibrio mundial pero también ese punto de inflexión fue usado para ofrecer una nueva forma de ver la vida, y tener un poco de esperanza en el mundo y sus circunstancias en ese entonces.

El primer contacto que se tiene es con el Comité UNAM, con la presidenta, la cual contacte por medio de un amigo al cual le platique mi interés por estudiar un organización no gubernamental, la presidenta se mostró muy interesada en lo que le expuse sobre la investigación y la visión organizacional, ya que su licenciatura es en ciencias de la comunicación y mencionaba "me parece genial que puedan verse aspectos como el poder, la estructura, la toma de decisiones sin que se parezca tanto a lo que se ha visto en un libro de administración, por que mi comité no se acerca mucho la idea de una "gran organización", osea una organización perfectamente estructurada, pero a pesar de ello mi comité es de los mejores" (Entrevista presidenta comité UNAM, 2011). 
Con este primer contacto se muestra la organización, sus funciones, como se estructura, es ahí donde se brindan los datos como que AIESEC es una ONG internacional que tiene presencia en México a través de comités dentro de algunas universidades en toda la republica mexicana pero por la cercanía y la factibilidad se enfoca a los comités ubicados en el Distrito Federal.

El comité UNAM que como primer contacto y la que brindó el mapeo inicial sobre la organización, como funciones generales, la actividad principal que es la oferta de experiencias de intercambio en otras universidades del mundo, como funciona cada área, los organigramas y las funciones de cada área además de mencionar inicialmente que no tiene espacio físico en este sentido la presidenta comenta " discúlpame que no nos reunamos en una oficina, pero desafortunadamente no tenemos, desde la huelga del 98 de la UNAM se nos quito nuestra oficina ubicada en la colonia Alvaro Obregón y se le dio al Comité Nacional y desde ahí dicho comité se encuentra funcionando ahí, y a pesar que la UNAM sabe de nuestros logros como organización estudiantil, no se nos ha brindado nisiquiera un cubículo, y eso de andar pegando propaganda con cinta adhesiva, que te reúnas con los interesados por mail o el cualquier parte, resta seriedad a mi comité" (Entrevista presidenta comité UNAM, 2010).

Como se comentó anteriormente dicho comité no cuenta con un espacio físico que les permita tener aún mas presencia dentro de la UNAM lo que para ellos refleja ante la comunidad estudiantil falta de seriedad, ausencia de compromiso o reconocimiento ante los interesados, además que para ellos facilitaría la ejecución de las actividades propias del comité como el uso de PC, manejo de propaganda, resguardo de material y atención personalizada. Recalcando que otros comités si cuentan con un espacio definido, se comunican de forma personal de acuerdo a una agenda de reuniones que se realizan en sus instalaciones, hay una supervisión mas formal y directa de los miembros y de las actividades, debido a la ausencia del espacio han tenido que echar mano de otra forma de comunicación y seguimiento de las tareas del comité menos personales como la plataforma de WISIQ $^{16}$ lo que ha generado una especie de desmembramiento de las áreas y de sus miembros, pero de sobre manera en los miembros del comité crea un sentimiento de inferioridad ante los recursos con que cuentan los otros comités.

Lo anterior abre la mirada a cuestionarse sobre si este comité no cuenta con espacio físico, como es que puede lograr la supervisión y la sinergia necesaria para la realización de las tareas de cada área. Siguiendo con entrevista la presidenta cuenta que existen 6 áreas en el

\footnotetext{
${ }^{16}$ Plataforma de comunicación de mensajería instantánea vía internet donde se puede trabajar en línea con varios miembros la vez y compartir documentos con todos aquellos miembros que cuenten con una cuenta de esa plataforma.
} 
comité supervisadas por un presidente y que su vez esas áreas se subdividen pero en realidad corresponde a un staff, tal y como sigue:
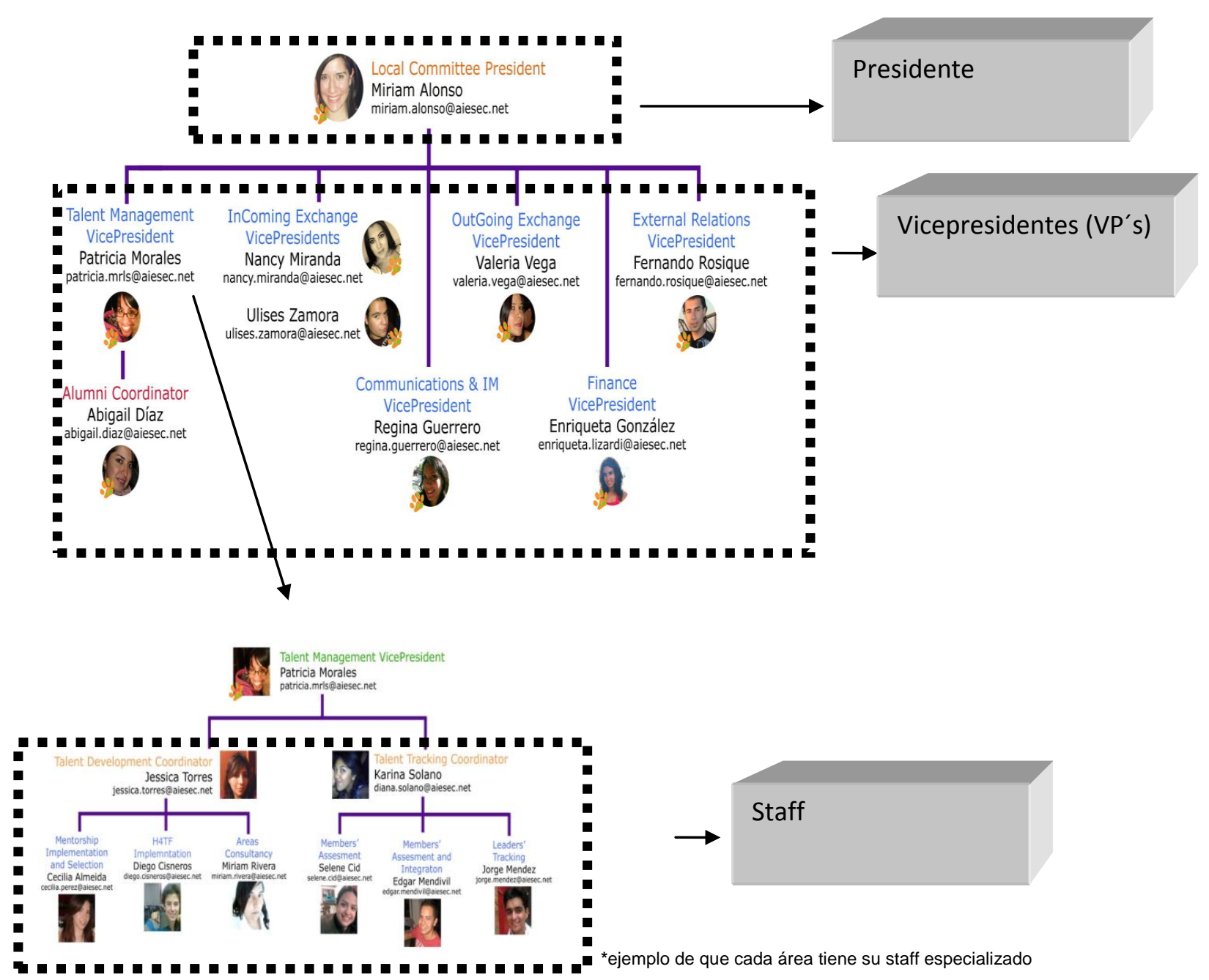

Entonces de esta forma se sistematizaron las entrevistas, se reunió a la partes del comité por separado para obtener la visión de cada área en cuanto a ciertos aspectos.

Las entrevistas en la caso de el Comité UNAM se realizan en una cafetería que esta frente al biblioteca central: "disculparás que ni a oficina llegamos, pero se podría decir que esta cafetería es nuestra oficina, espero no pienses que no hay seriedad en la entrevista" (Entrevista Vicepresidenta de Talent Management comité UNAM, 2011)

En el transcurso de la investigación a través de el primer acercamiento con e comité se da cuenta de el sentimiento de los miembros del comité, un ejemplo es lo siguiente: "que te parece 
la oficina (risas) así es esto, tenemos muchos logros como organización estudiantil, pero la UNAM no pone atención, y si yo fuera una interesada, si me citaran en la cafetería o la biblioteca me daría la sensación que es una organización fantasma" (Entrevista Vicepresienta Intercambios salientes comité UNAM, 2011)

Un punto importante fue cuado se mencionó lo siguiente "Ni a oficina llegamos, y eso nos resta seriedad, somos el único comité que no tiene oficina, y pues imagínate el triunfo que es coincidir para reunirnos, entregar las tareas y tomar decisiones; y ni modo tenemos que echar mano de comunicación impersonal" (Entrevista Staff Finanzas Comité UNAM, 2010).

Entonces se da cuenta de una de las problemáticas, es el espacio físico aunque considerando que a pesar de dicho aspecto, el comité si funciona y puede llevar a cabo sus actividades, situación que parece rebuscada pero atractiva para la visión organizacional.

El siguiente paso para alimentar la investigación es la fase de entrevistas, se procede a realizarlas y sistematizar los hallazgos, sin embargo, para ampliar la investigación y tener una visión mas general de la organización se procede a convocar a todas la áreas del comité y siguen surgiendo factores de queja que dan la sensación de construir la problemática de dicho comité. De viva voz se obtuvo lo siguiente: “Imagínate, no oficina, no computadora, no lápices, y tenemos que usar nuestros propios recursos materiales, nuestra computadora, no me molesta pero pues si somos de los mejores, que pasa y a pesar de ello hay que sacar la chamba" (Entrevista Vicepresidenta Finanzas comité UNAM, 2011). "Tengo que usar mi compu para las tareas del comité, no es que me este quejando, pero los otros comités tienen todo lo material necesario y nosotros pues tenemos que sacar todo sin ayuda de nadie" (Entrevista Vicepresidente de External Relations comité UNAM, 2011).

Al parecer el sentimiento se dispersa e cada una de las áreas de comité UNAM, otro ejemplo es el siguiente: "Todos los comités tienen como proveedor de recursos materiales a la universidad que pertenecen, y ve, nosotros ni un lápiz nos da la UNAM, hojas, internet, todo sale de nosotros, osea nada de provisión de recursos materiales" (Entrevista Staff Outcoming Exchanges comité UNAM, 2011). "Es bien raro, como podrás ver, no tenemos ni oficina y si mucho trabajo, y aunado a ello no tenemos sueldo, sin embargo esta muy padre estar aquí por que aprendes mucho de cómo se maneja una organización y esa oportunidad no te la cualquiera hoy en día" (Entrevista Vicepresidenta Finanzas comité UNAM, 2011). Otro miembro comparte el sentimiento y comento lo siguiente: "Sin oficina y sin sueldo es algo que a cualquiera vuelve loco, pero adquieres una fuerte responsabilidad con el comité, por que al ingresar pues ya sabes que 
no tendrás ninguna ayuda económica ni nada por el estilo, esperarías que después de mucho trabajo aunque sea un apoyo económico pero nada, solo te queda la experiencias de laborar para una organización internacional y quedarte con el aprendizaje" (Entrevista Presidente External Relations comité UNAM, 2011)

Simultáneamente se da cuenta de un nuevo factor a considerar muy importante, los recursos materiales son importantes y les causan mucho ruido, no perciben sueldo y la presión que tienen es fuerte ya que sino se cumplen las tareas se incurre en multas: "sino cumplimos con las tareas tenemos que pagar una multa a comité nacional, pero lo que mas nos preocupa es que eso queda evidenciado en la pagina y no da buena imagen el comité" (Entrevista Vicepresidente Finanzas La Salle, 2011); pero a pesar de las quejas hechas por los miembros siguen permaneciendo al comité, siguen comprometidos y no deciden abandonarlo, lo que da como otra parte importante, saber que sucede con la rotación de miembros en lo comités y como a pesar de las limitantes de los recursos logran cumplir con las tareas como los otros comités lo que sigue construyendo nuestra problemática organizacional.

En particular, a pesar que la presidenta sugiere que su comité es uno de los más sanos y productivos, hay aspectos que merman su estancia y el entusiasmo con que permanecen en el comité. (Entrevistas 2010-2011):

- Debido a que la supervisión se presenta más a distancia y su relevancia es esencial, porque WISIQ e Intranet es lo que da vida y control al comité fundamentalmente, dicha red permea en su totalidad las actividades del comité, desde la normalización hasta la supervisión que permite al comité funcionar de la forma que lo han hecho hasta hoy en día.

- El Comité-UNAM bien es cierto en términos de eficiencia ante comparativos con otros comités tiene fuerte presencia, sin embargo para los miembros del comité eso no es de gran relevancia, mediante la entrevista realizada a los miembros de la mesa directiva, ellos comentan que existen algunos aspectos negativos que para su funcionamiento interno merman las actividades diarias y el futuro del comité.

Un punto de inflexión para el comité es la huelga 1998 de la UNAM, al regreso se encontraron con una nueva asignación de espacios pero el comité no fue favorecido y quedo despojado del espacio con el que contaban, dicha situación les causa molestia ya que otros 
comités cuenta con una oficina bien acondicionada y con recursos materiales propios del comité como computadoras, teléfono, Internet, insumos de papelería, por el contrario, los miembros del comité UNAM trabajan desde casa y hacen uso de sus propios recursos materiales.

Sin embargo a pesar de dichas particularidades, el comité funciona y es uno de los más productivos a pesar de la opinión de sus miembros y de los recursos con los que cuentan otros comités. La interrogante sería ¿Bajo la perspectiva de los Estudios Organizacionales, como es que entonces dicho comité ha logrado sobrevivir y cómo explicar sus particularidades?

Entonces nos encontramos ante dos vetas investigación:

No cuenta con un espacio físico que les permita tener aún más presencia dentro de la UNAM, lo que para ellos refleja ante la comunidad estudiantil falta de seriedad, ausencia de compromiso o reconocimiento ante los interesados, además que para ellos facilitaría la ejecución de actividades propias del comité como el uso de PC, manejo de propaganda, resguardo de material y atención personalizada. Recalcando que otros comités sí cuentan con un espacio definido, lo que ha generado una especie de desmembramiento de las aéreas y de los integrantes del comité, pero de sobremanera en los miembros del comité crea un sentimiento de inferioridad ante los recursos con los que cuentan otros comités.

Complejidad inherente al comité en cuanto a su organización y actividades; pero a pesar de esa complejidad que en el mejor de los casos orienta a la flexibilidad, en el caso del comité no ha permitido la creación de una estructura flexible que permita hacer frente a las crisis así como entradas y salidas de miembros del comité.

Anualmente se cambia la mesa directiva y no se da continuidad total a las actividades logradas por comités anteriores. Simultáneamente se presenta duplicidad de funciones, por la ausencia de documentos que quien la ejecución de actividades de cada área por lo que hay poca planificación y comprensión de las actividades especificas de cada miembro, la entrada y salida de miembros del comité modifica continuamente la estructura orgánica con la que cuentan.

Ahora bien, nos preguntamos lo siguiente: 

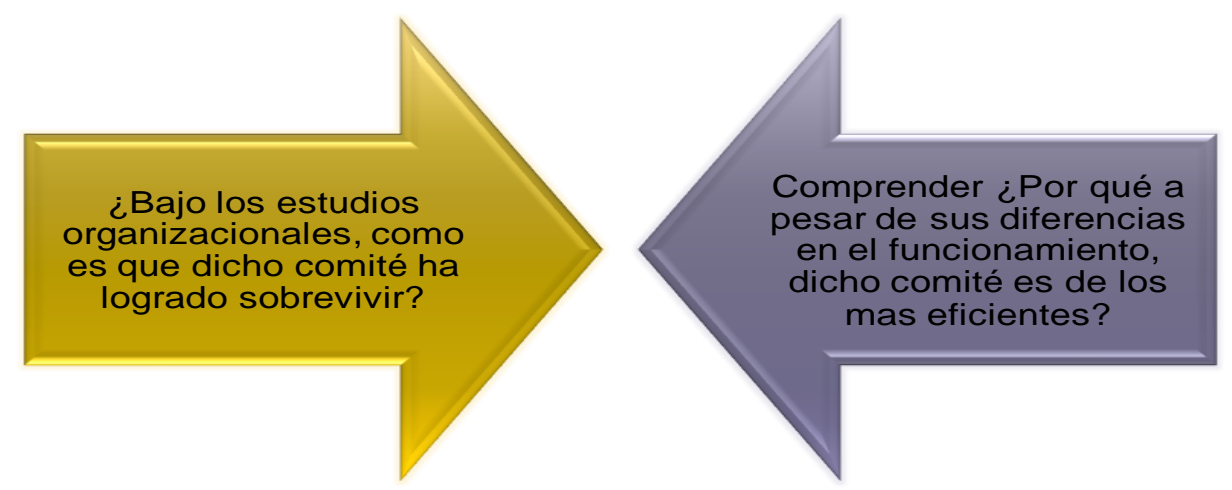

A fin de mostrar los logros de comité UNAM y mostrar como dicho comité es de los más productivos en intercambios estudiantiles, que es la actividad primordial de la organización, ver el anexo 5, refiriéndose a algunas tablas proporcionadas donde gráficamente se demuestra el desempeño de comité UNAM. 
Hasta ese momento hay factores de importancia que coexisten dentro de los comités como se presenta acontinuación:

\subsection{Factores de la problemática.}

Entonces hasta el momento nos encontramos con factores que son recurrentes y coexisten en comité UNAM, es preciso comentar como ya se señalo anteriormente, que inicialmente el contacto y acceso a la organización se dio en comité UNAM, sin embargo la facilidad de adentrarse a otros comités pudo ser posible ya que como esquema comparativo, entrevistar a otros comités permite ofrecer el panorama completo del por qué comité UNAM funciona de manera particular así como la posibilidad de reconocer alguna otra problemática. El acceso a otros comités se dio de manera gradual, inicialmente se acudió a Comité Nacional, posteriormente a Comité La Salle, Instituto Politécnico Nacional, Universidad Panamericana y el de mas difícil acceso el Comité de Universidad Iberoamericana, lo que enriqueció la información y el esquema comparativo con comité UNAM.

Los factores itinerantes que se observaron a manera de comparación se verificaron en otros comités.

Como sigue acontinuación: 
FIGURA 6: Comparación de factores itinerantes en comités.

UNAM

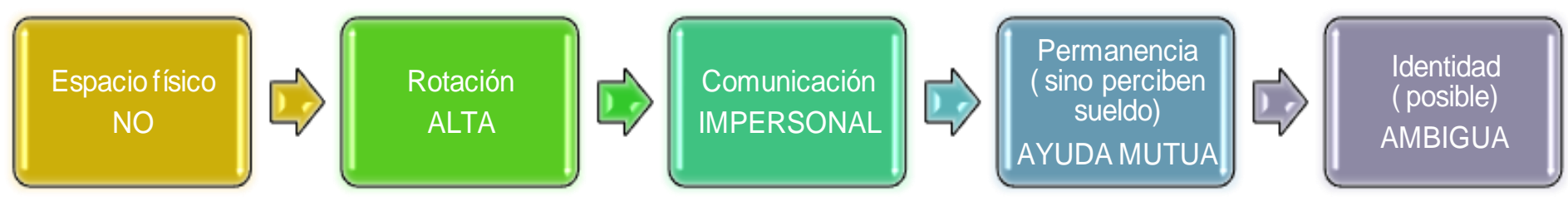

Comité

Nacional
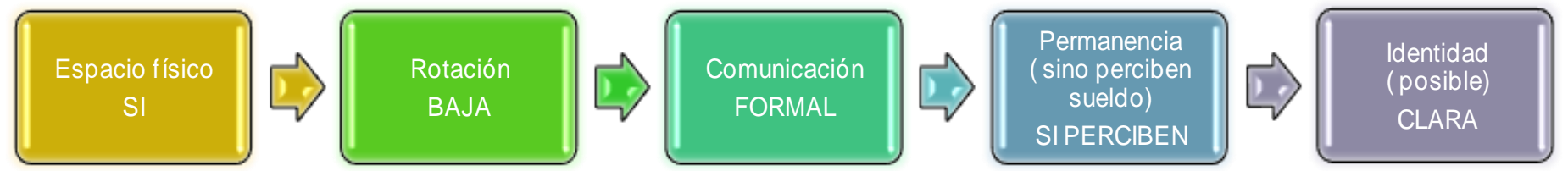

La Salle
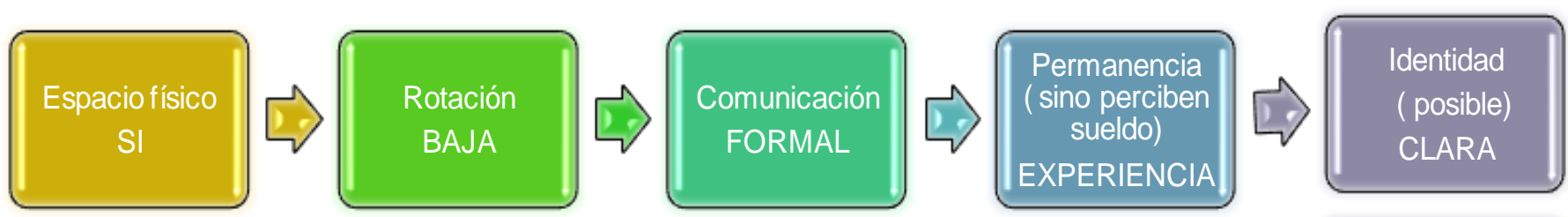

Politécnico
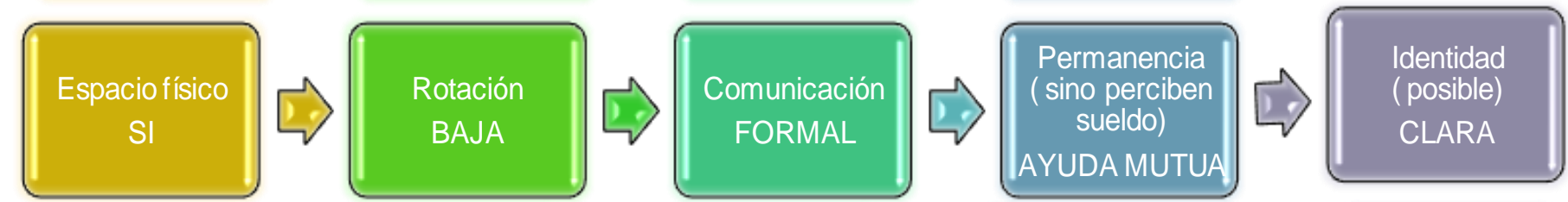

Universidad

Iberoamericana
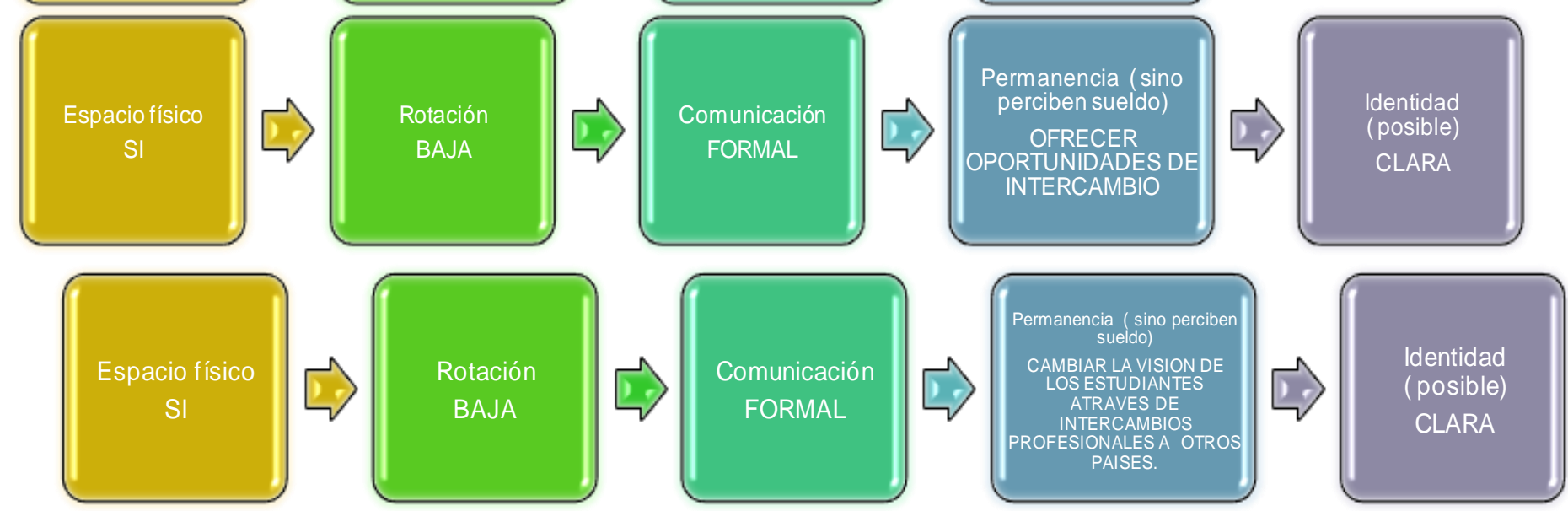
Fuente : Elaboración propia en base a informaron recabada. 
Entonces dichos factores como eje de comprensión permite reconocer las particularidades de cada comité y simultáneamente identificar que comité UNAM a pesar de las diferencias es eficiente y es de los mejores en términos de los intercambios que promueven, entonces nos encontramos hasta este momento ante un fenómeno que es interesante y pertinente explicar a través de los Estudios Organizacionales, debido a que la construcción heterogénea de dicha área de estudio, permite como una primera explicación conocer y reconocer la pertinencia de las teorías de ambigüedad organizativa, que apunta de forma mas puntual a la propuesta de sistemas flojamente acoplados de tal suerte que el comité UNAM a pesar de las diferencias en funcionamiento no impacta en la operación de AIESEC como un todo organizativo así como analizar bajo esta mirada como el comité UNAM logra el cumplimiento de las tareas, funciones a pesar de que los factores antes mencionados son nulos o ambiguos.

Como una forma de acercarnos a lo que los comités opinan sobre los factores antes mencionados, y de tal suerte que la sistematización de la información recabada durante las entrevistas, la estructura orgánica se divide en tres partes: Presidente, Vicepresidentes (Jefes de área), Staff (que se comprime en un solo bloque a fin de que la entrevista sea mas fácil de sistematizar).

La tabla 7 es resultado de las entrevistas realizadas a fin de conocer a profundidad cada comité y que la información fuera más precisa y de viva voz, entorno a construir la posible explicación sobre el funcionamiento de dicha organización; entonces se sistematiza como sigue a continuación: 
Tabla 7: Factores itinerantes en comités.

\begin{tabular}{|c|c|c|c|c|c|c|c|}
\hline $\begin{array}{l}\text { Comité (Nombre } \\
\text { del comité) }\end{array}$ & Espacio físico & Permanencia & Comunicación & Sueldo & Rotación & Visión & Valores \\
\hline \multicolumn{8}{|l|}{ Comité Nacional } \\
\hline Presidente & $\begin{array}{l}\text { Si, es el que se } \\
\text { encuentra el la } \\
\text { colonia Álvaro } \\
\text { Obregón, y que se } \\
\text { proporciono de } \\
\text { parte de la UNAM }\end{array}$ & $\begin{array}{l}\text { Yo estoy aquí por } \\
\text { que crecí } \\
\text { profesionalmente } \\
\text { crecí con AIESEC, } \\
\text { y me siento } \\
\text { retribuido } \\
\text { profesional y } \\
\text { económicamente }\end{array}$ & $\begin{array}{l}\text { Tenemos } \\
\text { reuniones } \\
\text { semanales todas } \\
\text { la áreas, y } \\
\text { verificamos } \\
\text { como van los } \\
\text { otros comités en } \\
\text { el cumplimiento } \\
\text { de tareas }\end{array}$ & $\begin{array}{l}\text { Si, en el } \\
\text { caso de } \\
\text { comité } \\
\text { nacional si } \\
\text { tenemos } \\
\text { sueldo }\end{array}$ & Casi nula & $\begin{array}{l}\text { Seguir } \\
\text { expandiendo } \\
\text { AIESEC }\end{array}$ & $\begin{array}{l}\text { Honestidad, } \\
\text { integridad y } \\
\text { liderazgo }\end{array}$ \\
\hline Vicepresidentes & $\begin{array}{l}\mathrm{Si} \text {, cada área tiene } \\
\text { su oficina } \\
\text { respectivamente }\end{array}$ & $\begin{array}{l}\text { me encanta estar } \\
\text { aquí, me siento } \\
\text { libre y que estoy en } \\
\text { una empresa joven }\end{array}$ & $\begin{array}{l}\text { semanalmente } \\
\text { nos reunimos }\end{array}$ & $\begin{array}{l}\mathrm{Si} \\
\text { percibimos }\end{array}$ & Casi no & $\begin{array}{l}\text { Seguir siendo } \\
\text { una } \\
\text { organización } \\
\text { que ofrezca } \\
\text { nuevas } \\
\text { experiencias } \\
\text { al los } \\
\text { estudiantes }\end{array}$ & $\begin{array}{l}\text { Excelencia y la } \\
\text { diversidad, } \\
\text { además de la } \\
\text { integridad de } \\
\text { cada miembro }\end{array}$ \\
\hline Staff & $\begin{array}{l}\text { En efecto, todos } \\
\text { contamos con } \\
\text { nuestro espacio de } \\
\text { trabajo }\end{array}$ & $\begin{array}{l}\text { Aprendemos cada } \\
\text { día en una } \\
\text { organización de } \\
\text { presencia } \\
\text { internacional y el } \\
\text { ambiente aquí es } \\
\text { muy abierto y } \\
\text { eficiente. }\end{array}$ & Cada semana & $\mathrm{Si}$ & No & $\begin{array}{l}\text { Poder ofrecer } \\
\text { mas } \\
\text { experiencias } \\
\text { de intercambio } \\
\text { a mas jóvenes } \\
\text { en México }\end{array}$ & $\begin{array}{l}\text { Sustentabilidad, } \\
\text { diversidad y el } \\
\text { liderazgo }\end{array}$ \\
\hline
\end{tabular}




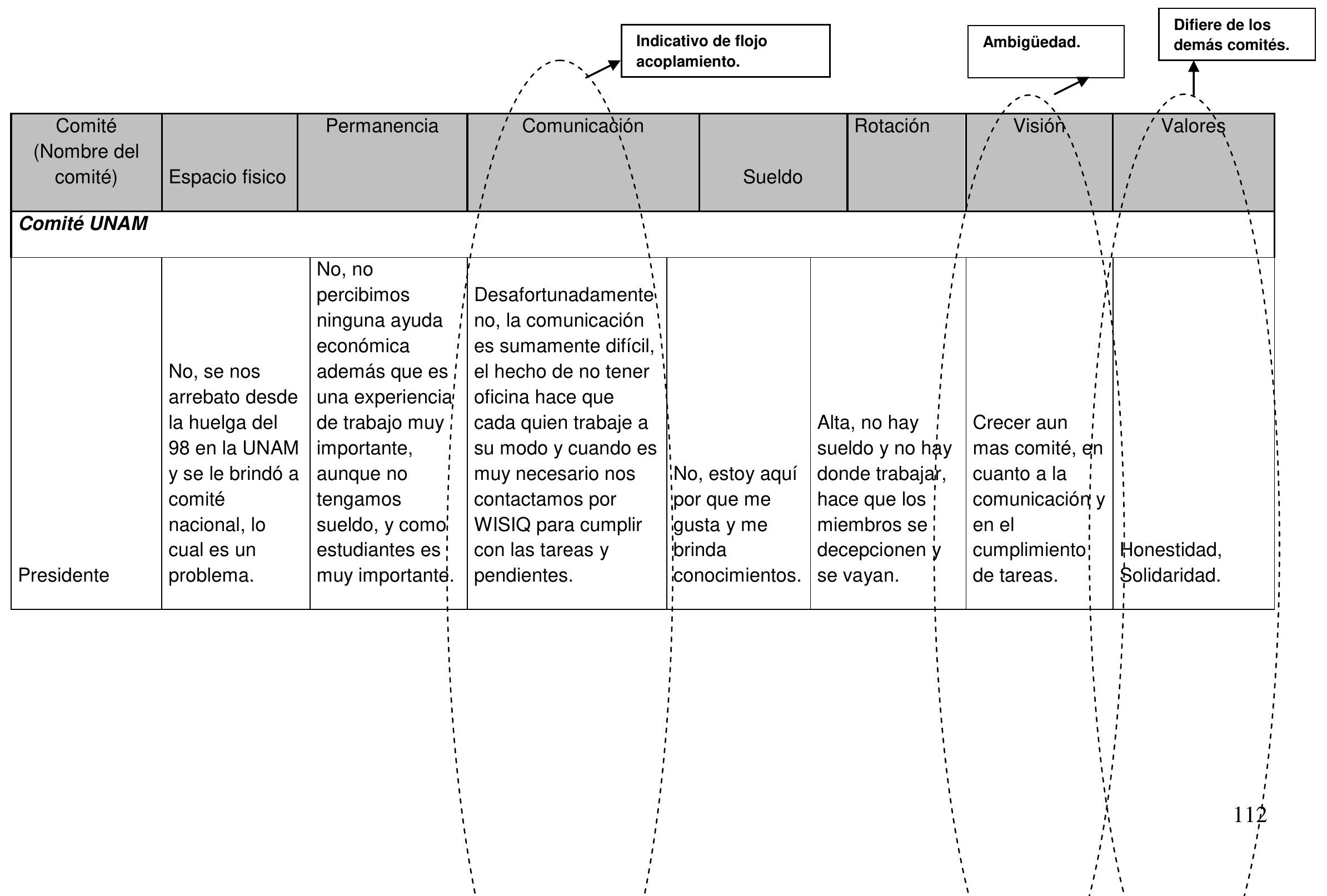




\begin{tabular}{|c|c|c|c|c|c|c|c|}
\hline Vicepresidentes & $\begin{array}{l}\text { No contamos } \\
\text { con oficina y es } \\
\text { muy triste, por } \\
\text { que eso nos } \\
\text { quita } \\
\text { presencia. }\end{array}$ & $\begin{array}{l}\text { No percibimos, } \\
\text { trabajamos aquí } \\
\text { por que } \\
\text { queremos y nos } \\
\text { gusta, de otra } \\
\text { manera sería } \\
\text { muy difícil, } \\
\text { además que } \\
\text { adquieres } \\
\text { responsabilidad } \\
\text { con todo el } \\
\text { comité. }\end{array}$ & \begin{tabular}{|l|} 
Algo muy complicado \\
cuando ni contamos \\
ni con un escritorio, \\
ni computadora, todo \\
lo que usamos es de \\
nosotros, y pues \\
ponerse de acuerdo \\
para reunirnos a la \\
misma hora es \\
demasiado \\
complicado, seria un \\
reto.
\end{tabular} & $\begin{array}{l}\text { No recibimos, } \\
\text { solo es } \\
\text { aprender lo } \\
\text { mas que } \\
\text { pueda, para } \\
\text { tener } \\
\text { experiencia en } \\
\text { dirección y } \\
\text { liderazgo de } \\
\text { un área. }\end{array}$ & $\begin{array}{l}\text { Alta, es muy } \\
\text { difícil trabajar } \\
\text { cuando no } \\
\text { tienes en donde } \\
\text { y eso te quita } \\
\text { presencia ante } \\
\text { los chavos que } \\
\text { atendemos. }\end{array}$ & $\begin{array}{l}\text { Ofrecer otras } \\
\text { opciones de } \\
\text { intercambio a } \\
\text { los } \\
\text { estudiantes. }\end{array}$ & $\begin{array}{l}\text { Honestidad, } \\
\text { Responsabilidad }\end{array}$ \\
\hline Staff & $\begin{array}{l}\text { No, y trabamos } \\
\text { como } \\
\text { podemos, a } \\
\text { veces ni } \\
\text { sabemos como } \\
\text { sacamos el } \\
\text { trabajo si no } \\
\text { nos vemos. }\end{array}$ & $\begin{array}{l}\text { No contamos } \\
\text { con sueldo, } \\
\text { estamos por } \\
\text { amor al arte. }\end{array}$ & $\begin{array}{l}\text { Es muy difícil } \\
\text { concretar un junta o } \\
\text { algo similar, } \\
\text { entonces todo se } \\
\text { hace usando } \\
\text { herramientas como el } \\
\text { Internet. }\end{array}$ & $\begin{array}{l}\text { No tenemos } \\
\text { ningún sueldo, } \\
\text { en realidad, } \\
\text { estamos aquí } \\
\text { por la idea de } \\
\text { ayudar a otros } \\
\text { alumnos. }\end{array}$ & $\begin{array}{l}\text { Salen personas } \\
\text { muy rápido, } \\
\text { pero es debido } \\
\text { a que las } \\
\text { condiciones } \\
\text { materiales no } \\
\text { motivan a } \\
\text { quedarse. }\end{array}$ & $\begin{array}{l}\text { Ser el comité } \\
\text { con mayor } \\
\text { presencia y } \\
\text { ofrecer mas } \\
\text { oportunidades } \\
\text { de intercambio } \\
\text { a estudiantes. }\end{array}$ & $\begin{array}{l} \\
\text { Responsabilidad, } \\
\text { Sinergia, } \\
\text { Sustentabilidad. }\end{array}$ \\
\hline
\end{tabular}

\begin{tabular}{|l|l|l|l|l|l|l|}
\hline $\begin{array}{c}\text { Comité } \\
\text { (Nombre del } \\
\text { comité) }\end{array}$ & Espacio físico & Permanencia & Comunicación & Sueldo & Rotación & Visión \\
\hline
\end{tabular}




\begin{tabular}{|c|c|c|c|c|c|c|c|}
\hline Presidente & \begin{tabular}{|l}
$\mathrm{Si}$, la universidad \\
no brindó un \\
excelente espacio \\
de trabajo, con \\
recursos materiales \\
suficientes, lo que \\
genera un \\
excelente ambiente \\
organizacional.
\end{tabular} & $\begin{array}{l}\text { No, estamos en } \\
\text { el comité por } \\
\text { que nos agrada } \\
\text { el ambiente, los } \\
\text { compañeros, la } \\
\text { oficina y } \\
\text { motivamos a los } \\
\text { chavos de la uni } \\
\text { a que tengan } \\
\text { una experiencia } \\
\text { en otro país. }\end{array}$ & $\begin{array}{l}\text { Así es, se forma } \\
\text { semanal, los } \\
\text { lunes } \\
\text { específicamente } \\
\text { se da la } \\
\text { asignación de } \\
\text { tareas y } \\
\text { además de } \\
\text { platican } \\
\text { pendientes, o } \\
\text { situaciones } \\
\text { importantes. }\end{array}$ & $\begin{array}{l}\text { No se recibe } \\
\text { sueldo, pero la } \\
\text { retribución } \\
\text { profesional que } \\
\text { se nos acumula } \\
\text { es el mejor pago } \\
\text { que se puede } \\
\text { tener. }\end{array}$ & $\begin{array}{l}\text { No, en su } \\
\text { mayoría los } \\
\text { miembros } \\
\text { permanecen } \\
\text { todo el ciclo, } \\
\text { al parecer } \\
\text { están agusto } \\
\text { y les agrada } \\
\text { lo que aquí se } \\
\text { hace. }\end{array}$ & \begin{tabular}{|l|} 
Consolidarnos \\
como el comité \\
con más \\
intercambios \\
salientes a fin \\
de que \\
nuestras \\
estadísticas \\
sean favorables \\
y se reconozca \\
nuestro trabajo \\
que es muy \\
eficiente.
\end{tabular} & $\begin{array}{l}\text { Liderazgo, } \\
\text { Responsabilidad, } \\
\text { Honestidad, } \\
\text { Integridad. }\end{array}$ \\
\hline Vicepresidentes & $\begin{array}{l}\text { Si, tenemos una } \\
\text { muy bonita oficina } \\
\text { que nos da } \\
\text { seriedad como } \\
\text { comité, la cual nos } \\
\text { proporcionó la } \\
\text { universidad y aquí } \\
\text { tenemos todo para } \\
\text { trabajar de forma } \\
\text { eficiente, como } \\
\text { pc's, plumas, } \\
\text { hojas, folders etc.... }\end{array}$ & $\begin{array}{l}\text { No, pero el } \\
\text { ambiente de } \\
\text { esta oficina te } \\
\text { atrapa, además } \\
\text { que adquirimos } \\
\text { experiencia } \\
\text { laboral dentro } \\
\text { de una } \\
\text { organización } \\
\text { internacional. }\end{array}$ & $\begin{array}{l}\text { Si, los lunes nos } \\
\text { reunimos y la } \\
\text { comunicación se } \\
\text { da de forma } \\
\text { abierta de tal } \\
\text { forma que se } \\
\text { puedan expresar } \\
\text { ideas } \\
\text { importantes. }\end{array}$ & $\begin{array}{l}\text { El sueldo es nulo, } \\
\text { pero estar aquí } \\
\text { en términos } \\
\text { personales y } \\
\text { profesionales, es } \\
\text { muy valioso, } \\
\text { sabemos que es } \\
\text { una organización } \\
\text { no } \\
\text { gubernamental y } \\
\text { el hecho es } \\
\text { apegarse a ello. }\end{array}$ & $\begin{array}{l}\text { No, se cumple } \\
\text { con el tiempo } \\
\text { de cada mesa } \\
\text { directiva y no } \\
\text { se de } \\
\text { miembros que } \\
\text { hayan dejado } \\
\text { el comité }\end{array}$ & \begin{tabular}{|l|} 
Seguir el \\
camino de la \\
mejora y \\
ofrecer una \\
amplia gama de \\
oportunidades \\
de intercambio \\
a más \\
estudiantes.
\end{tabular} & $\begin{array}{l}\text { Integridad, } \\
\text { liderazgo. }\end{array}$ \\
\hline Staff & \begin{tabular}{|l|}
$\mathrm{Si}$, y como ves es \\
muy acogedor, \\
tenemos todos los \\
recursos materiales \\
necesarios y \\
estamos muy \\
agusto aquí.
\end{tabular} & \begin{tabular}{|l|} 
Lo que se \\
aprende aquí es \\
invaluable por \\
que nos permite \\
saber como \\
trabajar y saber \\
que somos \\
útiles para otros \\
\end{tabular} & $\begin{array}{l}\text { Los lunes nos } \\
\text { ponemos al } \\
\text { corriente de } \\
\text { todo, charlamos } \\
\text { y es muy } \\
\text { agradable }\end{array}$ & $\begin{array}{l}\text { No recibimos } \\
\text { pero lo que se } \\
\text { aprende aquí es } \\
\text { invaluable, por } \\
\text { que nos acerca a } \\
\text { la realidad } \\
\text { laboral. }\end{array}$ & $\begin{array}{l}\text { No, cada } \\
\text { miembro } \\
\text { permanece. }\end{array}$ & \begin{tabular}{|l|} 
Ofrecer una \\
plataforma mas \\
amplia de \\
oportunidades \\
de intercambio.
\end{tabular} & $\begin{array}{l}\text { Liderazgo, } \\
\text { Honestidad, } \\
\text { Creatividad, } \\
\text { Sustentabilidad. }\end{array}$ \\
\hline
\end{tabular}




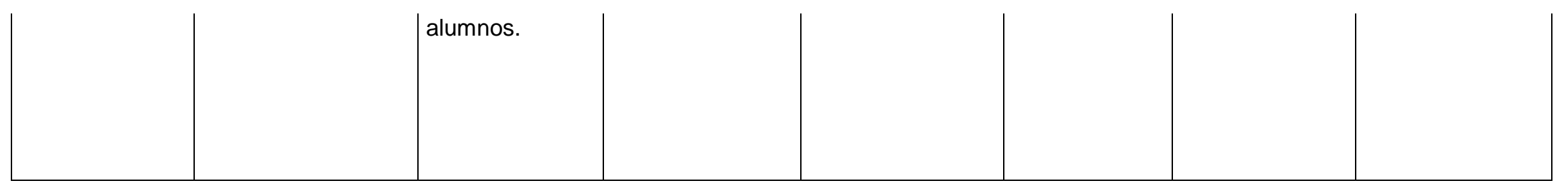

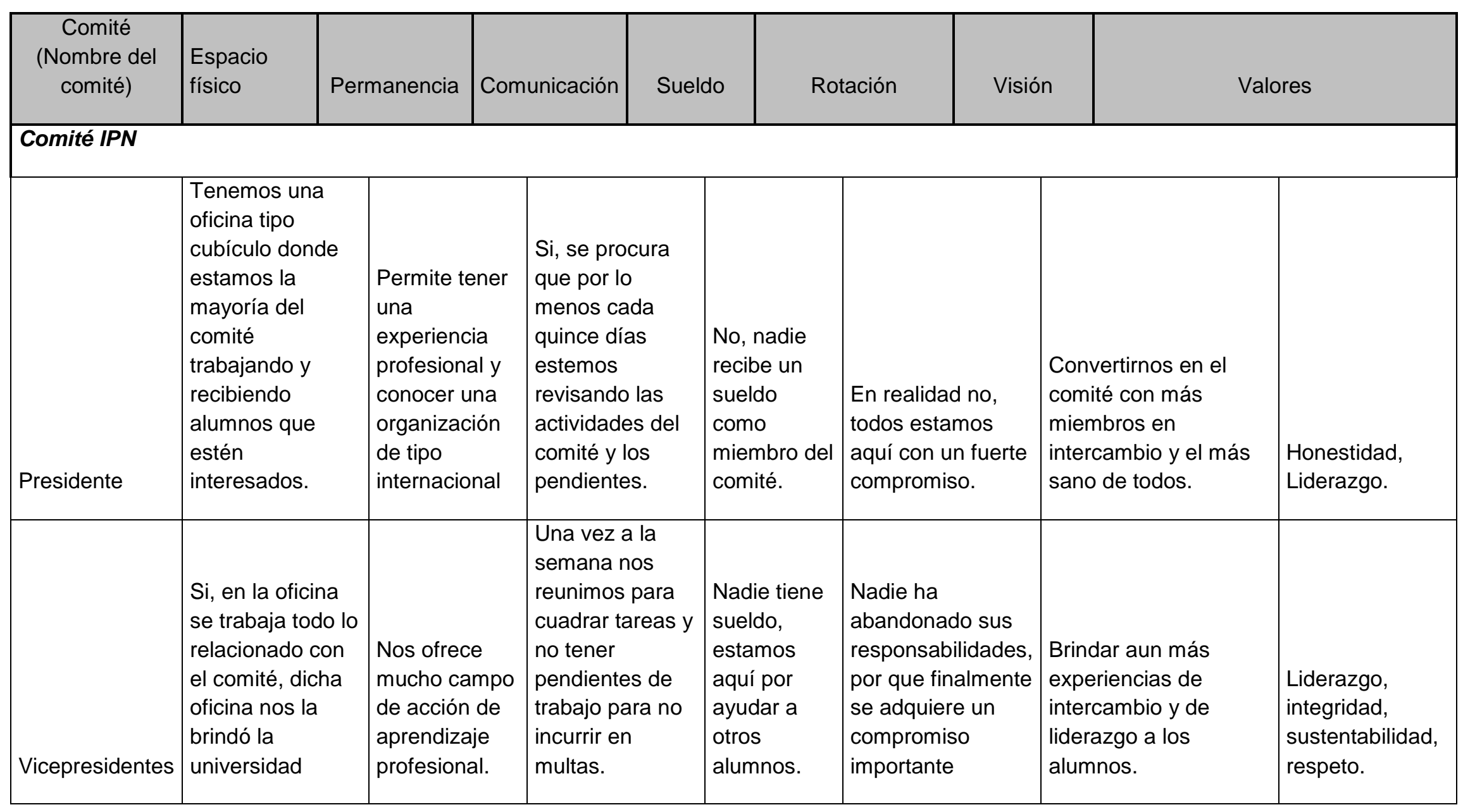




\begin{tabular}{|l|l|l|l|l|l|} 
& $\mid \begin{array}{l}\text { Nos brinda } \\
\text { oportunidades } \\
\text { de } \\
\text { crecimiento } \\
\text { laboral } \\
\text { teniendo una } \\
\text { experiencia } \\
\text { de trabajo } \\
\text { aquí. }\end{array}$ & $\begin{array}{l}\text { Se trata de que } \\
\text { sea una vez a la la oficina } \\
\text { estamos la } \\
\text { semana. } \\
\text { cumpliendo cona } \\
\text { las actividades. }\end{array}$ & $\begin{array}{l}\text { No, no } \\
\text { apoyo } \\
\text { económico, } \\
\text { ni beca. }\end{array}$ & $\begin{array}{l}\text { No, el compromiso } \\
\text { que se adquiere } \\
\text { es fuerte, además } \\
\text { que estar aquí te } \\
\text { brinda muchas } \\
\text { oportunidades } \\
\text { para aprender. }\end{array}$ & $\begin{array}{l}\text { Crecer como comité } \\
\text { en términos de } \\
\text { concretar mas } \\
\text { intercambios }\end{array}$ \\
\hline
\end{tabular}

\begin{tabular}{|l|l|l|l|l|l|l|l|}
\hline $\begin{array}{c}\text { Comité } \\
\text { (Nombre del } \\
\text { comité) }\end{array}$ & $\begin{array}{l}\text { Espacio } \\
\text { físico }\end{array}$ & Permanencia & Comunicación & Sueldo & Rotación & Visión & Valores \\
\hline \multicolumn{2}{|l|}{ Universidad Panamericana } & $\begin{array}{l}\text { Si, tenemos } \\
\text { una oficina } \\
\text { en donde la } \\
\text { mayoría } \\
\text { sabe donde } \\
\text { encontrarnos }\end{array}$ & $\begin{array}{l}\text { Ofrecer una } \\
\text { experiencia } \\
\text { estudiantil } \\
\text { diferente }\end{array}$ & $\begin{array}{l}\text { Si, tratamos } \\
\text { que sea cada } \\
\text { jueves a fin } \\
\text { seguimientos } \\
\text { a las tareas } \\
\text { de cada área }\end{array}$ & $\begin{array}{l}\text { No, no brinda } \\
\text { tenemos visión } \\
\text { remuneración } \\
\text { distinta de } \\
\text { lo que } \\
\text { aprendes } \\
\text { aquí en } \\
\text { México a } \\
\text { través de } \\
\text { un }\end{array}$ & $\begin{array}{l}\text { Mejorar } \\
\text { intercambios } \\
\text { calificaciones } \\
\text { estudiantil } \\
\text { y como comité } \\
\text { posicionarnos } \\
\text { como el mas } \\
\text { eficiente }\end{array}$ & $\begin{array}{l}\text { Respeto, } \\
\text { Creatividad }\end{array}$ \\
\hline
\end{tabular}




\begin{tabular}{|c|c|c|c|c|c|c|c|}
\hline Vicepresidentes & $\begin{array}{l}\text { Si, ahí todos } \\
\text { los } \\
\text { interesados } \\
\text { nos localizan }\end{array}$ & $\begin{array}{l}\text { Cambiar } \\
\text { nuestra } \\
\text { experiencia } \\
\text { como } \\
\text { profesionistas }\end{array}$ & $\begin{array}{l}\text { Tratamos que } \\
\text { sea los jueves }\end{array}$ & $\begin{array}{l}\text { No hay } \\
\text { salario para } \\
\text { ningún } \\
\text { miembro }\end{array}$ & $\begin{array}{l}\text { Tener una } \\
\text { experiencia } \\
\text { de } \\
\text { liderazgo } \\
\text { muy } \\
\text { importante }\end{array}$ & $\begin{array}{l}\text { Ser el comité } \\
\text { con mejores } \\
\text { calificaciones } \\
\text { y con mas } \\
\text { miembros de } \\
\text { intercambio }\end{array}$ & $\begin{array}{l}\text { Creatividad, } \\
\text { Respeto, } \\
\text { Creatividad }\end{array}$ \\
\hline Staff & $\begin{array}{l}\text { Si, hay } \\
\text { realizamos } \\
\text { las tareas y } \\
\text { como oficina } \\
\text { para atender } \\
\text { a los } \\
\text { interesados }\end{array}$ & $\begin{array}{l}\text { Tener una } \\
\text { visión como } \\
\text { profesionistas } \\
\text { a través de } \\
\text { esta } \\
\text { experiencia }\end{array}$ & $\begin{array}{l}\text { Los jueves se } \\
\text { realizan para } \\
\text { checar } \\
\text { pendientes y } \\
\text { seguimiento } \\
\text { de las tareas }\end{array}$ & $\begin{array}{l}\text { No, nadie } \\
\text { percibe } \\
\text { sueldo }\end{array}$ & $\begin{array}{l}\text { Liderar un } \\
\text { grupo de } \\
\text { trabajo y } \\
\text { tomar } \\
\text { decisiones } \\
\text { y apoyar } \\
\text { en las } \\
\text { tareas del } \\
\text { comité }\end{array}$ & $\begin{array}{l}\text { Ser el mejor } \\
\text { comité en } \\
\text { cuanto a } \\
\text { calificaciones } \\
\text { y el más } \\
\text { eficiente en la } \\
\text { ejecución de } \\
\text { las tareas }\end{array}$ & $\begin{array}{l}\text { Respeto, } \\
\text { Sustentabilidad, } \\
\text { Creatividad y } \\
\text { Liderazgo }\end{array}$ \\
\hline
\end{tabular}

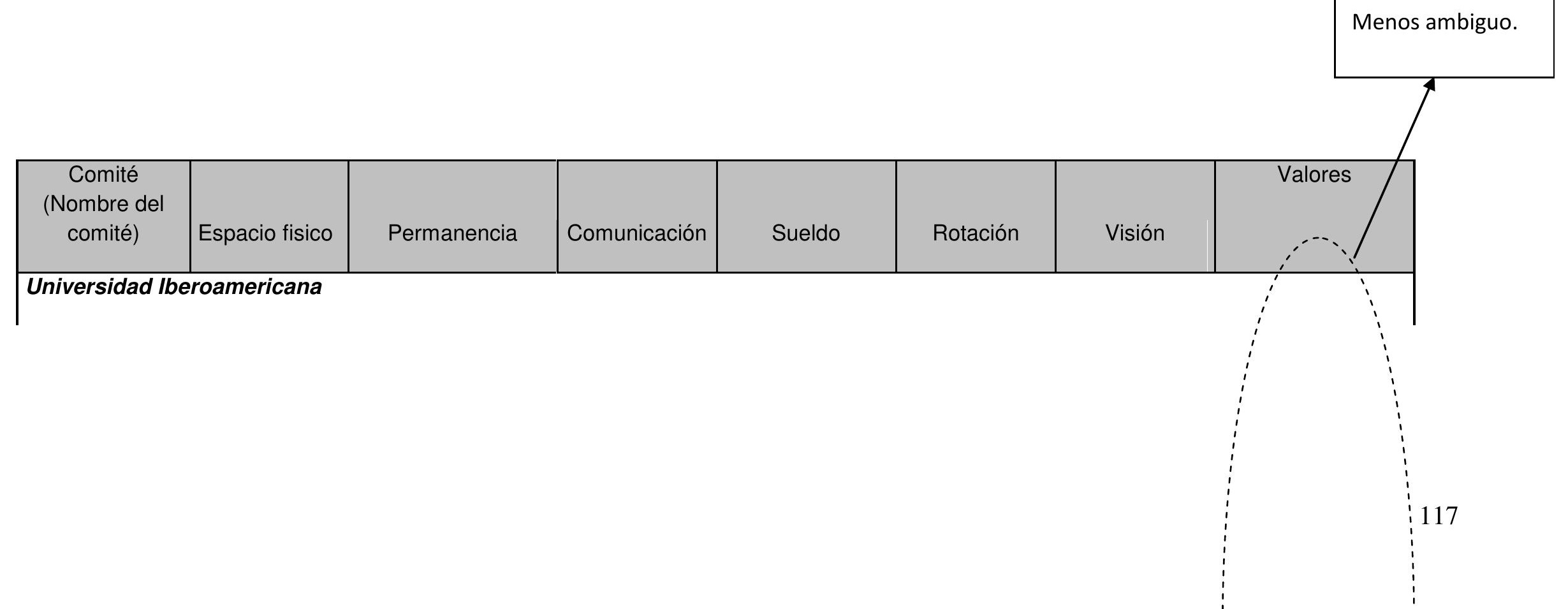




\begin{tabular}{|c|c|c|c|c|c|c|c|}
\hline Presidente & $\begin{array}{l}\text { Si, tenemos } \\
\text { una oficina } \\
\text { para atender } \\
\text { al público } \\
\text { interesado }\end{array}$ & $\begin{array}{l}\text { Dar la oportunidad } \\
\text { de durante } \\
\text { nuestros estudios } \\
\text { podamos adquirir } \\
\text { nuevos } \\
\text { conocimientos en } \\
\text { otros lugares del } \\
\text { mundo }\end{array}$ & $\begin{array}{l}\text { Los lunes } \\
\text { asignamos } \\
\text { tareas y } \\
\text { conversamos } \\
\text { sobre temas } \\
\text { de interés } \\
\text { para el comité }\end{array}$ & $\begin{array}{l}\text { No se pagan } \\
\text { ningún tipo de } \\
\text { remuneración } \\
\text { económica }\end{array}$ & $\begin{array}{l}\text { Adquirir una } \\
\text { experiencia } \\
\text { profesional } \\
\text { con un } \\
\text { intercambio } \\
\text { que les brinde } \\
\text { herramientas } \\
\text { de trabajo de } \\
\text { vanguardia }\end{array}$ & $\begin{array}{l}\text { Mejorar } \\
\text { nuestras } \\
\text { calificaciones } \\
\text { como comité y } \\
\text { posicionarnos } \\
\text { como el mas } \\
\text { eficiente }\end{array}$ & $\begin{array}{l}\text { Integridad, } \\
\text { Sustentabilidad, } \\
\text { Respeto, } \\
\text { Creatividad }\end{array}$ \\
\hline Vicepresidentes & $\begin{array}{l}\text { Si contamos } \\
\text { con una } \\
\text { oficina de } \\
\text { atención }\end{array}$ & $\begin{array}{l}\text { Tener una } \\
\text { experiencia en una } \\
\text { organización } \\
\text { internacional }\end{array}$ & $\begin{array}{l}\text { Los lunes se } \\
\text { hacen las } \\
\text { reuniones }\end{array}$ & $\begin{array}{l}\text { No, nadie } \\
\text { percibe }\end{array}$ & \begin{tabular}{|l} 
Tener \\
experiencia \\
en manejo de \\
grupos \\
entorno a un \\
ambiente de \\
eficiencia en \\
todos los \\
ámbitos
\end{tabular} & $\begin{array}{l}\text { Ser el mejor } \\
\text { comité y el } \\
\text { que tenga el } \\
\text { mayor } \\
\text { número de } \\
\text { miembros en } \\
\text { intercambio }\end{array}$ & $\begin{array}{l}\text { Respeto, } \\
\text { Integridad, } \\
\text { Sustentabilidad, } \\
\text { Creatividad }\end{array}$ \\
\hline Staff & $\begin{array}{l}\text { Contamos con } \\
\text { una oficina } \\
\text { bien } \\
\text { acondicionada } \\
\text { para atención } \\
\text { al público }\end{array}$ & $\begin{array}{l}\text { Transformas a los } \\
\text { estudiantes de hoy } \\
\text { en día a través de } \\
\text { una experiencia de } \\
\text { intercambio }\end{array}$ & $\begin{array}{l}\text { Los jueves se } \\
\text { realizan para } \\
\text { checar } \\
\text { pendientes y } \\
\text { seguimiento } \\
\text { de las tareas }\end{array}$ & $\begin{array}{l}\text { No, nadie } \\
\text { percibe sueldo }\end{array}$ & $\begin{array}{l}\text { Liderar un } \\
\text { grupo de } \\
\text { trabajo y } \\
\text { tomar } \\
\text { decisiones y } \\
\text { apoyar en las } \\
\text { tareas del } \\
\text { comité }\end{array}$ & $\begin{array}{l}\text { Ser el mejor } \\
\text { comité en } \\
\text { cuanto a } \\
\text { calificaciones } \\
\text { y el más } \\
\text { eficiente en la } \\
\text { ejecución de } \\
\text { las tareas }\end{array}$ & $\begin{array}{l}\text { Respeto, } \\
\text { Sustentabilidad, } \\
\text { Creatividad y } \\
\text { Liderazgo }\end{array}$ \\
\hline
\end{tabular}

Fuente: Elaboración propia de acuerdo a información recabada en entrevistas. 
La información obtenida es sumamente importante, ya que de viva voz se conoce la situación y las particularidades de cada comité y a su vez permite identificar distintos niveles de análisis y de manera puntual sí todos los comités condicen en los estatutos predeterminados, particularmente lo que corresponde a valores y visión, ya que por una parte el comité UNAM muestra ambigüedad y por otra parte los demás comités muestran mas homogeneidad en dichos estatutos. 


\subsection{El flojo acoplamiento en comité UNAM: Una aproximación.}

Sin embargo a pesar de que el discurso nos dice que es una organización de talla internacional, una vez que es posible reconocer sus particularidades e introducirse en la organización misma, lo que se da cuenta es que dicha organización es el resultado de un fuerte control, alta formalización, apego a las normas, y la similitud en la ejecución de las actividades en la consecución de las metas organizacionales.

En el paso por la organización, la primera entrada fue en el comité UNAM, el cual contribuyó y se comprometió con la investigación. Durante el transcurso fue posible contactar e investigar otras partes de la organización, que fue cuando se dio el contraste entre los 6 comités que conforman AIESEC México, presentando diferencias en su operación, la realización de sus actividades y a primera vista constatar que la idea de permanencia en la organización es fuerte; ya que pesar de que su estancia es sin goce de sueldo y con las presiones y actividades propias de un trabajo asalariado.

Las particularidades se hacen presentes en el Comité UNAM siendo éste, el único sin espacio físico, con ambigüedad en el sentido de pertenencia a AIESEC, donde la supervisión y la comunicación es impersonal, pero a pesar de ello durante la revisión documental y vía intranet a través de Regina Guerrero miembro del comité UNAM, fue posible avizorar que a pesar de dichas características era uno de los comités mas sanos ${ }^{17}$ y de los mas productivos en términos de alumnos que son candidatos y logran concretar un intercambio a otros países, entonces se hace necesario y pertinente lo que corresponde a los estudios organizacionales y comprender por que a pesar de lo anterior la organización funciona.

Entonces nos acercamos al terreno interesante y como marco que permita comprender dicho fenómeno organizacional, y considerando las premisas fundamentales de las Teorías de Ambigüedad Organizativa, refiriéndonos a los sistemas flojamente acoplados.

Las premisas fundamentales de los sistemas flojamente acoplados se refiere a que una organización o parte de esta cuyos elementos se corresponden unos con otros, mantienen una identidad y especificidad propias, varios medios pueden producir un mismo fin, relativa necesidad de coordinación o baja coordinación, relativa ausencia de regulación y la impresión de que no importa lo que se haga, "las cosas siguen igual", que la relación entre los elementos es

${ }^{17}$ Con salud se refiere a que los comités son evaluados de 1 al 10 por comité nacional en cuanto a la entrega de actividades en tiempo y forma y no incurrir en multas por no entregar actividades a tiempo, tales como informes, reportes de intercambio y finanzas y labores de reclutamiento. 
intermitente, ocasional, indirecta, eventual acercándonos de forma modesta a una posible explicación del por que a pesar de las particularidades del comité UNAM es de los mas productivos en términos de intercambios que es la actividad esencial; y de los mas saludables a pesar de no contar con los recursos con que los otros comités cuentan.

Sin embargo para Diciembre de 2013, AIESEC UNAM planea tener más de 30 intercambios salientes y alrededor de 20 intercambios entrantes, y con un total del $90 \%$ de sus metas organizacionales alcanzadas.

Respecto de Comité Nacional es un sistema flojamente acoplado por que comité UNAM difiere en cuantos los factores expuestos en la tabla 7 como lo son valores, visión, espacio físico, permanencia y simultáneamente comité UNAM en si mismo es una especia de sistema flojamente acoplado. Las premisas teóricas de los sistemas flojamente acoplados en nuestro caso de estudio AIESEC Comité UNAM aparecen de la siguiente forma:

- Ocasiones cuando hay una excesiva cantidad de recursos en relación con las demandas: En este sentido como tal Comité UNAM no cuenta con los recursos necesarios para llevar a cabo su actividad sin embargo lo ha logrado.

- Varios medios pueden producir un mismo fin: En comité UNAM como parte de un gran Comité Nacional, puede llevar acabo su actividad principal, el intercambio estudiantil.

- Relativa necesidad de coordinación o baja coordinación: El caso de Comité UNAM consiguen llevar acabo los objetivos de la organización sin necesidad de una fuerte coordinación por parte de la Presidenta Regina Guerrero hacia los miembros del comité derivado de la ausencia de un espacio físico y la supervisión virtual que se ha implementado por la carencias de material y espacio para el comité. Sin embargo los resultados son destacables en términos comparativos con otros comités que conforman AIESEC México.

- Relativa ausencia de regulación: Aunque pareciera que Comité UNAM trabaja con su propias reglas, Comité UNAM en términos de operación y resultados esta regulado por Comité Nacional como un organismo regulador por excelencia hacia otros comités que conforman AIESEC México, de tal forma que se regula sus formas de organización y sus resultados. 
- Casi independencia de las partes: Bien es cierto aunque Comité UNAM opera de forma particular, la interdependencia es parte esencial del comité, ya que cada una de las partes contribuye a los resultado de la organización por que cada una de las partes en si misma tiene una tarea que alimenta otras partes de la organización y dicha tarea al final contribuye al cumplimiento de las metas organizacionales.

- Infrecuente inspección de actividades dentro del sistema: Este aspecto aunque a simple vista pareciera que cada una de las partes trabajara de forma paralela y la Presidenta de comité al interior de Comité UNAM y a su ves Comité Nacional no inspeccionara la operación de comité, al adentrarse en la organización da cuenta de todo lo contrario, la inspección es una acción que prevalece a fin de vigilar el cumplimiento de las metas organizacionales.

- Delegación de discreción: este aspecto no es visible es el comité, la comunicación es parte esencial del comité.

- La observación de que la estructura de la organización no se corresponde con sus actividades: La estructura organizacional es un aspecto muy delineado, ya que desde Comité Nacional la estructura organizacional debe ser similar en cada una de las área que las componen, y cada área como se menciono anteriormente tiene una razón ser ya que cada área contribuye al cumplimiento de las metas organizacionales, los intercambios estudiantiles.

- La impresión de que no importa lo que se haga, "las cosas siguen igual": Esa es la impresión de los miembros de comité UNAM por las carencias de infraestructura, por que a pesar de ser el comité mas productivo, no consiguen obtener los recursos necesarios con los que cuentan otros comités, y no recibe un apoyo integral por parte de comité nacional, sin embargo a pesar de las carencias logran funcionar de manera optima.

- La relación entre los elementos es intermitente, ocasional, indirecta, eventual: Aunque comité UNAM en lo que se refiere a la organización del trabajo cada parte trabaja de forma separada ya que no cuentan con espacio físico y cada una de las partes de reúnen físicamente de manera eventual, aunque no por ello deja de funcionar cada una de as partes, se cumple cada una de sus funciones de tal manera que el objetivo de la organización es cumplido.

- La yuxtaposición de fuerzas contradictorias pertenecientes a un mismo sistema (diferenciación vs coordinación): este aspecto no se delinea en la organización, no existen 
como tal fuerzas contradictorias, las fuerzas fluyen y cooperan entorno al cumplimiento de metas.

Sin embargo hay aspectos que rodean dicho concepto como sigue a continuación (Weick,1976:5):

1) tiempos de holgura, cuando hay una cantidad excesiva de recursos en relación con las demandas: en este sentido es la escasez de recursos sin embargo logran satisfacer la demanda de estudiantes que desean ser candidatos a un intercambio estudiantil.

2) ocasiones en las que cualquiera de varios medios produce el mismo fin: en si mismo cada una de las partes de comité funciona de manera de conjunta aunque físicamente no se logre una reunión como tal.

3) redes ricamente conectadas en las que la congruencia separatista es lenta o débil mientras se están separando: este aspecto es fundamental ya que en efecto prevalece una congruencia separatista que logra que cada parte del comité funcione aunque físicamente no estén conectadas por la ausencia de un espacio físico.

4) una relativa falta de coordinación, coordinación lenta o coordinación que es desalentada cuando se mueve a través de un sistema. En efecto es "relativa" la falta de coordinación en comité UNAM por que físicamente se reúnen de manera eventual, sin embargo la coordinaron existe cuando desde su estructura son regulados por Comité Nacional.

5) una relativa ausencia de regulaciones: en efecto es relativo por que a simple vista da cuenta de ser una comité que funciona de acuerdo a sus reglas, la regulación prevalece por que Comité Nacional regula sus funciones y el cumplimiento de sus metas.

6) falta de respuestas previstas; no ocurre como tal al interior del comité, por que lo que realizan de tareas tendrá impacto en los resultados del comité.

7) causales reales de independencia; la causal real del comité va desde la forma en la cual debe ser su estructura organizacional que es regulada y similar a comité 
nacional, lo que hace que cada parte del comité retroalimente a la otra conformando un ambiente de sinergia, de tal forma que si alguna parte no funciona por consiguiente el resultado no será el mismo

8) escasa capacidad de observación por parte de un espectador: no se identifico en comité UNAM.

9) inspección escasa de las actividades dentro del sistema: como se comento anteriormente la inspección se da de manera directa por parte de comité nacional pero al interior comité UNAM la inspección no se da de manera optima por que las reuniones y trabajar de manera conjunta en un espacio no se da debido a la carencia de espacio físico.

10) descentralización; este aspecto no es visible en la organización, las fuerzas se encuentran centralizadas en comité nacional y en cada uno de los presidentes de los comités.

11) la delegación de discrecionalidad. No se identificó en el comité.

12) la falta de vínculos que deben estar presentes con base en una teoría, por ejemplo, en las organizaciones educativas la retroalimentación de vínculos exteriores, a manera de insumos del sistema, frecuentemente es inexistente: no aparece como tal, ya que comité nacional como organismo regulador, constantemente vigila las actividades de cada comité y si alguno de ellos presenta dificultades se les convoca a reunión y se exponen probemos y alternativas que coadyuven al cumplimiento de las metas.

13) la observación de que la estructura de una organización no está vinculada para durar el mismo tiempo que la actividad: la estructura organizacional esta regida, diseñada y asentada por comité nacional de tal forma que cada área contribuya al cumplimento de las metas

14) aquellas ocasiones en que, sin importar lo que se haga, las cosas siempre resulta lo mismo: el aspecto crucial de Comité UNAM, ha mostrado una evolución importante, estabilidad, menos rotación de miembros, y sobre todo mejore resultados, pero el sentir de los miembros del comité es "somos de los mejores, nuestros miembros permanecen por las tiempo y están mas agusto, se sienten bien con su trabajo y responsabilidades, y comité UNAM creo no lo reconoce al 
cien por ciento, por que no nos apoya con un espacio par podernos reunir y por mas que les mostramos nuestros avances creo todo sigue igual". Entrevista con presidenta y miembros de comité UNAM

Como se dio cuenta, las realidades organizativas no son espejos de las premisas teóricas, sin embargo lo que se puede avizorar es ese acercamiento, y de manera gradual los conceptos y nuestras organizaciones se adaptan a las premisas teóricas lo que nos permite acercarnos a un posible explicación de que acontece en nuestras organizaciones.

Gráficamente se puede entender el fenómeno organizacional que tiene lugar en AIESEC México que podría entenderse en flojo acoplamiento en dos niveles, por una parte al interior del comité UNAM y su relación ò flojo acoplamiento con otras partes de la organización, a manera grafica se muestra lo siguiente: 
Figura 6: El flojo acoplamiento en AIESEC a distintos niveles:

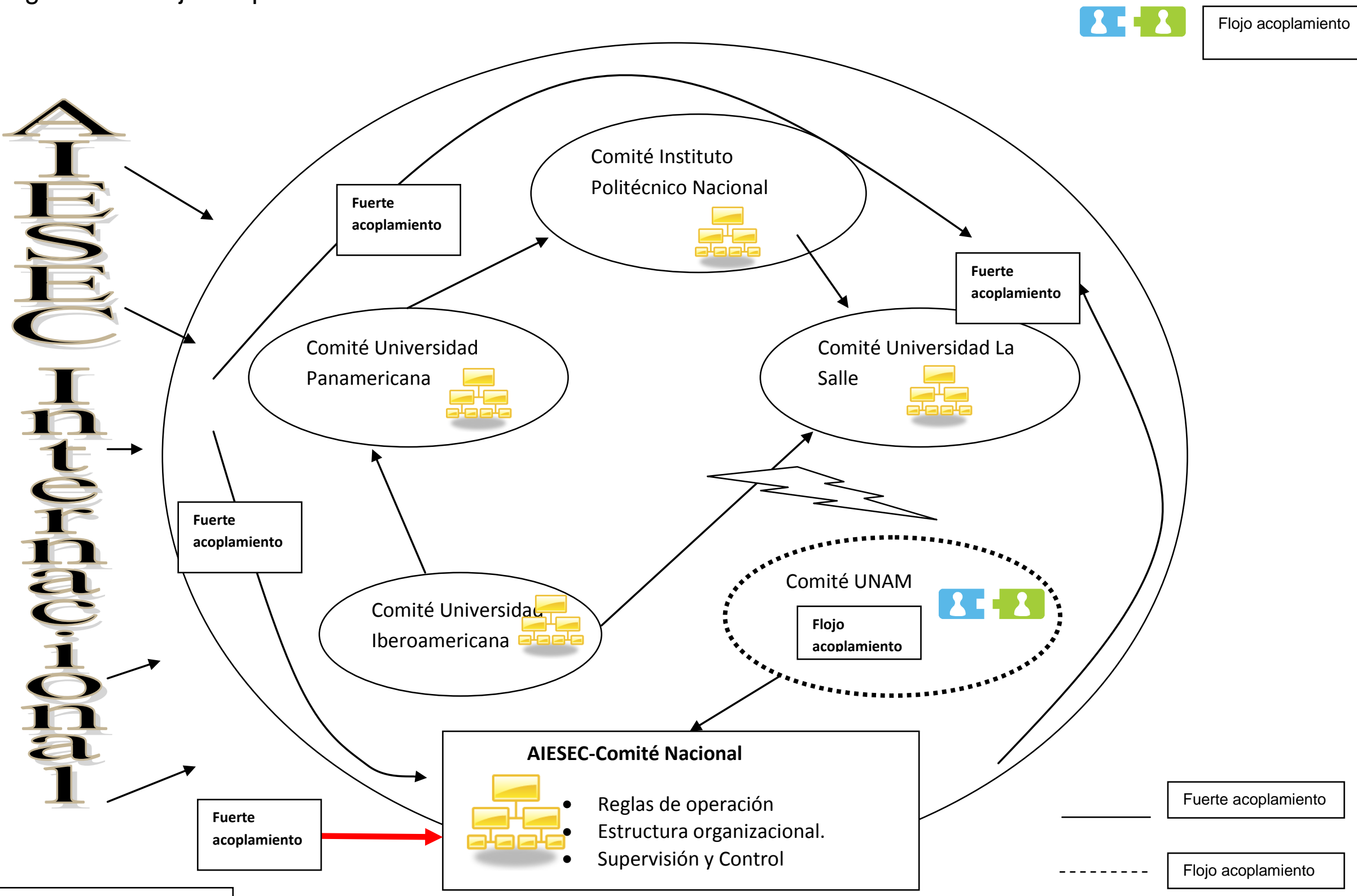




\subsection{La ambigüedad en comité UNAM.}

Como se puede apreciar de acuerdo a la información recabada en la tabla 7, la ambigüedad se muestra de manera itinerante en comité UNAM, sin embargo la información y el acceso a la organización permite analizar a distintos niveles:

1. a nivel comité nacional y comités.

2. entre comités

3. al interior de cada comité

Lo anterior se puede explicar grafícamele de la siguiente manera:

1. a nivel comité nacional y comités: se observa homogeneidad en cuanto a valores y visión sin embargo con comité UNAM, los valores difieren y en lo que corresponde a visión es una visión diferente a la que establece el estatuto de comité nacional, y el mas homogéneo en cuanto a visión y valores es comité Universidad Iberoamericana, en una primera apreciación podría ser por que el presiente de comité Nacional fue alumno y miembro de esa universidad.

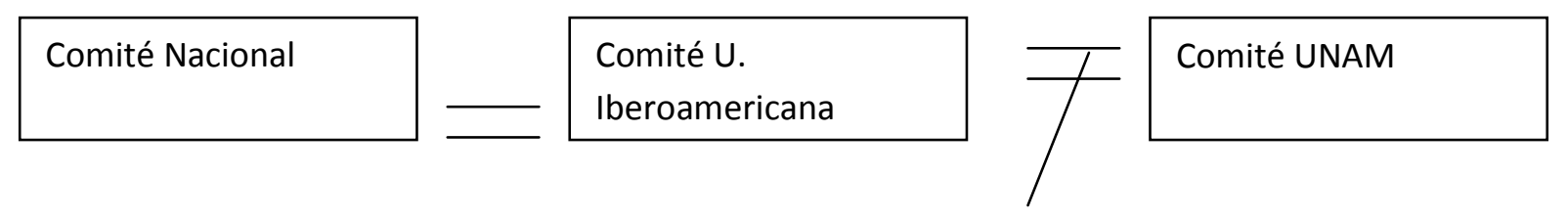

2. entre comités: podemos observar homogeneidad en los estatuos de valores y visión sin embargo comité UNAM presenta diferencias importantes ya que sus valores y visión a pesar de que deberían apegarse a lo establecido por comité nacional, marca una esencia meramente social, debido a la naturaleza pública de la UNAM, lo cual afecta impacta en establecimiento de valores y visión.

Figura 5. Diferencias comités.

$$
\}
$$



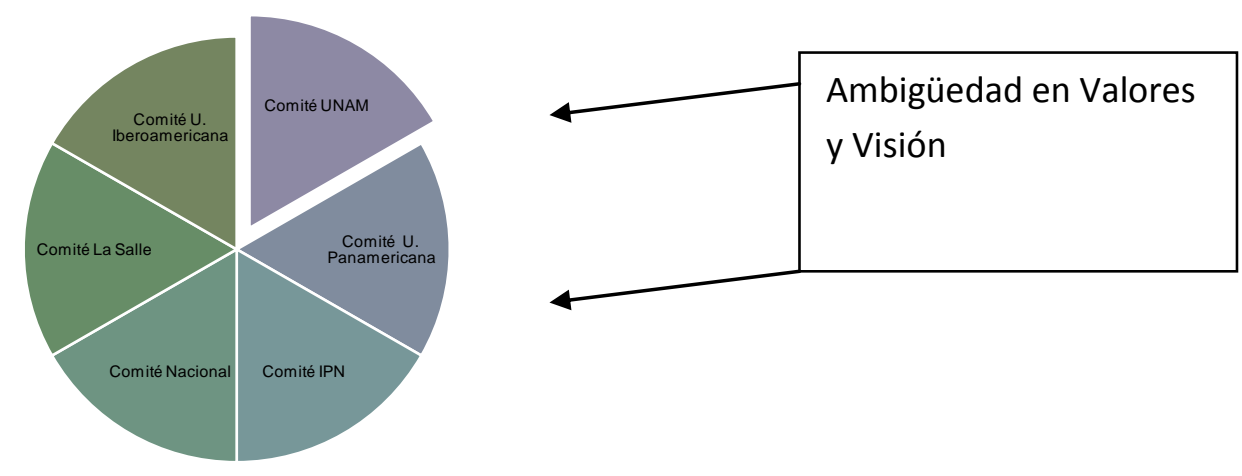

Fuente: Elaboración propia de acuerdo a información recabada.

3. Al interior de cada comité: Al interior de cada comité de acuerdo a los establecido se percibe y plasma homogeneidad en cuanto a los factores de espacio físico, permanencia, comunicación, sueldo, rotación a reserva de ambigüedad en comité UNAM en cuanto al establecimiento de valores y visión, al interior derivado de no contar con un espacio físico, alta rotación de miembros, comunicación poco presencial, al acoplamientos se torna difícil y débil y los esfuerzos se encaminan a mantener cohesionado el comité a pesar de las carencias con las que opera.

4. Cada comité: entre cada comité se marca la diferencia entre el comité UNAM y los demás comités (ver figura 6) donde UNAM muestra un tipo de identidad y objetivos distintos a los que plantea comité nacional.

En lo que corresponde a los supuestos básicos sobre el concepto de ambigüedad en comité UNAM se idéntica lo siguiente, cabe señalar que dichas apreciaciones son un acercamiento a las premisas de ambigüedad organizativa, mas no un espejo de las mimas:

- Ambigüedad de intención: por parte de comité UNAM derivado de las carencias con las que operan, adicionalmente que a naturaleza publica de la universidad permea sus objetivos, a diferencias de los que plantea comité nacional.

- Ambigüedad de entendimiento: los aspectos como tecnología son pocos claros por que a pesar de que en si mismo AIESEC cuenta con una plataforma de comunicación extensa, comité UNAM derivado de la carencia de equipo de computo, presenta dificultades al entender del por que una plataforma tecnológica tan ambiciosa, si ellos no cuentan con equipo de computo y deben hacer uso de 
sus equipos personales. En lo que corresponde al ambiente es difícil de interpretar por que para comité UNAM el ambiente se presenta como algo difuso por el hecho de no estar reunidos en un espacio físico en comparación a otros comités que si cuentan con un espacio que les permita convivencia mas personal.

- Ambigüedad de organización: existe dificultad para controlar y establecer los patrones de conducta dentro de comité UNAM debido a que la supervisón no es directa ni personal, y la participación de los miembros de comité UNAM en los procesos decisorios pareciera difusa y sin compromiso.

- Ambigüedad del éxito: un aspecto fundamental dentro de comité UNAM es que por ser una universidad publica el éxito para ellos mas allá de los rendimientos económicos y de reconocimiento, el éxito es una visión social enfocada a ofrecer oportunidades de crecimiento profesional a los estudiantes de la universidad, siendo que para otras universidades el éxito radica en ser el más productivo, la competencia y el reconocimiento social, aspectos que se repiten en otros comités como el la universidad Iberoamericana, La Salle y Panamericana. dificultad para definir que significa el éxito en un contexto de diversidad de actividades.

Entonces lo anterior nos muestra un panorama difuso y de desmembramiento, sin embargo no por ello comité UNAM no ofrece resultados, sino que corresponde a una lógica no convencional, y comité UNAM ha logrado sobrevivir y dar resultados desde su ámbito y espacio de acción marcando un referente de organización y operación, donde la ambigüedad esta presenta y como sistema no encontramos ante uno que es flojamente acoplado.

\subsection{Conclusiones}

El estudio de las organizaciones, en su formación académica, los Estudios Organizacionales, dan cuenta de ser un cuerpo teórico heterogéneo, diverso, donde la diversidad en vías de ofrecer o dar paso a una comprensión creciente, sobre el fenómeno organizacional, se ha buscado un dialogo constante entre las distintas disciplinas que alimentan los Estudios Organizacionales, donde se abra paso a un puente entre una disciplina y otra sin perder de vista nuestro objeto de estudio. 
Al mismo tiempo es ineludible comprender los cambios de perspectiva respecto a como se habían y se han venido estudiando las organizaciones, aparecen nuevos enfoques, nuevas corrientes paradigmáticas, incluso nuevas formas organizacionales, para lo cual es necesario ofrecer una vía para su comprensión, tal es el caso de lo que hoy conocemos como Estudios Organizacionales que nos abre paso a darnos cuenta de la existencia de nociones nuevas por comprender y variables que agregar para dar cuenta a realidades actuales y el ideal será dar paso a un espacio de fricciones reflexivas que coadyuven a la compresión de las realidades locales organizacionales.

Dicha evolución ha sido tarea ardua, cada forma de pensamiento marca un referente que permea la forma de ver a las organizaciones, atreves de nuevos paradigmas y nuevos principios, voltear la mirada hacia otros horizontes, es dar paso a decir; ¿el contexto determina la forma?, ¿la tecnología determina la estructura de la organización? ¿o en función de variables contextuales? (Pugh, 1997: 16) o bajo la misma línea de ideas, ¿a mayor complejidad ambiental mayor grado de diferenciación?, ¿existe una "mejor forma de organización"? o (Lawrence y Lorsch, 1973). En realidad "todo depende", o seguir empeñados en buscar relaciones lineales, unidireccionales, de orden, equilibrio y uniformidad en las organizaciones en las organizaciones o la simple pretensión del tipo ideal (Hinings, 1993).

Lo organizacional es una amplio espacio donde se interrelacionan distintos elementos que conforman una organización, pero dichos elementos no siempre fueron a primera vista reconocidos, todo parte del análisis organizacional y la forma de acercarse a ella también ha sido una construcción constante en la búsqueda de respuestas que coadyuven en la compresión de las organizaciones.

Como nos hemos dado cuenta nuevamente la teoría y la practica suelen diferir, incluso cuando nos encontramos bajo ciertos enfoques es posible que no se distingan otros aspectos igualmente importantes.

Primeramente es necesario acercarnos al análisis de le estructura en las organizaciones ya que nos permite acercarnos a una posible explicación sobre las problemáticas organizacionales como una forma de garantizar la permanencia de la organización antes ambientes turbulentos y complejos y orientar el diseño a formas flexibles de organización.

Conformar el mapa cognitivo de la organización, orienta a la obtención de resultados particulares pero también nos brinda explicaciones a cerca del funcionamiento de la 
organización y los individuos que la conforman; lo cual nos acercan al entendimiento de la organización y su comportamiento en su interior y su relación con el entorno.

Entonces es necesario dotar los trabajos de investigación con herramientas cognitivas para comprender a la organización, sin embargo habrá otros enfoques que nos permitan ver fenómenos no identificados y nos permitan seguir comprendiendo la complejidad organizacional como un constructo inacabado.

Por que bien es cierto que en comprensión de las realidades organizativas, se ha dado cuenta de un abanico con múltiples aristas que por una parte enriquece el conocimiento sobre la organización y sus problemáticas, pero a su vez la diversidad y las similitudes se hacen presentes.

Comenzar por explorar toda una serie de rompimientos paradigmáticos y las implicaciones teórico-metodológicas que implica un salto de esa magnitud; así como también el impacto de ese cambio en la forma de ver el mundo, el mundo que nos atañe, el de las organizaciones. De la transición a la que se refiere dentro de un aporte particular y que como uno de muchos caminos posibles para entender el fenómeno organizacional se refiere a la noción de transición de organizaciones burocráticas-modernas al paso a organizaciones postburocraticaspostmodernas; lo cual no solo implica un cambio en su adjetivo, sino toda una revolución en el cambio de pensamiento que gira en torno a su explicación, sobre todo la necesidad incipiente de construir marcos teórico-metodológicos que coadyuven a su comprensión que nos permita hacer referencia y mostrar una posible explicación de lo que acontece en las organizaciones hoy en día.

Por una parte se reconoce la tendencia hacia la homogenización, hacia la simplificación tanto de estructuras, como de procesos, pero en lo que no se hace hincapié o en menor medida es en los efectos colaterales que conlleva tanto a nivel individuo como a nivel organización, como parte de la cotidianeidad en el terreno organizacional.

Se debe hacer énfasis en la necesidad imperante de reconocer particularidades dentro de una realidad multidimensional que debe reconocer las dimensiones culturales, históricas, sociales, incluso geográficas que permean la acción cotidiana de las organizaciones, pero que también parece ser que aspectos tan fundamentales se dejan en ultima instancia y los resultados llegan a ser insospechados, lo que nos abre la mirada a pensar no en un puro, sino en la idea de 
la conformación de un hibrido por lo menos en la realidad mexicana, pero con el constante enriquecimiento sobre este fenómeno organizacional.

Entonces todo parece apuntar a que la "estructura organizacional universal pura", o "las recetas universales" no existen; ya que al toparse con particularidades socio-culturaleshistóricas, las acostumbradas explicaciones encuentran sus contradicciones.

Sobre la importancia de la ONG en la actualidad es preciso recalcar que el espacio social de caracteriza por la diferencia o marcadas esferas sociales con un acceso a bienes y servicios limitados o en exceso, donde la distribución de la riqueza es visible en distintos sectores sociales, entonces el individuo recibe de forma simultanea impactos colaterales en amplios aspectos de su vida, lo grave es que los impactos en su mayoría tienen una connotación negativa conformando un escenario de deterioro, descomposición y desencanto y es cuando los referentes colectivos actualmente tiene fuerza y presencia lo que mantienen unido a un grupo social traducido en lo que se conoce como la sociedad civil a través de formas distintas como lo son la ONG, asociaciones sin fines de lucro, de asistencia privada, asociaciones civiles, etc, y como ya se había mencionado todo lo anterior tiene una temporalidad y una espacialidad, se podría decir que la década de los 70's marcan un referentes a través del cual surgen toda una serie de transiciones que dieron cambio en la forma en la que se estaba acostumbrado a concebir a la sociedad, de una sociedad pasiva hacia una sociedad que logra cohesionarse en beneficio de ella misma ante el cumplimiento de sus demandas básicas ante el aparato estatal o con el fin de conseguir beneficios a nivel social que coadyuven al desarrollo de las mismas, llámese seguridad publica, educación, apoyo a la salud, apoyo en desastres naturales, todo en pro de mejores oportunidades y al acceso a un mejor nivel de vida el cual ha sido descuidado desde quienes deben procurarlo.

El estudio de AIESEC permitió transitar por distintos niveles de análisis y a su vez en los distintos niveles de la organización, lo cual permitió identificar lo referente al diseño de la organización es preciso reconocer sin titubeos el carácter contingente al interior y exterior de AIESEC, la postura ante ello sería adecuarse a un diseño flexible que permita la incorporación de acciones emergentes ante lo dinámico del entorno AIESEC, donde puedan coexistir distintos elementos de la organización en una interacción simbólica muy cercana con el apoyo de marcos teórico-metodológicos como los Estudios Organizacionales que coadyuven a dar cuenta de los que acontece en las organizaciones hoy en día. 
Es entonces cuando a la luz de las Teorías de Ambigüedad Organizativa como vehículo a través del cual podemos estudiar a las organizaciones de hoy en día, se ofrecen explicaciones adhoc de las realidades organizativas que durante la investigación se dio cuenta que dichas realidades necesitan de marcos de análisis que expliquen la complejidad con la que operan algunas organizaciones, y tal vez acercándonos a una predicción, enunciar como van a operar las organizaciones en un futuro no muy lejano, incluso superar lo que podemos imaginar. La organización que fue objeto de estudio AIESEC México a través de sus comités y particularmente Comité UNAM, en este trabajo dio inicialmente los primeros indicios de que nos encontrábamos ante una organización muy particular, con una forma de operar igualmente particular y por lo tanto habría que acercarse a un constructo teórico que por una parte diera cuenta mas allá de lo funcional, lo relacionado a ambigüedad organizativa referente a sistema flojamente acoplado permitió sacar a la luz lo que parecía no tener una forma de explicarlo, entonces dicho concepto con las premisas básicas sobre la ambigüedad de los objetivos, la indeterminación y la variabilidad de los procesos, así como la dificultad de evaluar y, aún más, de determinar los resultados adecuados permite explicar porque una organización como AIESEC-Comité Nacional y Comité UNAM funciona de forma particular y la existencia de indeterminación y sobre todo variabilidad de los procesos a dos niveles, nos acercaba hacia lo conocido como "sistema flojamente acoplado" orientándonos a la idea de flexibilidad y nuevamente aseverar que las organizaciones no son entes monolíticos, que están en constante evolución y que como una forma de vida están encontrando formas de adaptabilidad hacia su interior y al exterior.

También nos invita como estudiosos de las organizaciones a considerar en actuales y futuras investigaciones que en las organizaciones existe un número finito de relaciones estrechas que ocurren en cualquier momento, pero que estas "relaciones estrechas" se dan lugar a "relaciones flojas" que pueden dar lugar a patrones de "acoplamiento" en los casos que puedan ser observados.

Lo anterior es resultado de que los conceptos relacionados con el orden, la coordinación y la sistematización han sido privilegiados, sin embargo a la luz de un caso de estudio como el que da forma a este trabajo nos encontramos antes la organización desde una perspectiva más cercana a su realidad, es decir, tomando en cuenta que la organización puede estar flojamente acoplada y que el concepto de orden pasa a un segundo plano dando paso a los conceptos de diversidad de intereses, la competencia, la incertidumbre y la ambigüedad.

Hablar de AIESEC-Comité UNAM y Comité Nacional nos ha invitado a sugerir que la idea de orden y estabilidad es un sueño, y que a la luz de un esquema para tratar de explicar su 
funcionamiento a través de indagar sobre ella, da cuenta de que las organizaciones están inmersas en procesos de cambio y será su forma de afrontarlo lo que asegure o no su sobrevivencia, recordando que en el ambiente actual las organizaciones sufren dinamismo y opacidad, a su vez nos da cuenta de otra realidad sobre cómo se ha venido estudiando las organizaciones y es sobre la racionalidad con la que en su mayoría se ha tratado de explicar su comportamiento, y la realidad es que la organización no se comporta en forma permanente como un sistema estrechamente acoplado, como una estructura coordinada e interdependiente, dinámica y dirigida a unos fines explícitos; tan sólo lo hace en momentos concretos y lugares específicos, y nosotros como investigadores hemos dado por hecho dichas ideas no considerando que los conceptos relacionados con el orden, la coordinación y la sistematización pueden ser una utopía en las organizaciones de hoy en día y en un futuro cercano.

En la medida que las organizaciones crecen y se hacen más complejas, los ambientes también son más inciertos, se hace necesario introducir cierto grado de flexibilidad para afrontar los cambios y las transformaciones que tienen lugar hoy en día.

Aunque la propuesta teórica sobre sistemas flojamente acoplados podría verse como la antítesis sobre la organización misma, el aporte es que a la luz de dicha propuesta teórica a diferencia de los estudios realizados en torno a la visión racional de las organizaciones como un sistema compacto e integrado, es decir, un todo constituido por partes estrechamente relacionadas entre sí de tal manera que si una parte varía, también varían las demás permite reconocer que tan solo una parte de la organización puede introducir cambios, mientras que otros subsistemas permanecerán igual y que al mismo tiempo pueden existir diferencias a un nivel o en un aspecto de la organización sin que ello suponga el fin de la organización y que como es el caso de Comité-UNAM donde los miembros pueden estar trabajando con escasa coordinación entre sí y considerar que en un nivel pueden tomarse determinadas decisiones que sean ignoradas en otros niveles o llevadas a cabo según interpretaciones diferentes

Entonces es en esta parte donde la propuesta de Weick (1976) sale nuevamente a luz como una forma de decir "tenía razón"; porque bien es cierto las organizaciones flojamente acopladas presentan una débil articulación porque en ellas, los dos mecanismos típicos de conexión organizativa (tecnología y autoridad) no tienen una presencia tan sólida y precisa como en otras organizaciones, justamente como en comité UNAM ocurre, aunado a que el comité como sistema flojamente acoplado, dio cuenta sobre las posiciones de autoridad ya que el ejercicio de autoridad y control es cambiante y difuso, las posiciones de autoridad son débiles, sin embargo se logra mantener cohesionada a la organización a fin de cumplir con las metas que les 
son asignadas y que sus logros son por mucho más sobresalientes que otros comités que funcionan de forma "estructurada y con recursos materiales y humanos más completos".

El flojo acoplamiento puede iluminar las respuestas a varias interrogantes organizacionales y que tal vez han sido eludidas por nosotros los estudiosos de las organizaciones, nos hemos acostumbrado a que la mayoría de las definiciones de la organización consisten en al menos dos componentes: la primera, una fuente de orden que consolida, unifica, o une diversos elementos o fragmentos y los elementos y por otra los fragmentos que se consolidan como un todo unificado por una fuente de orden y que las organizaciones darían cuenta (bajo esa noción) de ser entes monolíticos que no están en constante adaptación, transformación y adaptación a su ambiente-contexto.

La tregua es que los investigadores deberíamos por comenzar con definiciones más amplias y construidas con una visión integral de la organización, para llegar a conclusiones más precisas, y es cuando el concepto de flojo acoplamiento se puede mantener en su forma dialéctica, y si puede ayudar a los investigadores iniciar los estudios con definiciones más sutiles e intrincadas y poder elevar la calidad de la investigaciones sobre la organización.

El flojo acoplamiento puede ayudar a los teóricos a entender la fluidez, la complejidad y la construcción social de las organizaciones, la estructura organizativa, el flojo acoplamiento en una organización se refiere en un sentido a que todo el mundo puede hacer todo y los enlaces entre las diversas partes no necesariamente tiene que seguir relaciones de interdependencia donde prácticamente son intercambiables e independientes y a la luz de la realidad organizacional actual se pudo encontrar como reflejo en dicho trabajo que el concepto "ocurre" en las organizaciones contemporáneas, que coexisten sistemas flojamente acoplados, anarquías organizadas aunque las discursos actuales insistan en la lógica de racionalidad y perfección en las organizaciones.

Es necesario adaptar los referentes teóricos a la realidad en la que operan las organizaciones de tal modo que se haga necesario seguir construyendo conceptos a través de los referentes teóricos clásicos que nos permita crear conceptos actuales de organizaciones actuales y reformular lo que los clásicos plantearon en sus tiempos.

Un sistema flojamente acoplado lejos o más que como un defecto, son características de algunas o muchas organizaciones hoy en día en el espacio organizacional y que bien es cierto a 
la luz de otras miradas podrá arrojar nuevas vetas de investigación que construyen el universo de explicaciones presente y futuro sobre las organizaciones.

Por que bien es cierto el análisis y el trabajo de campo en general y particularmente el caso de AIESEC-Comité UNAM dio cuenta que esta fuera de lo ortodoxo, de la lógica de la eficiencia y el "ser" ser de las organizaciones, por que dicha organización mediante el mecanismo de coordinación "adaptación mutua virtual" un concepto al que dio lugar este trabajo de investigación logra coordinar a cada unas de las partes fundamentales de la organización sin espacio físico ni reuniones físicas y de acuerdo a la información vista y recabada dicho comité es de los mas productivos, su razón de ser son los intercambios estudiantiles y la mayoría de aplicantes (estudiantes candidatos a intercambio) lograr establecer un intercambio real que perdura en su vida económica y profesional.

Considerando de igual forma una "supervisión diría virtual" que permite controlar y retroalimentarse dentro del comité y cumplir con las metas organizacionales impuestas por el Comité Nacional, el comité calificador por excelencia.

Finalmente el conocimiento ha dado cuenta de estar en constante evolución y construcción, por que dejo a la mirada de otros investigadores estudiar otras vetas de este trabajo de investigación, de formular nuevos términos sobre la realidad organizacional en el siglo $\mathrm{XXI}$, por que nos encontramos en la era de la tecnología y la información y esta era nos permite ver una realidad que los clásicos no observaron de acuerdo a su época, por lo que bien es cierto AIESEC-Comité UNAM puede conformar un concepto nuevo, el de la organización virtual. 


\section{Referencias bibliográficas}

Ander Egg, Ezequiel (1995), Métodos y Técnicas de Investigación Social, Ed. Lumen Humanitas, Argentina.

Baptista R., Hernández, M., J. Fernández y, (1991) Metodología de la Investigación Científica, Mc Graw Hill, Buenos Aires.

Barba Antonio, Solís Pedro (1996), Cultura en las Organizaciones. Enfoques y Metaforas en los Estudios Organizacionales, Ed. Vertiente, México, pp. 45-86

Beck, Ulrich, A. Giddens y S. Lash, (1997) Modernización Reflexiva, Política, Tradición y Estética en el Orden Social Moderno, Madrid, Alianza Universidad.

Caldera Gonzáles Diana, (2008), La Identidad de las Organizaciones de la Sociedad Civil. Aproximación a las Organizaciones Humano-Solidarias. Tesis Doctoral.

Calvillo Miriam, León Alfonso, Martínez Pablo, (2004), Organizaciones civiles: una propuesta organizativa, Revista Iztapalapa 56, año 25.

Cortes Graciela (2008), La coordinadora estatal de productores de café de Oaxaca, en Puga Cristina y Luna Matilde (Coords), "Acción colectiva y Organización. Estudios sobre desempeño asociativo" UNAM, Instituto de Investigaciones Sociales, México, pp. 227-264.

Cohen Michael D. March James G., Olsen Johan P. (1972), A Garbage Can Model of Organizational Choice, Administrative Science Quarterly, Vol. 17, No. 1. 
Del Castillo Arturo, (2001), Ambigüedad y decisión: una revisión a la teoría de las anarquías organizadas, Colección de documentos de trabajo, CIDE, numero 36, pp. $1-31$.

De la Rosa Albuquerque Ayuzabet y Contreras Julio. (2007) Entre la ciencia política y los Estudios Organizacionales, Revista Polis, Vol. 3, Num. 2, pp. 17-67

De la Rosa Albuquerque Ayuzabet, (2010) Notas de clase Teoría de la Organización II, trimestre 10-P

Documentos internos AIESEC.

Etzioni, Amitai (1979). Organizaciones modernas. Ed. UTEHA. México.

Friedberg, Erhard. (1997) Le Pouvoir et la Règle. Dynamiques de l'action organisée, Éditions du Seuil, Paris, págs. 151-193.

García Canclini Nestor, et al, 2004, De lo local a lo global: perspectivas desde la antropología, UAM, México.

Galindo Cazares Jesús, (1998), Técnicas de Investigación en sociedad, cultura y comunicación, Ed. Pearson, México.

Gunderman Kroll Hans, (2004), El método de estudio de caso. En Tarrés Maria Luisa (Coordinadora) Observar, Escuchar y comprender sobre la tradición cualitativa en la investigación social, (págs. 251-286). London: Sage.

Hall, Richard 1996 Organizaciones. Estructuras, procesos y resultados, Ed. Prentice Hall, México. 
Hinings, C.R., Alan Meyer D. y Anne S. Tsui (1993) Configurational Approaches to organizational analysis, Academy of Management Journal, vol. 36, num. 6, pp. 11751185.

Lawrence Paul R. y Lorsch (1973) Organización y ambiente, Editorial Labor,S.A. pp.11-30

March James G y Olsen Johan P. (1975), The Uncertainty of the Past: Organizational Learning Under Ambiguity, European Journal of Political Research 3 147-171.

Mazzotti Pabello Giovanna, Solís Pérez Pedro C., "Las nuevas formas de organización de la sociedad civil ante la globalización", Revista Administración Organizaciones, Noviembre 2002, México, Ed. UAM, pp.37-51

Mintzberg Henry, (1991) “Mintzberg y la dirección”, Ed. Díaz de Santos, España.

Mintzberg, H. (1984). La estructuración de las organizaciones. Ed. Ariel, Barcelona

Montaño, Luis (2000), Luis, "Diversidad y similitud organizacionales, Perspectivas y controversias, Revista Iztapalapa, Año 20, Num.48, México, pp.35-52

Montero Delia y Charry Clara Inés, (2004), Globalización y sociedad en las Américas ¿Es posible una convivencia conjunta?, Universidad Autónoma Metropolitana, México.

Naime, Alexander (2004), "Los estudios organizacionales. Prolegómenos de un campo de conocimiento en América Latina", en Luis Montaño (coord.) Los Estudios Organizacionales en México. Cambio, poder, conocimiento e identidad, Coedición 
UAM, Universidad de Occidente, Cámara de Diputados y Miguel A. Porrúa, México, pp. $41-61$.

Puga Cristina y Luna Matilde. (2008) (Coords), Acción colectiva y Organización. Estudios sobre desempeño asociativo, UNAM, Instituto de Investigaciones Sociales, México, pp. 227-264.

Pugh, Dereck S. (1997) "Does context determine form?" en Pugh, Derek, Organization Theory. Penguin Books, London, pp.16-35 (1971)

Romo Morales Gerardo y Quintero Castellanos Carlos (2011), El bote de basura como modelo de elección organizacional, Revista Gestión y Política Pùblica, Vol. 20, Numero 2, pag 247-290

Sabino Carlos A. (1996), El proceso de investigación, Ed. Lumen-Humanitas, Argentina.

Sampieri Hernández Roberto (1998), Metodología de la Investigación, Ed. Mc Graw Hill, México.

Stake Robert E. (1995), Investigación con estudio de caso, Ed. Morata, Madrid.

Scott Richard W (1981), Organizations: rational, natural and open systems, Prentice Hall, Nueva Jersey.

Weick, Karl, (1976), Educational Organizations as Loosely Coupled Systems", Administrative Science Quarterly. Vol. 21, núm. 1, Published by Johnson Graduate School of Management, Cornell University, pp. 1-19. 
Referencias electrónicas

www.aiesec.org.mx

Anexo 1 Listado de preguntas.

1. ¿Por qué llegaste y porque te quedas en el comité? Platícame tu historia

2. ¿Tienes claras tus funciones?

3. ¿Sino percibes un sueldo, porque estas en el comité?

4. ¿Cómo se comunican?

5. ¿Te agrada tu espacio de trabajo?

6. ¿Cuentas con recursos materiales necesarios para realizar las actividades que realizan?

7. ¿Por qué crees que a pesar de esto funcionan? 
8. ¿Cuentas con espacio físico para el comité?

9. ¿Te sientes parte de AIESEC Internacional o del Comité?

10. ¿Qué te motivó a entrar en el comité?

11. ¿Te llegas a sentir comprometido?

12. ¿Qué aportas al comité para que permanezca?

13. ¿En cuanto a rotación de miembros, como se encuentran en ese sentido?

14. ¿Conoces alguna historia de alguien que dejó el comité y por qué?

15. ¿Cómo logran sobrevivir?

16. ¿A pesar de los aspectos que crees que no funcionan adecuadamente, por qué crees que aun así funcionan?

17. ¿Han realizado cambios estructurales, Que tanta libertad tienes para realizarlos?

18. ¿Qué valores tiene AIESEC, con cuales te identificas?

\section{Anexo 2. Directorio AIESEC}




\begin{tabular}{|c|c|c|c|}
\hline $1+1 / y$ & 14to & H.Ime & 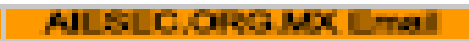 \\
\hline \multirow[t]{8}{*}{$\mathrm{ED}$} & TWE & 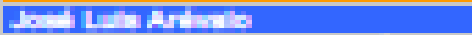 & 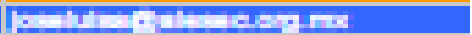 \\
\hline & HECX & 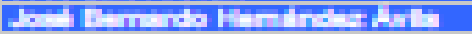 & 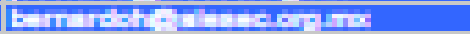 \\
\hline & Binth & Hithellaren & 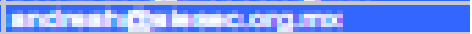 \\
\hline & Fintar & Thabang & Thent $=0$ \\
\hline & Brit=2 & 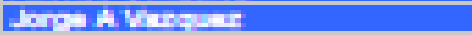 & 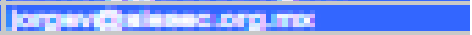 \\
\hline & FF & 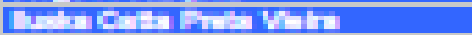 & 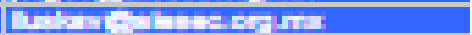 \\
\hline & Fintrath & 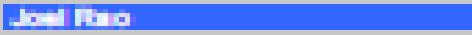 &  \\
\hline & ErPI & Emalem & 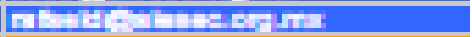 \\
\hline \multirow{8}{*}{ C.eter Hom } & LeF & 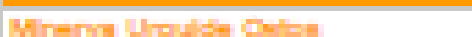 & 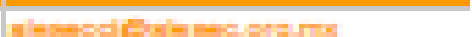 \\
\hline & HPM & 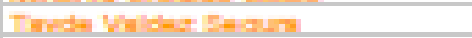 & 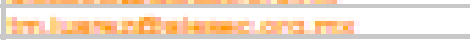 \\
\hline & HPl: & 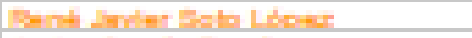 & 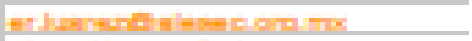 \\
\hline & FPI & 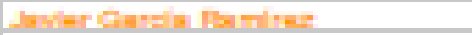 & 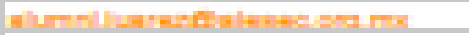 \\
\hline & Hert & 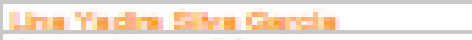 & 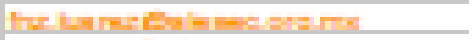 \\
\hline & GPHergun & 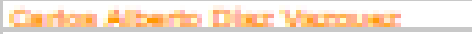 & 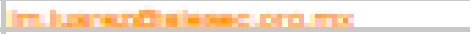 \\
\hline & MFin & 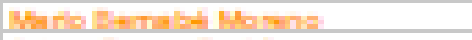 & 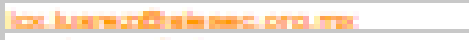 \\
\hline & Mods & 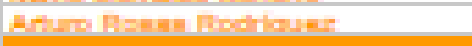 & 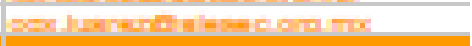 \\
\hline \multirow[t]{10}{*}{ Bube } & LEF & 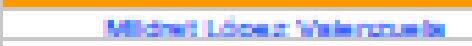 & 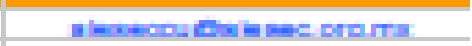 \\
\hline & VPTा & Alan benti tarra & 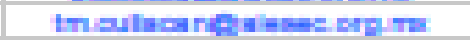 \\
\hline & MPRE & 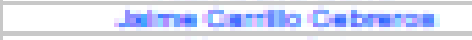 & 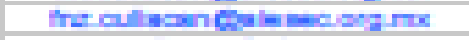 \\
\hline & Matus & Hermen Sods & 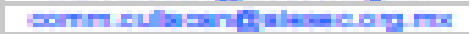 \\
\hline & NAH & Enas Aaroo- Gahur & 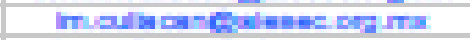 \\
\hline & Mhax capants & Easina Helenn Barpollen & 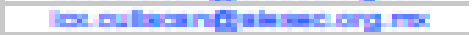 \\
\hline & Piter 4m Capant. & 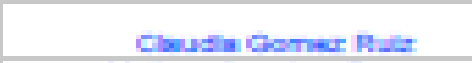 & 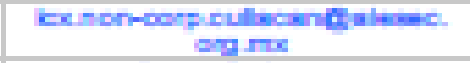 \\
\hline & VTom: & 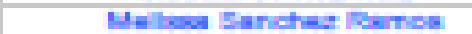 & 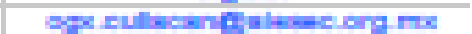 \\
\hline & VPEA & 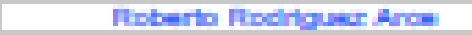 & 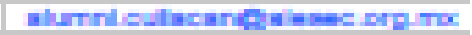 \\
\hline & YPTF & 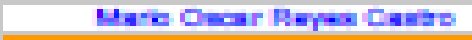 & 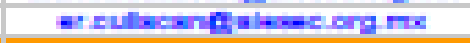 \\
\hline \multirow[t]{8}{*}{ Extrtan } & IEP & 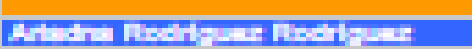 & 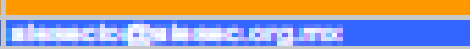 \\
\hline & 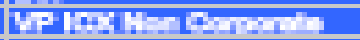 & 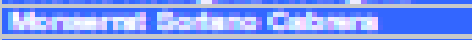 & 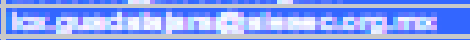 \\
\hline & Welaterath & Martionthlares & 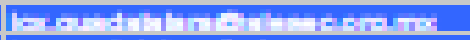 \\
\hline & PEII & Horpanth & 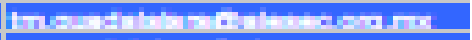 \\
\hline & FeFARImL & 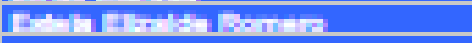 & 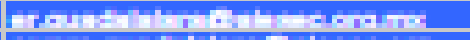 \\
\hline & LPMAperM & 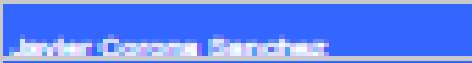 & 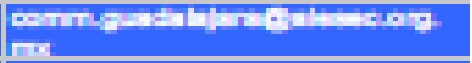 \\
\hline & Fint2 & 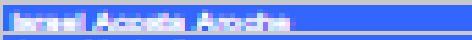 & 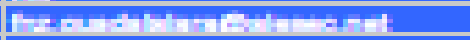 \\
\hline & HePAT & rhathirithet & 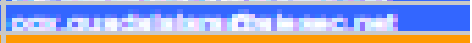 \\
\hline \multirow[t]{10}{*}{ Astipuate } & LEF & 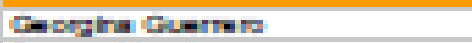 & 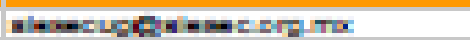 \\
\hline & Hen & Buten Mending & $\ldots$ \\
\hline & Nity & Marts Luba Rere & 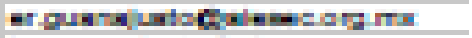 \\
\hline & vitie & Pulina ithega & 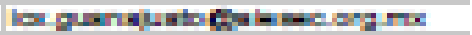 \\
\hline & M & Abritsm lub=rir & 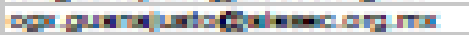 \\
\hline & MT TM & 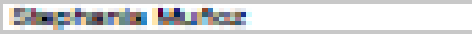 & 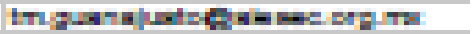 \\
\hline & UTFEI & Itran Conat & 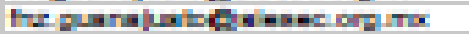 \\
\hline & HT HIF & Ans ban & 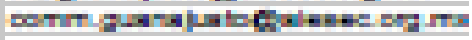 \\
\hline & MT IY & 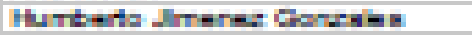 & $-\ldots$ \\
\hline & UF AIIUHA & & 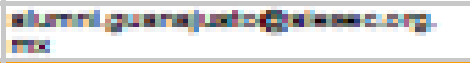 \\
\hline \multirow[t]{4}{*}{ IIET } & PFF & Ats Plomerth & 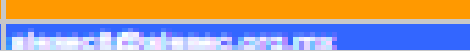 \\
\hline & CPFPFALAREAT & 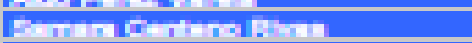 & 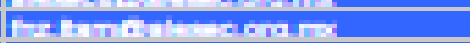 \\
\hline & Fin & 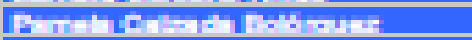 & 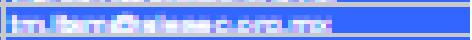 \\
\hline & IEPEA & 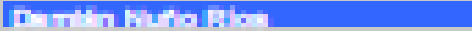 & 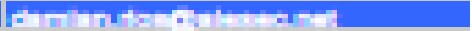 \\
\hline
\end{tabular}




\begin{tabular}{|c|c|c|c|}
\hline Inty & Hats & Hame & AILLLOHANA LTA \\
\hline & MPEH & 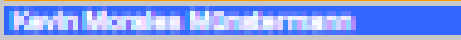 & 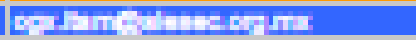 \\
\hline & MPाम & 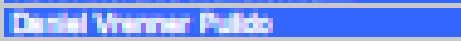 & Erm-mantm \\
\hline & MPETII & 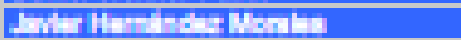 & 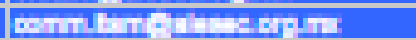 \\
\hline \multirow[t]{7}{*}{ anh } & IrF & Dentig Dhes & 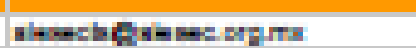 \\
\hline & IRNPTH & Lebri Uandas & 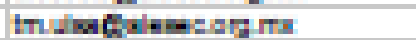 \\
\hline & IFPFA & Itater bander & 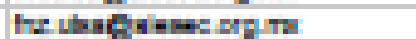 \\
\hline & IEP HMFAH & Fertela Cas: & Doti-uaholecogym \\
\hline & IFPFA & Ithere Coludo & erubabatogra \\
\hline & I Cup UA & Preteh Fter & 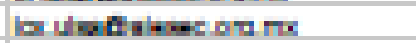 \\
\hline & matow & & 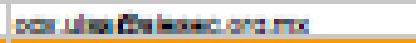 \\
\hline \multirow[t]{2}{*}{ Mritan } & LF: & 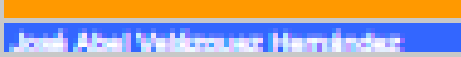 & Intedoughemint \\
\hline & LEPEAS & 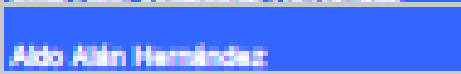 & 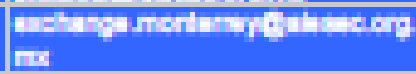 \\
\hline \multirow[t]{6}{*}{ 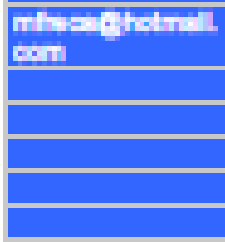 } & LETtex & 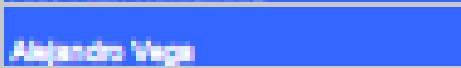 & 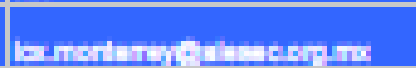 \\
\hline & 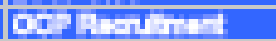 & 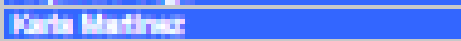 & Litintr. \\
\hline & LEMPIS & gementring & 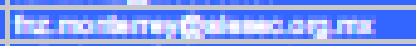 \\
\hline & arenta & 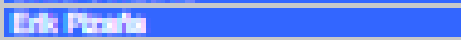 & कामनल \\
\hline & Ginerre w & Bringunn & 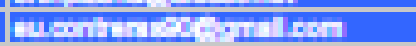 \\
\hline & WHAEre I I & 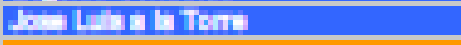 & 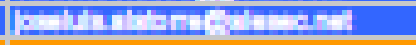 \\
\hline \multirow[t]{11}{*}{ Prtwrin } & IOF & Devid thel Patrier To te: & 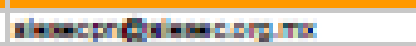 \\
\hline & IP Ey & Drita himea & 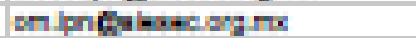 \\
\hline & IPFH & Dohedor Debado Doth & 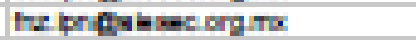 \\
\hline & UPT & Fuld knanoserva & 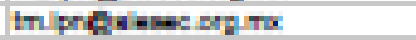 \\
\hline & Grohdy PFer &  & 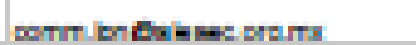 \\
\hline & Conholy Prith &  & 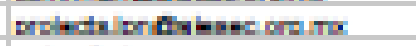 \\
\hline & ipH & Martaly Mar & erlscherechit \\
\hline & HAth & Druta Hermen & 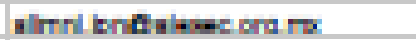 \\
\hline & Min & AHo A=atro & 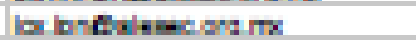 \\
\hline & H. & Intrellendinder & polstivescrits \\
\hline & n'Iu & Ltd Marife: & 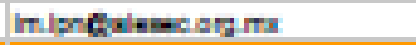 \\
\hline \multirow[t]{8}{*}{ rraty } & LEP & otatmind charefoh & 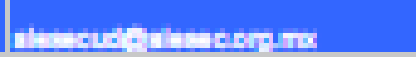 \\
\hline & FT & 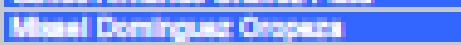 &  \\
\hline & MPETI & & 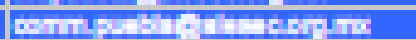 \\
\hline & MPAF & & Heprom \\
\hline & पPतम & 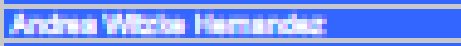 & 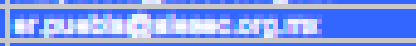 \\
\hline & MPHA & 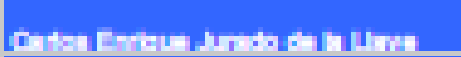 & 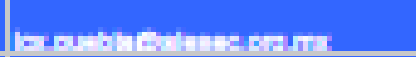 \\
\hline & HPFA & 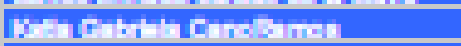 & 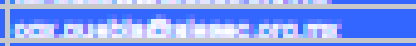 \\
\hline & MPM & & 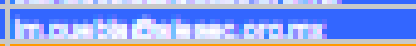 \\
\hline \multirow[t]{7}{*}{ T4EN } & ire & 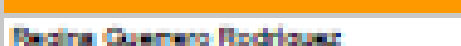 & 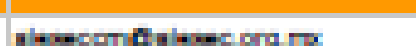 \\
\hline & 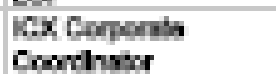 & 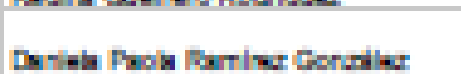 & 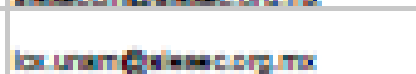 \\
\hline & $\begin{array}{l}\text { IIX hor Dapast } \\
\text { Cowthiss }\end{array}$ & Andila Geta Nenha & 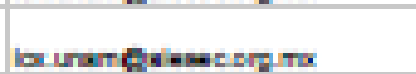 \\
\hline & H Loorator & Hrolutinder Arbo & \\
\hline & NT Cemm & 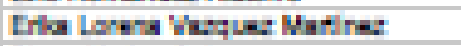 & 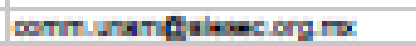 \\
\hline & HT TW & Dang Wirts Evire & IтL-MTfal-mogpra \\
\hline & H & Wh ta boa carei & 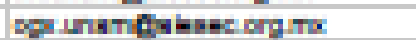 \\
\hline
\end{tabular}




\begin{tabular}{|c|c|c|c|}
\hline Inty & Arth & N:me & ALSLCDRAHX LTal \\
\hline & UPCH & Femind Radqut Finul & 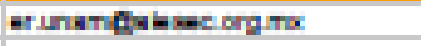 \\
\hline & UFF & Rome Darce brated & He urankdectogari \\
\hline \multirow[t]{11}{*}{ TP } & $\mathrm{LE}$ & 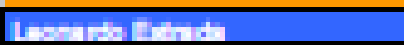 & 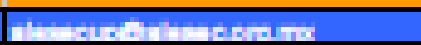 \\
\hline & Bill & 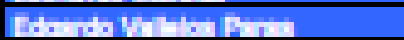 & In \\
\hline & Haring & 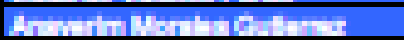 & 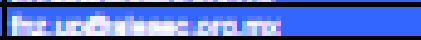 \\
\hline & MrEa & 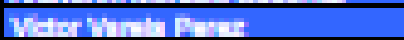 & 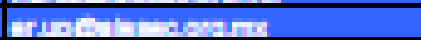 \\
\hline & Hat+4 & 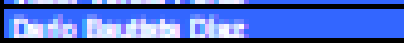 & 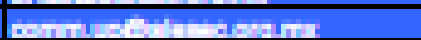 \\
\hline & Brte &  & 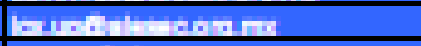 \\
\hline & Lath & 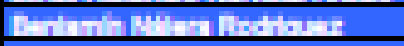 & 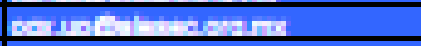 \\
\hline & Lith & 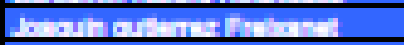 & 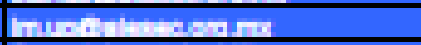 \\
\hline & Hothen & 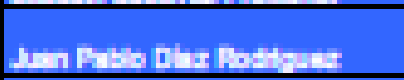 &  \\
\hline & Mondr & 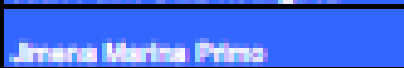 &  \\
\hline &  & 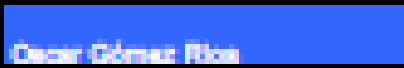 & 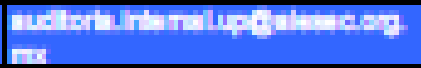 \\
\hline & & & \\
\hline \multirow[t]{6}{*}{ Whrm? } & IF & 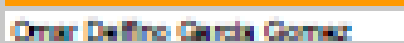 &  \\
\hline & HP EMm A IU & 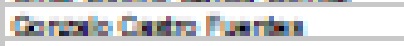 & 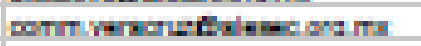 \\
\hline & YPFII & $M a t^{2}=1$ & 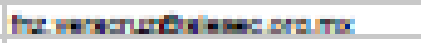 \\
\hline & HPIA & 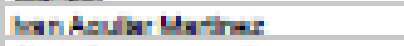 & 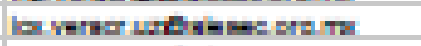 \\
\hline & HAws & 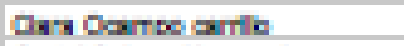 & 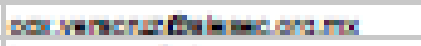 \\
\hline & HT TH & 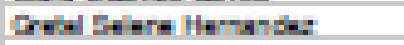 & 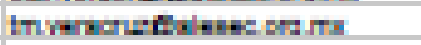 \\
\hline & & & \\
\hline \multirow[t]{9}{*}{ Filindy } & LEF & Hancteris & 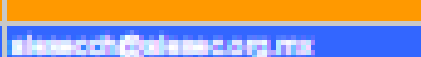 \\
\hline & Bitin & Thing & 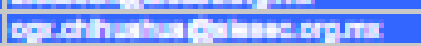 \\
\hline & HF & Dearingin & 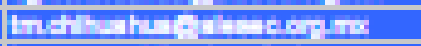 \\
\hline & MatII & 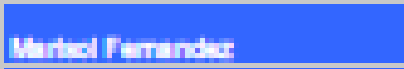 & 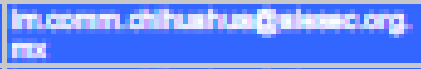 \\
\hline & MF & 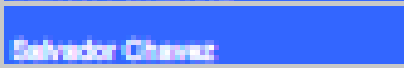 & 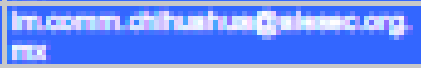 \\
\hline & MrF & pistrasout & 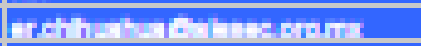 \\
\hline & WEF & Finituath & 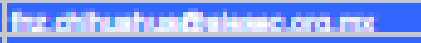 \\
\hline & nats & Irminging & 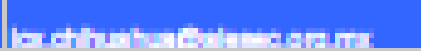 \\
\hline & 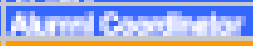 & $12+4=0$ & 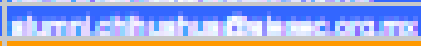 \\
\hline \multirow[t]{7}{*}{ Arution } & LEF & 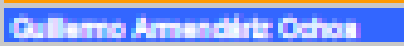 & 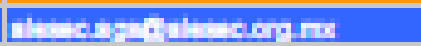 \\
\hline & $\mathrm{Hin}_{\mathrm{L}}$ & 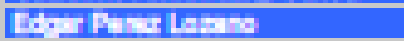 & hes \\
\hline & HAPA & 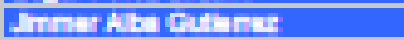 & 5 \\
\hline & BTEA & Mulpminglan & 5 \\
\hline & MPL & Lin lenhatera & tos \\
\hline & Harin & Aridumang & Win \\
\hline & MPreTn & 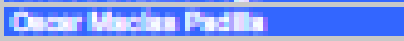 & $\overline{5 n}$ \\
\hline & & & \\
\hline \multirow[t]{3}{*}{ anthm } & ICF & Whetal Mens Wea &  \\
\hline & IFT! & Wancer Hengub Fineta & \\
\hline & IP Crmt & 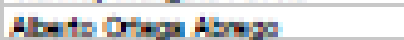 & 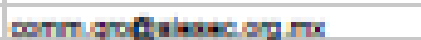 \\
\hline
\end{tabular}




\begin{tabular}{|c|c|c|c|}
\hline $1+1 y$ & Asts & Mame & AILSLCDFA LX LTal \\
\hline & VPCH & Alandh Abrba Former & \\
\hline & UPITr & Ahnham Dranfo Mone & \\
\hline & ир о.т & 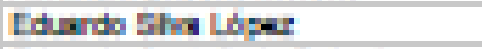 & \\
\hline & IP $F \mathbf{P}$ & 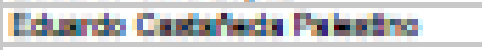 & \\
\hline & & & \\
\hline \multirow[t]{7}{*}{ Fithe } & $1 \mathrm{PP}$ & Hevilan & 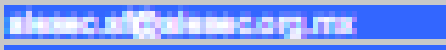 \\
\hline & BrD & 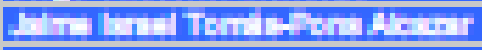 & \\
\hline & GPFHin & 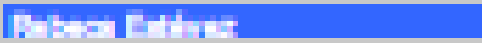 & 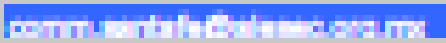 \\
\hline & MPEA & 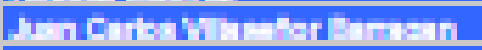 & \\
\hline & FPlE: & Putratolath & \\
\hline & MPEAE & 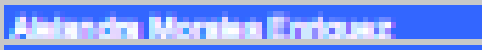 & \\
\hline & HER & 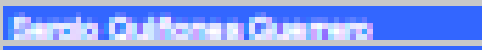 & \\
\hline & & & \\
\hline Tersilen & ict & & \\
\hline & & & \\
\hline & & & \\
\hline & & & \\
\hline & & & \\
\hline & & & \\
\hline & & & \\
\hline
\end{tabular}




\section{Anexo 3. Recorrido histórico en imágenes}

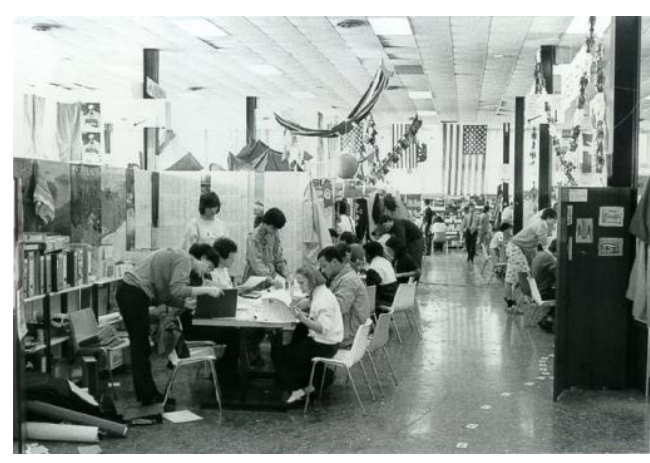

40 y 50’s Primeras reuniones de planeación 


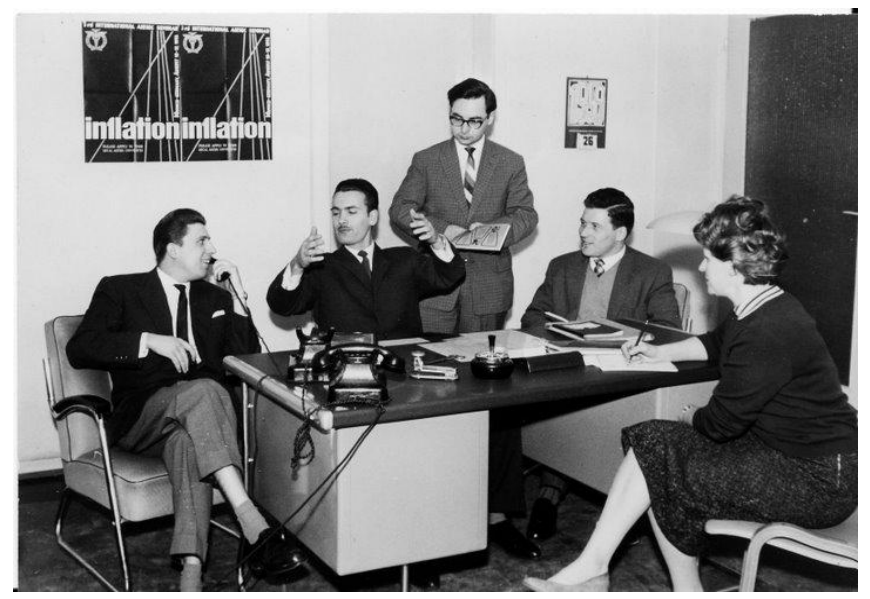

Discusiones en materia de intercambio estudiantiles

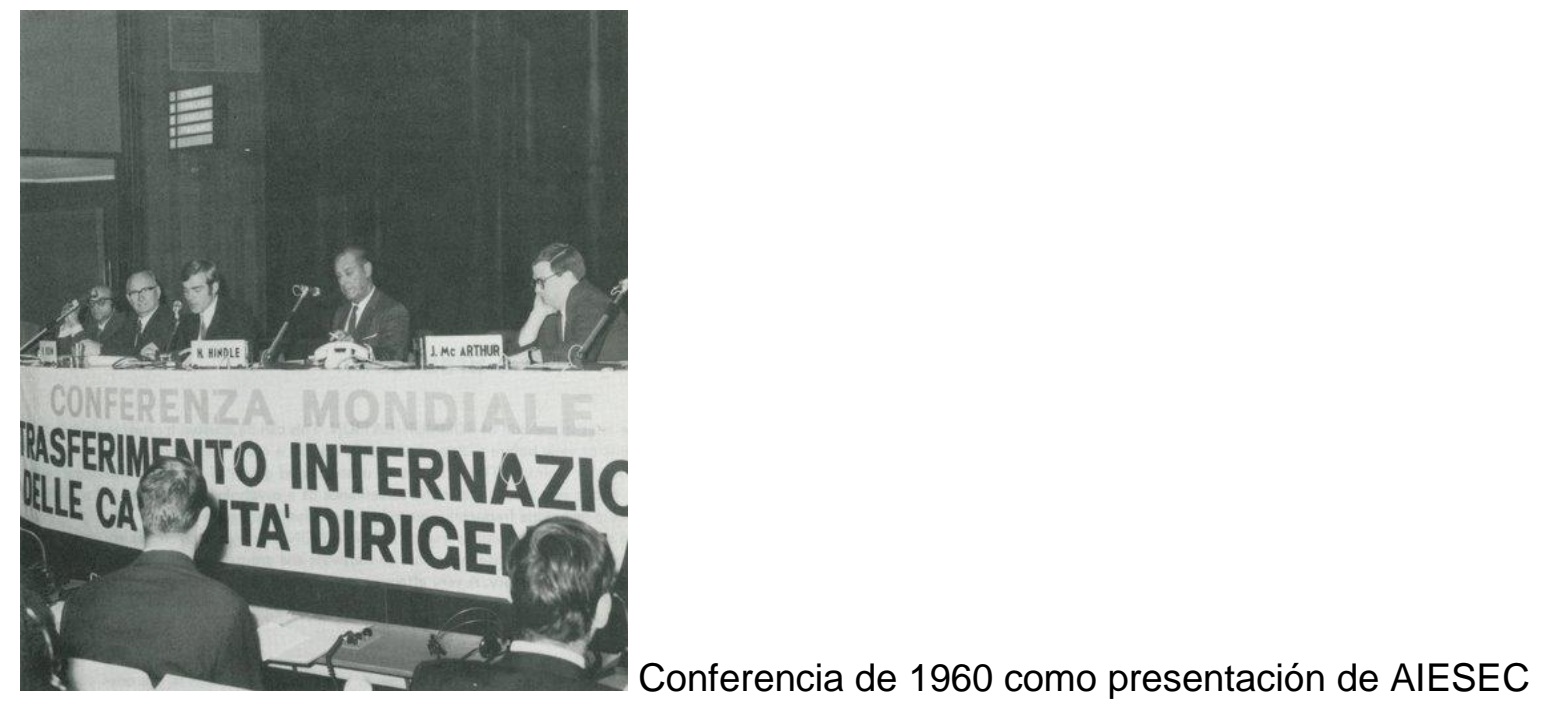




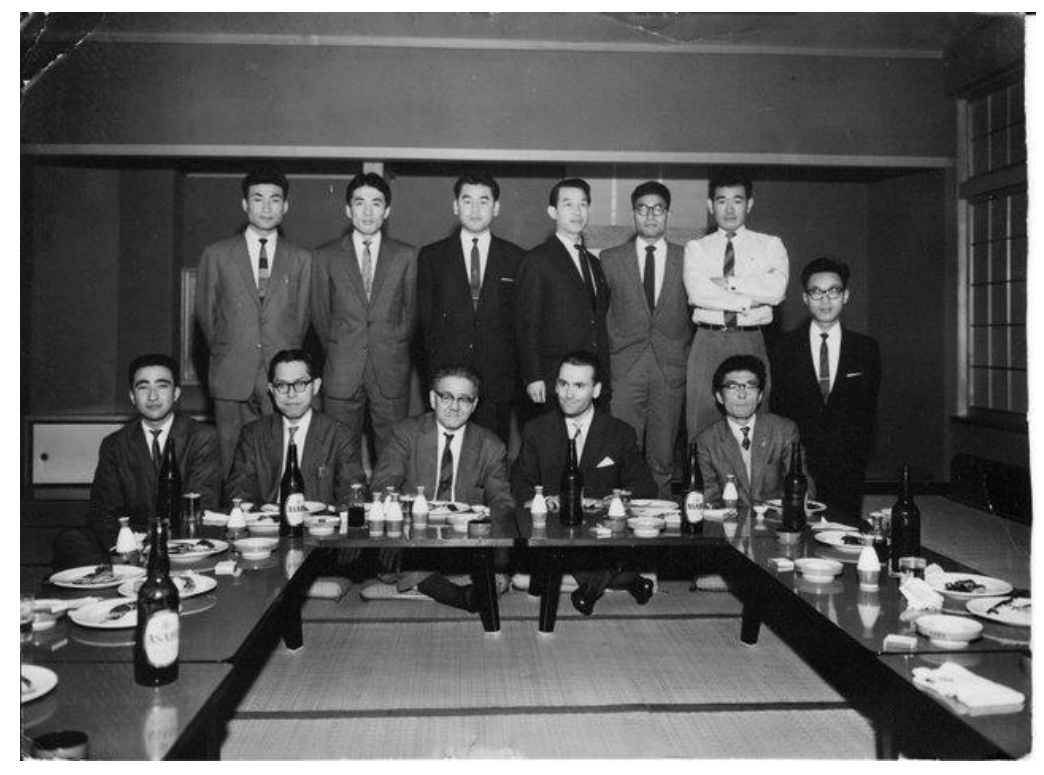

1960 presencia del primer comité de AIESEC en Japón

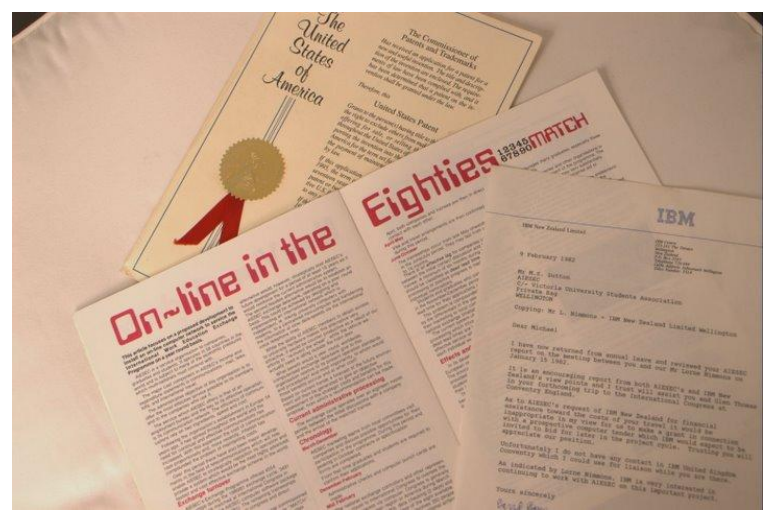

80s se crean los primeros sistemas de información 


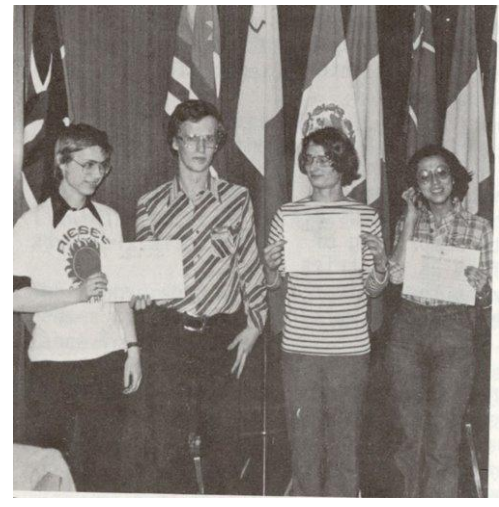

80s Seminario Internacional en Bruselas.

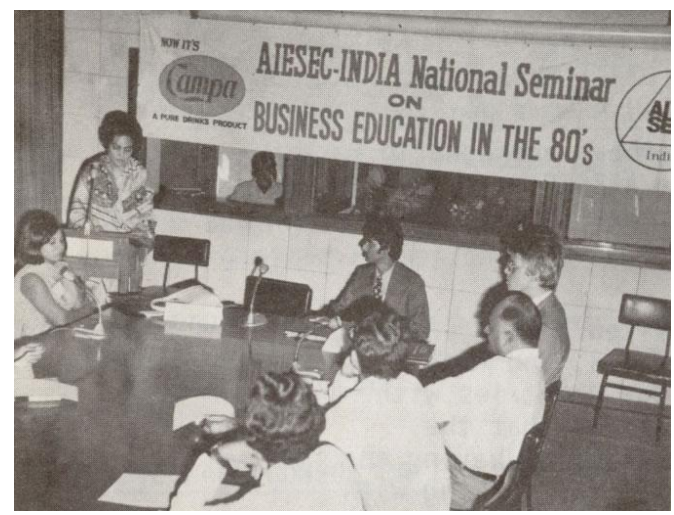

80s Primera conferencia en India.

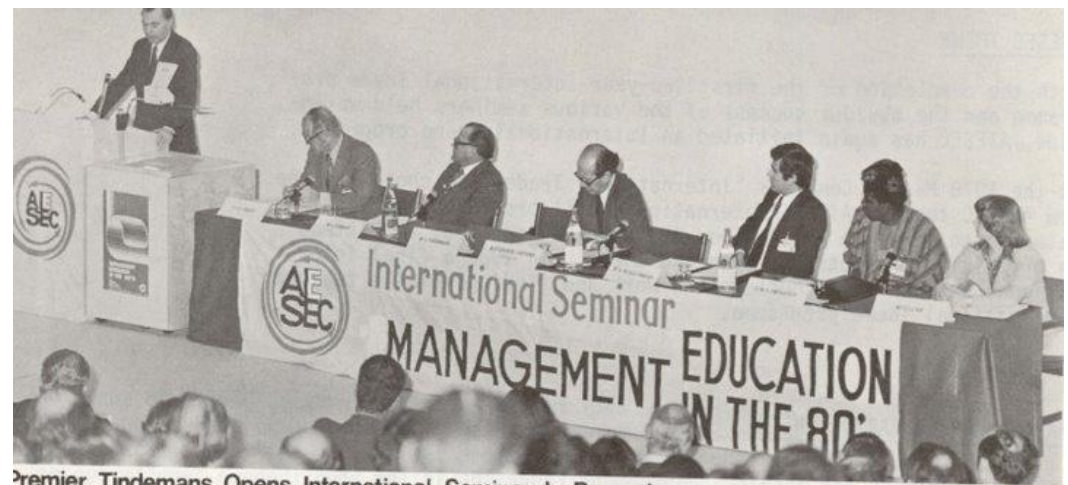

remier Tindemans Opens International Seminar In Brussels 


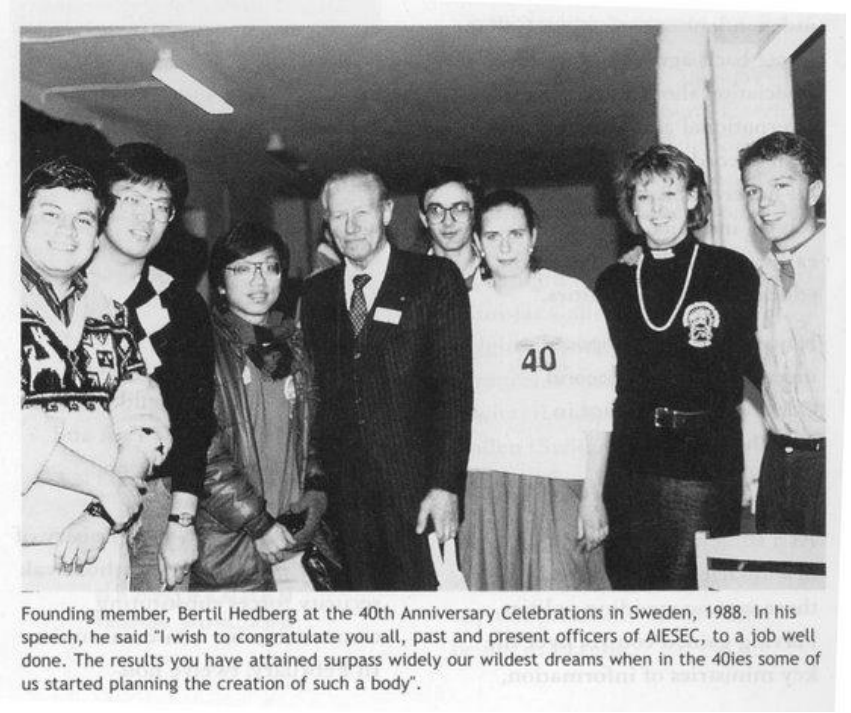

40 aniversario en Suiza.

\section{Anexo 4. Análisis estructural de Comité UNAM}

Es necesario a fin de comprender el estado actual en términos de estructura, remitirse a la historia estructural del comité. El comité ha trabajado durante 45 años, hace 20 años el comité se componía en su mayoría por estudiantes y graduados de la carrera de Economía, en su mayoría hombres. Poco a poco se fue diversificando y ahora existen de muchas carreras y de cinco años a la fecha el comité ha sido dirigido por mujeres.

Es uno de los más productivos en términos de intercambios de estudiantes y promoción de prácticas profesionales a empresas públicas y privadas.

La estructura la han diseñado de forma similar a la del comité nacional a fin de concordar en las tareas. La justificación es que así debe funcionar y a su vez para evitar discrepancias con las requerimientos del comité nacional. 
Como enfoque esencial se retomará la propuesta de Henry Mintzberg (1999) en cuanto a la estructuración de organizaciones a fin de reconocer las partes que conforman la organización analizar y reconocer de manera más precisa a la organización. La propuesta de Mintzberg permite identificar partes de la organización que en su conjunto se orienta a la división del trabajo en tareas distintas, consiguiendo luego la coordinación de las mismas (Mintzberg, 1999:26). Con la figura de cómo concibe a la organización, permite avizorar las partes que la conforman que para el autor son: el ápice estratégico, la línea media, la tecnoestructura, el staff de apoyo y el núcleo de operaciones. Mencionando también que estas partes de la organización se controlan y coordinan mediante los llamados "mecanismos de control" que muestran la manera en que se toman las decisiones y fluye la comunicación, estas son: la adaptación mutua, la supervisión directa, la normalización de las habilidades, la normalización de los procesos de trabajo y la normalización de los outputs.

Conjuntamente las partes de la organización están unidas entre sí mediante distintos flujos de autoridad, de material de trabajo, de información y de procesos de decisión, proporcionando la estructura de la organización como: un sistema de autoridad formal, como un sistema de flujos regulados, como un sistema de comunicación informal, como un sistema de constelaciones, y como un proceso de decisión Adhoc. Otra de sus grandes aportaciones son los nueve parámetros de diseño que relaciona con los mecanismos de control y con los sistemas de flujos que establece para describirlos en cuatro grupos:

Parámetros son:

Diseño de puestos

- Especialización del puesto

- Formalización del comportamiento

- Preparación y adoctrinamiento

Diseño de la superestructura

- Agrupación de unidades 
- Tamaño de la unidad

- Diseño de vínculos laterales

- Sistemas de planificación y control

- Dispositivos de enlace

Diseño del sistema de toma de decisiones

- Descentralización vertical

- Descentralización horizontal

Diseño del sistema de información

- Centralizado

- Descentralizado

En cuanto a los aportes de Mintzberg (1999) sobre las partes de la organización, mecanismos de control, sistemas de flujo y parámetros del diseño) en lo que denomina las cinco configuraciones organizacionales, que dan cuenta del resultado de sus investigaciones, así como de la gran variedad y diferencias que existen dentro de las 5 configuraciones que propone.

Las configuraciones que se señalan permiten identificar hacia que configuración la organización que se analizará orienta su estructura y cuáles son los partes que intervienen en su estructuración y en el caso del rediseño de la estructura cual sería la configuración propuesta. 
En los que se refiere a las partes fundamentales (Mintzberg, 1999) nos propone lo siguiente:

Partes fundamentales

- Ápice estratégico: En dicha organización el ápice estratégico es la Lic. Regina Guerrero, la cual está a cargo de las demás 6 áreas, está al tanto de las actividades de cada área y reporta al comité nacional.

- Núcleo operativo: el núcleo operativo seria cada uno de los jefes de cada área de que llevan a cabo las actividades sustantivas correspondientes del área refiriéndose a los vicepresidentes.

- Línea media: En esta parte de la estructura son las subáreas en las que se divide cada área principal, que se enfoca a actividades propias del área.

\begin{tabular}{|c|c|c|}
\hline $\begin{array}{l}\text { Configuración } \\
\text { estructural }\end{array}$ & Factores de contingencia & Figura representativa \\
\hline Estructura Simple & $\begin{array}{l}\text { Joven, pequeña, sistema técnico poco } \\
\text { sofisticado, entorno sencillo y dinámico, } \\
\text { posibilidad de extrema hostilidad o fuertes } \\
\text { ansias de poder del director general, escasa } \\
\text { influencia de la moda }\end{array}$ & \\
\hline Burocracia Maquinal & $\begin{array}{l}\text { Vieja, grande, reguladora, sistema técnico no } \\
\text { automatizado, entorno simple y estable, } \\
\text { control externo, escasa influencia de la moda. }\end{array}$ & \\
\hline $\begin{array}{l}\text { Burocracia } \\
\text { Profesional }\end{array}$ & $\begin{array}{l}\text { Entorno complejo y estable, sistema técnico } \\
\text { no regulador y carente de sofisticación, } \\
\text { influencia de la moda. }\end{array}$ & \\
\hline Estructura Divisional & $\begin{array}{l}\text { Mercados diversificados (productos o servicios } \\
\text { particularmente), grandes, viejas, directivos } \\
\text { medios ansiosos de poder, influencia de la } \\
\text { moda. }\end{array}$ & \\
\hline Adhocracia & $\begin{array}{l}\text { Entorno complejo dinámico (a veces dispar), } \\
\text { joven, (adhocracia operativa), sistemático } \\
\text { sofisticado y a menudo automatizado } \\
\text { (adhocracia administrativa), influencia de la } \\
\text { moda. }\end{array}$ & \\
\hline
\end{tabular}


Tabla de en base a datos de Mintzberg (1999)

- Tecnoestructura: Dependen directamente de Intranet por medio de cuenta que les proporciona AIESEC a la que acceden por medio de internet, existe una área que se llama Información Management que es el área que reúne la información de todas las áreas y por medio de la cuenta de correo que AIESEC les proporciona para ingresar información relevante sobre logros del comité, dicha actividad solo se lleva a cabo por una persona.

- Staff de apoyo: dicha parte de la organización se conforma por miembros que realizan funciones de la línea media la cuales son las que mas carecen de personal y que son esenciales para apoyar a dicha línea media. Se conforma de 29 personas pero el área de intercambios entrantes se encuentra desprovista de la totalidad de su staff y el aseguramiento de las actividades del área y su conjunción con demás actividades no son aseguradas por alguna área de apoyo. Como forma de mejorar el ambiente de todas las áreas se llevan a cabo congresos donde acuden otros comités entorno a convivencias, talleres, pláticas para que se mejore la relación dentro del comité e intercomités. 
La ideología es un elemento importante en el comité, la ideología se define como el elemento que brinda cohesión en las áreas y los miembros del comité.

Siguiendo el modelo de Minztberg se identificaran los elementos del comité como forma de contraste y recalcar los hallazgos.



De acuerdo al análisis que se realizó con los elementos de las organizaciones propuestos por Mintzberg y al ser encarados con la realidad de la organización parecen encontrar disfunciones y no encontrar coherencia en los postulados teóricos y lo que ocurre en la realidad, nos encontramos que el área de staff es muy amplia pero es justo ahí es donde 
se registran más salidas, no hay sinergia para apoyar a otras áreas en caso de ausencia de miembros no considerando que cada actividad o responsabilidad de cada área son esenciales para el cumplimiento de las metas del comité y no contraer sanciones estipuladas por el comité nacional.

El staff es muy amplio y no funge como tal, en el deber ser debería apreciarse como un área de apoyo incondicional para las áreas que pertenecen y para las otras áreas, sin embargo es muy grande en comparación a otras partes del comité y no hay apoyo ni sinergia.

En este apartado se hace un recorrido por los distintos mecanismos de coordinación según la propuesta de Mintzberg de tal forma que sea posible identificar lo que ocurre dentro de AIESEC

Mecanismos de coordinación

- Adaptación mutua: Debido a que el comité no cuenta con un espacio físico, el ambiente no se torna opresivo ni apegado a una estructura documental rígida, o la normalización de actividades, entre los miembros han creado la adaptación como una forma de cohesionarse como miembros y flujos de comunicación como lo es WIZIQ ${ }^{18}$ como una forma principal por excelencia de comunicación solo entre los miembros del comité ya que por las actividades de los miembros que van desde cubrir con sus actividades escolares como las obligaciones que contraen con el comité, en ocasiones es difícil coincidir en tiempos para reuniones presenciales, además de que hacen uso de su cuenta personal vía intranet que es la plataforma de AIESEC Internacional para consultar cualquier tipo de información relacionada con la operación, gestión, obligaciones y sanciones del comité, es una forma de coordinación a distancia.

\footnotetext{
${ }^{18}$ Es un chat vía internet por el cual se comunican los miembros del comité, creando llamadas de vos en línea para afinar actividades o externar avisos o obligaciones inmediatas.
} 
- Supervisión directa: Dicho mecanismo es llevado a cabo por la presidenta del comité la Lic. Miriam Alonso, la cual a través de reuniones mensuales y vía WIZIQ pide avances de las labores de cada área y el reporte de novedades o discrepancias en cada área a fin de encaminarse a la eficiencia del comité en todas las actividades y no caer en sanciones que afecten su imagen ante otros comités.

Sin embargo como se comentó anteriormente debido a la complicación de coincidir con los tiempos, se apuesta más por la coordinación a distancia, sin embargo la presidenta a su vez apuesta por este tipo de supervisión que en su opinión facilitaría mas el cumplimiento de las labores.

- Normalización de procesos: Aunque de forma general AIESEC Internacional cuenta con una estructura documental donde los comités tienen que consultar cualquier duda en cuanto a su operación, los miembros de comité debido a que no existe una supervisión directa como tal, los procesos deben cumplirse sin embargo no se apegan a lo establecido debido a que las contingencias hacen apegarse a procesos emergentes que podrían no estar dentro de la estructura documental.

- Normalización de resultados: Apegándose a los lineamientos de AIESEC Internacional deben cumplir con las labores asignadas a pesar de que no se ven físicamente deben, a través de la supervisión a distancia, controlar las actividades en el cumplimiento de las metas y sobre todo que los miembros inicialmente por su perfil de compromiso tienen como objetivo cumplir con las metas asignadas.

- Normalización de habilidades: Las habilidades son bien definidas desde el momento del reclutamiento, el perfil tiene que orientarse al cumplimiento de las metas para lo cual debe contar con aptitudes con las cuales puedan con 
las actividades que se les asignan como el manejo de base de datos, orientarse a resultados.

- Red de comunicaciones: Debido a que la supervisión se presenta más a distancia y su relevancia es esencial, porque WISIQ e Intranet es lo que da vida y control al comité fundamentalmente, dicha red permea en su totalidad las actividades del comité, desde la normalización hasta la supervisión que permite al comité funcionar de la forma que lo han hecho hasta hoy en día.

Retomando la información anterior entonces la adaptación mutua es el mecanismo por excelencia lo que permite a los miembros actuales y futuros cohesión con el comité y a su vez una manera de trasmitir el conocimiento propio de la operación del comité; por su parte la supervisión directa es necesaria para garantizar la consecución y cumplimiento de tareas. Lo que es importante y sumamente relevante es la red de comunicación que actúa como una red que interconecta a todas las áreas y permite la supervisión a distancia.

Ahora bien, en la misma línea en lo que se refiera a los sistemas de flujos, se desarrolla lo siguiente:

- Autoridad formal: la autoridad es ejercida por la presidenta del comité, quién no lo hace de manera rígida pero ella tiene la última palabra.

- Flujos regulados: se dan de tal forma que las actividades están cumplidas en los tiempos que se necesitan para entregar al comité nacional.

- Comunicación informal: mediante WISIQ e intranet y a distancia.

- Constelaciones de trabajo: Como círculos independientes tenemos a cada área del comité que pareciera trabajar de forma independiente pero en concordancia a requerimientos del comité nacional y las tareas sustantivas del comité.

- Procesos de decisión Adhoc: en el caso de tomar decisiones importantes se reúnen quincenalmente y mediante y una lluvia de ideas se dan resoluciones.

Es importante también referirse al diseño de puestos y factores de contingencia. 
El diseño de puesto de AIESEC Comité UNAM se presenta de la siguiente forma:

1. Especialización del puesto: tiene que cubrir el perfil, dichas características son emitidas por el comité nacional y el candidato debe cumplirlas en su totalidad en cuanto a habilidades y conocimientos.

2. Formalización del comportamiento: AIESEC es una forma de vida y los miembros deben ser portadores y emisores del ambiente que la organización pretende para sus miembros y su público.

3. Preparación y adoctrinamiento: Este punto dentro del comité no cuenta con una estructura documental que permita a los nuevos integrantes conocer ampliamente al comité, la preparación cuando se da el cambio de miembros del la mesa directiva se aplica mediante el coaching durante unas semanas. En este punto debería darse más énfasis en lo que corresponden desde el reclutamiento para garantizar la permanencia de los individuos en el comité.

Diseño de la superestructura

4. Agrupación de unidades: cada área cuenta con actividades definidas y con miembros con habilidades y conocimientos de acuerdo al área, dentro del comité en ocasiones dicha agrupación permite compartir recursos comunes y estimular la adaptación mutua

5. Tamaño de la unidad: las áreas están diseñadas en cuanto al comité nacional y sus áreas, con la adaptación mutua se pretende que el tamaño de las unidades de trabajo sea menor.

Factores de contingencia.

- Edad y tamaño: a pesar que en el caso del comité UNAM es un comité con más de 40 años de presencia, no ha generado que el comportamiento se formalice totalmente, el hecho de que se conforme por estudiantes de licenciatura y jóvenes profesionales permite un ambiente emprendedor. El 
comité no es muy grande lo que ha permitido que su estructura no sea tan compleja. En cuanto a la etapa de la estructura se encuentra en la etapa matricial por que la estructura se orienta a ser orgánica y agrupa al comité en base a más de dos agrupaciones dependientes del primer nivel.

- Sistema técnico: En cuanto a los instrumentos que utiliza el núcleo de operaciones para llevar a cabo sus funciones y tareas el sistema técnico se orienta por ser sofisticado, debido a que presenta una estructura administrativa más elaborada lo que hace que sea mayor la profesionalización del staff, lo que hace que se oriente a la descentralización selectiva (hacia el staff) y mayor uso de los dispositivos de enlace para coordinar las actividades del staff.

- Entorno: refiriéndonos al ambiente, en el comité como se ha mencionado anteriormente situaciones contingentes que hacen que la organización se descontrole y se genere un ambiente de incertidumbre para los miembros orientándose a que en este caso la complejidad del ambiente que rodea al comité como lo es la incertidumbre, no contar con un espacio físico, la búsqueda de financiamiento, debería contribuir a que la estructura sea descentralizada u orientarse a que sea más flexible.

- Poder: en el comité la última palabra la tiene la presidenta del mismo ejerciendo un tipo de liderazgo carismático y no coercitivo, el control se ejerce mediante la imposición de niveles de exigencia claramente definidos para cada unidad de trabajo, porque la presidenta reporta directamente al presidente de comité nacional quien tiene relación directa con AIESEC Internacional.

\section{Sobre la configuración estructural. AIESEC México-Comité UNAM como estructura simple y misionera}

La estructura es sencilla y parecida a una gran unidad que consiste en uno (o pocos) gerentes ejecutivos que dominan y un grupo de operarios que hacen el trabajo básico. 
Ahora bien en el caso del comité UNAM los puntos se trasladan de la siguiente forma:

Parte fundamental: Ápice estratégico la presidenta del comité Miriam Alonso

Mecanismo de coordinación: Supervisión directa.

Parámetros de diseño:

- Especialización del puesto: Poca

- Preparación y adoctrinamiento: Poca

- Formalización del comportamiento: Poca

- Agrupación: Funcional

- Tamaño de las unidades: Amplia

- Sistema de planificación y control: Pocos

- Dispositivos de enlace: Pocos

- Descentralización: Centralización

Factores de contingencia:

- Tamaño: Pequeña

- Edad: Joven

- Sistema técnico: Poco sofisticado

- Entorno: Sencillo y dinámico

- Poder: Fuerte por la presidenta del comité

Entonces comité UNAM se configura entorno a la estructura simple por su misma figura de comité.

Es importante considerar que la ideología existe fundamentalmente en forma de una fuerza dentro de organizaciones de otros tipos, fomentando el que sus miembros se aglutinen, pero a veces puede llegar a dominar, conforme la normalización de las reglas se convierte en el mecanismo de coordinación principal. Es lo que ocurre con AIESEC Comité México, la ideología permea la operación del comité, desde su creación, su 
permanencia y su operación diaria. Los miembros tienen poder de decisión y siempre se está en la búsqueda del beneficio colectivo.

Como parte del análisis anterior, nos ha permitido identificar los elementos estructurales de la organización analizada, pero a su vez nos debe orientar a la identificación de problemáticas en la organización que mermen las actividades diarias y la razón de ser de la organización.

La ideología debería ser el aspecto esencial que de forma a la organización y que a su vez proporcione cohesión de sus miembros, pero como se puedo dar cuenta, la incertidumbre orienta a la crisis en el comité y en su defecto al abandono de las áreas.

Alcanzar sus metas es en gran sentido la razón de ser de las organizaciones, entonces se piensa que como un posible camino es recurrir a patrones y regularidades en el diseño, la importancia es considerar que "todo depende" del espacio y tipo de organización a estudiar.

Uno de los temas de interés en este caso es la percepción de los miembros en el comité, debido a la naturaleza de la ONG, los miembros no perciben sueldo, por lo que una estructura organizacional fortalecida y espacio de incertidumbre mínimos que se encaminen a la creación de un espacio de trabajo agradable, que coadyuve a la permanencia y adhesión de miembros al comité.

En el caso de la ONG, en el discurso persiguen la idea de solidaridad, ayuda al prójimo, coadyuvar al desarrollo social, lucha por la igualdad dentro de la sociedad; es importante mencionar que a diferencia de la mayoría de las organizaciones que incentivan y recompensan a sus miembros mediante el pago de un salario proporcional a las actividades relacionadas lo cual es una forma por excelencia de asegurar la permanencia de sus miembros y la ejecución de las actividades, para las ONG bajo la idea de beneficio mutuo, solidaridad y ayuda sin esperar retribución económica, los miembros no perciben un salario por las actividades que realizan, ayudan al desarrollo de las actividades dentro de la organización para que sigan funcionando, entonces podría cuestionarse como es que sin percibir un salario los miembros deciden permanecer y desarrollarse para y dentro de la organización.

Entonces la ideología emerge como un elemento de cohesión por excelencia que permea a los miembros y los incorpora de manera activa en la organización buscando el 
bien común dentro y fuera de la organización, a su vez la ideología permite crear un fuerte compromiso de los miembros para con la organización para que permanezcan dentro de ella sin percibir un salario como en otras organizaciones se asegura dicho fin.

En el caso de Comité UNAM como una organización misionera no es la excepción, los miembros no perciben ningún sueldo, persiguen la idea de hacer eficiente el comité a largo plazo y de manera importante que dicho Comité logre permanecer por muchos años mas, persiguen la idea de coadyuvar a desarrollar las actividades de AIESEC como una organización no lucrativa que fomente una nueva forma de pensamiento en los estudiantes de todo el mundo en vías de proponer una forma distinta de management con una visión mas global pero a su vez no dejando atrás el aspecto social que como se ha visto en últimos tiempos, no ha sido de interés para los gobiernos.

En los miembros se crea la idea de pertenencia a través de la ideología, ofreciéndoles una experiencia única y que de sobre manera ayudará a su formación y crecimiento personal y a su vez profesional.

Durante los acercamientos con los miembros de dichos comités fue evidente la función de la ideología ya que en las entrevistas se recalcaban la esencia del trabajo que realizan encaminándose a fortalecer a AIESEC México ante la presencia internacional, pero de manera importante no olvidar la misión de la organización, que es desarrollar a jóvenes con una visión ante el mundo distinta que les permita crecer personal y profesionalmente desarrollando una plataforma eficiente y de fácil acceso que permita coadyuvar al desarrollo de miles de jóvenes en México y en el mundo; y los fines del comité permiten la cooperación, la cohesión y la pertenencia de sus miembros hacia el comité a pesar de no percibir sueldo alguno (Entrevistas 2010-2011)

La sinergia gira entorno a la promoción y difusión de la misión de la organización y la importancia de las actividades que realizan cada uno de los miembros de los comités a través de los programas de intercambio estudiantil, ya que las relaciones de trabajo se basan en una misma ideología con tintes asistencialistas y la comparten todos los miembros del comité, lo anterior forma parte del discurso, y en vías de contribuir al conocimiento y particularidades de este tipo de organizaciones, habrá que revisar que sucede al interior del comité. 
165 
Anexo 5. Graficas de resultados de Comité UNAM. 
-OUTGOING EXCHANGE (intercambios salientes)

\begin{tabular}{|c|c|c|c|c|c|c|c|c|c|}
\hline Month & 2011 & 2011 & 2011 & 2010 & 2010 & 2010 & 2009 & 2009 & 2009 \\
\hline & $\mathrm{Re}$ & Ma & Ra & $\mathrm{Re}$ & Ma & Ra & $\mathrm{Re}$ & Ma & Ra \\
\hline January & 4 & 6 & 2 & 1 & 0 & 0 & 1 & 0 & 1 \\
\hline February & 3 & 3 & 0 & 2 & 1 & 0 & 0 & 0 & 0 \\
\hline March & 2 & 0 & 0 & 0 & 2 & 0 & 0 & 0 & 0 \\
\hline Quarter 1 & 9 & 9 & 2 & 3 & 3 & 0 & 1 & 0 & 1 \\
\hline$\%$ Growth & 200.00 & 200.00 & 200.00 & 200.00 & 300.00 & -100.00 & -50.00 & -100.00 & 0.00 \\
\hline April & 1 & 2 & 3 & 0 & 0 & 1 & 0 & 0 & 0 \\
\hline May & 0 & 0 & 0 & 1 & 0 & 2 & 1 & 1 & 2 \\
\hline June & 0 & 0 & 0 & 2 & 3 & 2 & 0 & 0 & 0 \\
\hline Quarter 2 & 1 & 2 & 3 & 3 & 3 & 5 & 1 & 1 & 2 \\
\hline$\%$ Growth & -66.67 & -33.33 & -40.00 & 200.00 & 200.00 & 150.00 & 0.00 & 0.00 & 200.00 \\
\hline July & 0 & 0 & 0 & 3 & 2 & 1 & 0 & 0 & 0 \\
\hline August & 0 & 0 & 0 & 1 & 0 & 6 & 0 & 0 & 0 \\
\hline September & 0 & 0 & 0 & 0 & 2 & 1 & 0 & 0 & 0 \\
\hline Quarter 3 & 0 & 0 & 0 & 4 & 4 & 8 & 0 & 0 & 0 \\
\hline$\%$ Growth & -100.00 & -100.00 & -100.00 & 400.00 & 400.00 & 800.00 & -100.00 & 0.00 & 0.00 \\
\hline October & 0 & 0 & 0 & 2 & 0 & 2 & 1 & 1 & 0 \\
\hline November & 0 & 0 & 0 & 0 & 0 & 1 & 0 & 0 & 1 \\
\hline December & 0 & 0 & 0 & 0 & 1 & 0 & 0 & 2 & 4 \\
\hline Quarter 4 & 0 & 0 & 0 & 2 & 1 & 3 & 1 & 3 & 5 \\
\hline$\%$ Growth & -100.00 & -100.00 & -100.00 & 100.00 & -66.67 & -40.00 & 100.00 & 200.00 & 500.00 \\
\hline Total & 10 & 11 & 5 & 12 & 11 & 16 & 3 & 4 & 8 \\
\hline$\%$ Growth & -16.67 & 0.00 & -68.75 & 300.00 & 175.00 & 100.00 & -25.00 & 33.33 & 700.00 \\
\hline
\end{tabular}


- Tabla proporcionada por presidenta de comité.

$\mathrm{Re}=$ realized (realizados)

$M a=$ matched (comprometidos)

Ra $=$ Raised (en estancia)

LC= local committee

$E P=$ exchange participant

Q1= quarter 1 (enero, febrero, marzo)

Q2 = quarter 2 (abril, mayo, junio)

Q3= quarter 3 (Julio, agosto, septiembre)

Q4= quarter 4 (octubre, noviembre, diciembre)

\section{LC UNAM: Realized EPs ( intercambios realizados) July 2009-April 2011}

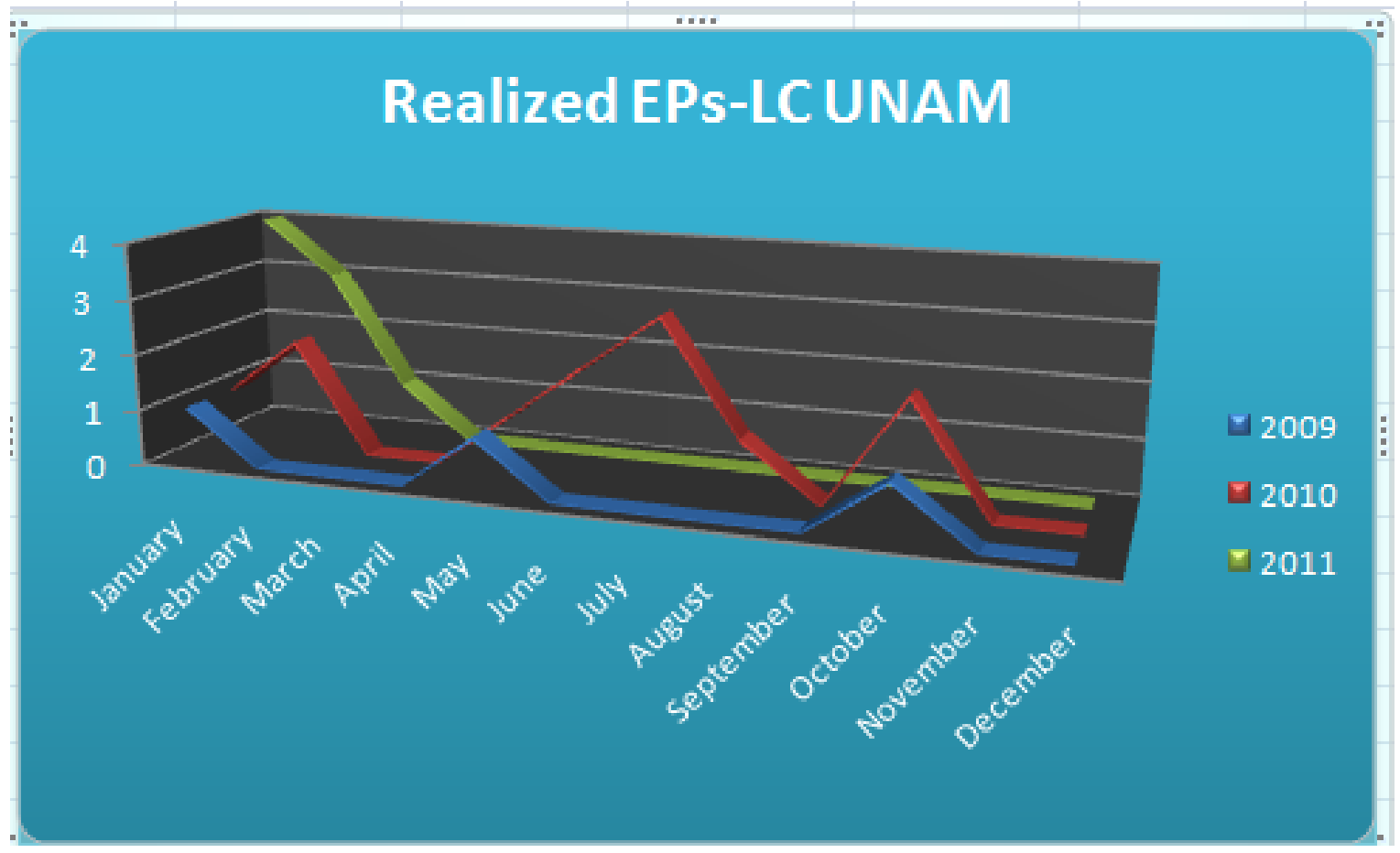


UNAM: Matched EPs

July 2009-April 2011

\section{Matched EPs-LC UNAM}

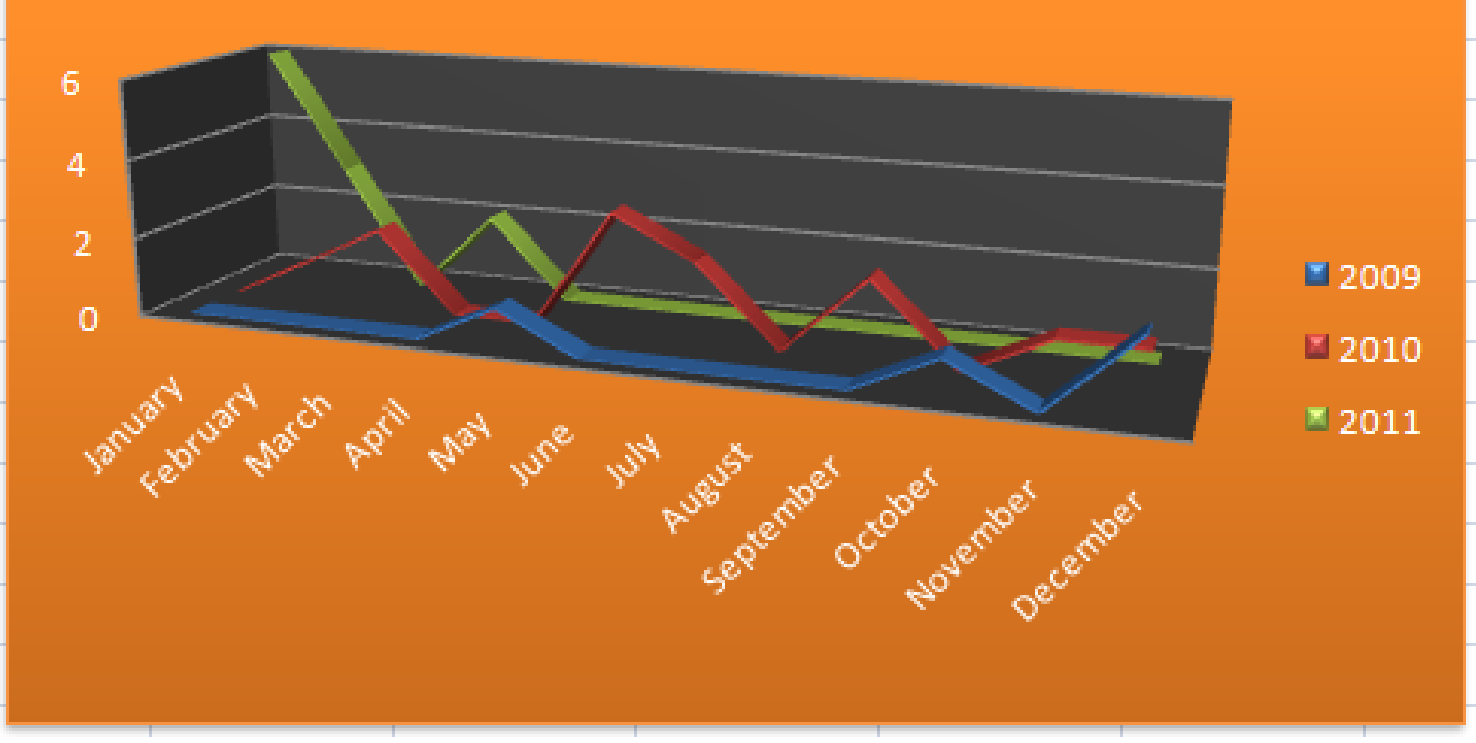

UNAM: Matched EPs

July 2009-April 2011 


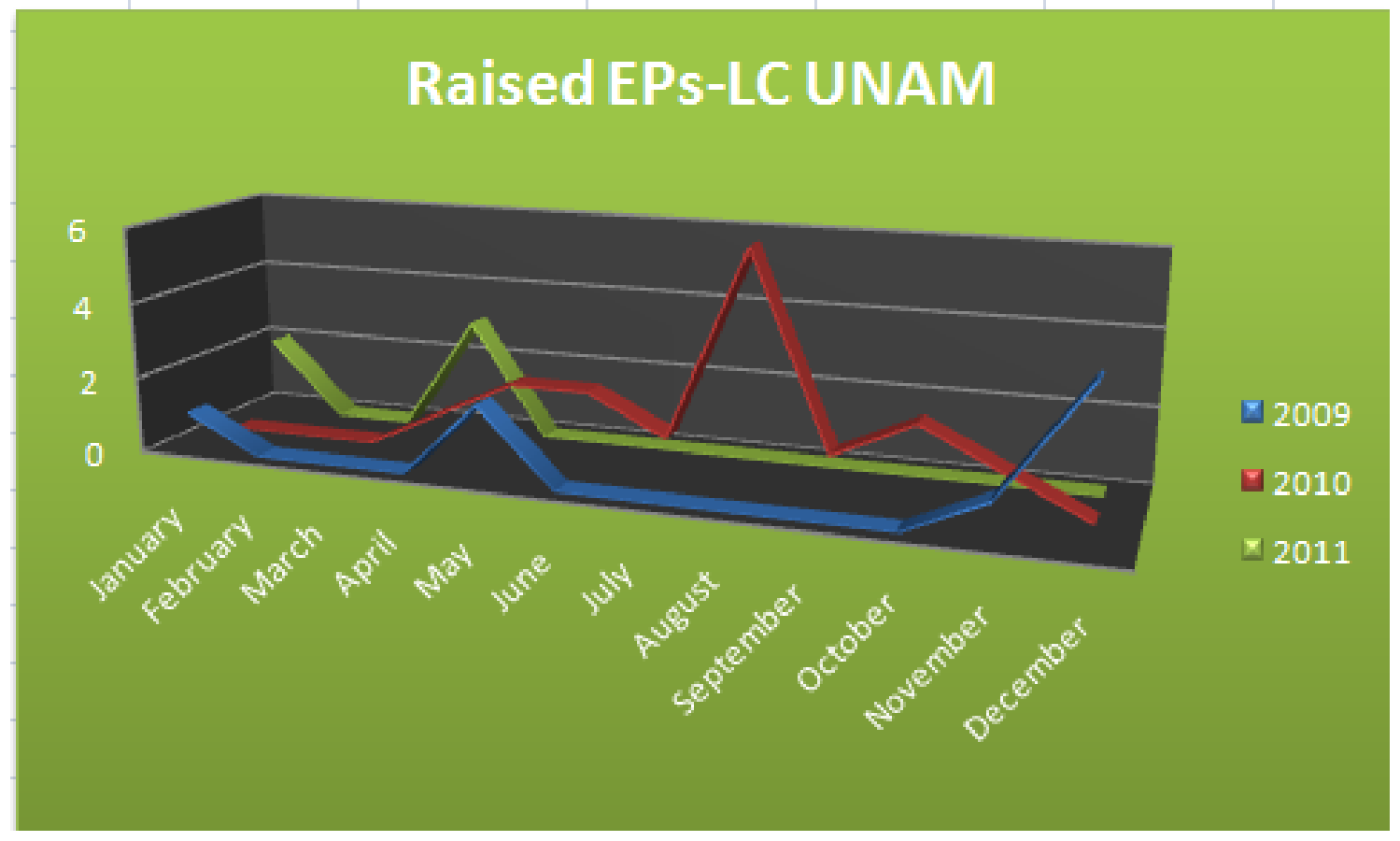

\section{Realized EP Growth percentage}

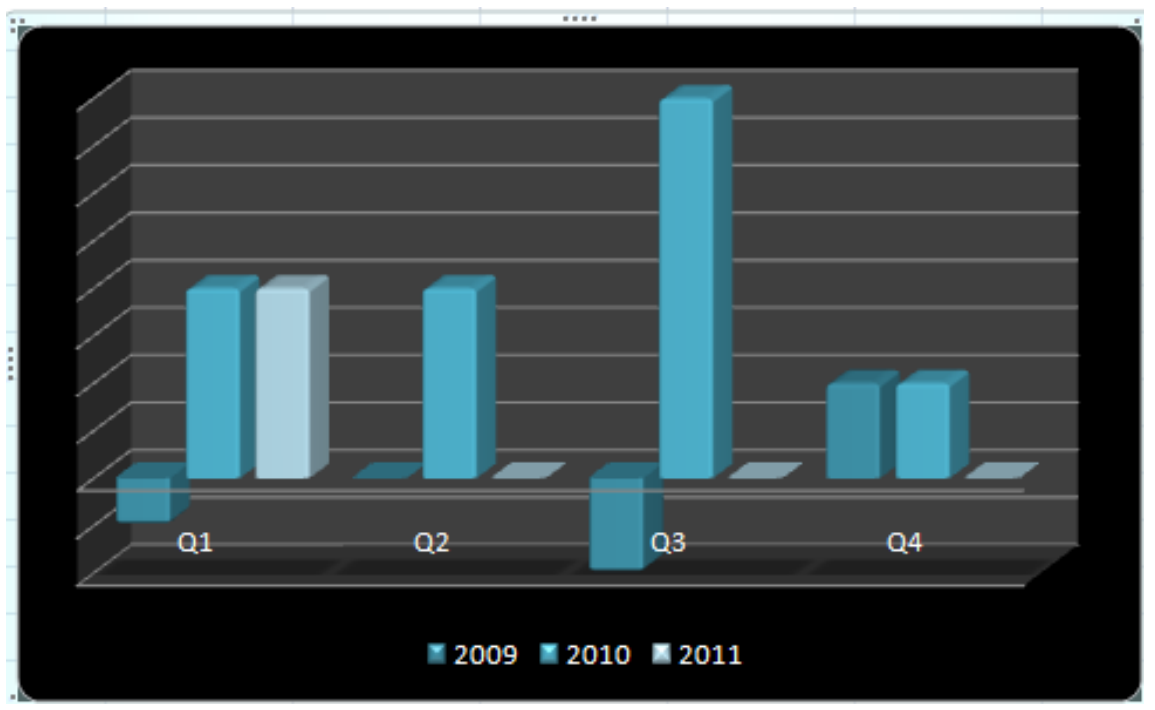

Ahora bien a fin de dar mas profundidad a la productividad del comité se muestra la siguiente tabla ${ }^{19}$ :

\footnotetext{
${ }^{19}$ Dicha tabla fue proporcionada por la presidenta del Comité UNAM, extraída de su página interna,
} INTRANET. 


\section{Comité AIESEC UNAM}

\section{Intercambios salientes}

\begin{tabular}{|l|l|l|l|l|l|l|l|l|l|l|l|l|l|l|l|l|l|l|}
\hline Month & 2011 & 2011 & 2011 & 2010 & 2010 & 2010 & 2009 & 2009 & 2009 & 2008 & 2008 & 2008 & 2007 & 2007 & 2007 & 2006 & 2006 & 2006 \\
\hline
\end{tabular} \begin{tabular}{l|l|l|l|l|l|l|l|l|l|l|l|l|l|l|l|l|l|}
$\mathrm{Re}$ & $\mathrm{Ma}$ & $\mathrm{Ra}$ & $\mathrm{Re}$ & $\mathrm{Ma}$ & $\mathrm{Ra}$ & $\mathrm{Re}$ & $\mathrm{Ma}$ & $\mathrm{Ra}$ & $\mathrm{Re}$ & $\mathrm{Ma}$ & $\mathrm{Ra}$ & $\mathrm{Re}$ & $\mathrm{Ma}$ & $\mathrm{Ra}$ & $\mathrm{Re}$ & $\mathrm{Ma}$ & $\mathrm{Ra}$ \\
\hline
\end{tabular}

\begin{tabular}{|c|c|c|c|c|c|c|c|c|c|c|c|c|c|c|c|c|c|c|}
\hline January & 4 & 6 & 2 & 1 & 0 & 0 & 1 & 0 & 1 & 1 & 0 & 0 & 0 & 0 & 1 & 0 & 1 & 1 \\
\hline February & 3 & 3 & 0 & 2 & 1 & 0 & 0 & 0 & 0 & 1 & 1 & 0 & 1 & 0 & 0 & 1 & 0 & 0 \\
\hline March & 2 & 0 & 4 & 0 & 2 & 0 & 0 & 0 & 0 & 0 & 0 & 1 & 0 & 0 & 0 & 0 & 0 & 0 \\
\hline Quarter 1 & 9 & 9 & 6 & 3 & 3 & 0 & 1 & 0 & 1 & 2 & 1 & 1 & 1 & 0 & 1 & 1 & 1 & 1 \\
\hline$\%$ Growth & 200.00 & 200.00 & 600.00 & 200.00 & 300.00 & 100.00 & -50.00 & 100.00 & 0.00 & 100.00 & 100.00 & 0.00 & 0.00 & 100.00 & 0.00 & 100.00 & 100.00 & 100.00 \\
\hline April & 1 & 2 & 5 & 0 & 0 & 1 & 0 & 0 & 0 & 0 & 0 & 0 & 0 & 2 & 2 & 2 & 1 & 1 \\
\hline May & 0 & 0 & 0 & 1 & 0 & 2 & 1 & 1 & 2 & 0 & 1 & 0 & 1 & 0 & 4 & 0 & 2 & 2 \\
\hline June & 0 & 0 & 0 & 2 & 3 & 2 & 0 & 0 & 0 & 1 & 0 & 0 & 2 & 2 & 0 & 1 & 1 & 0 \\
\hline Quarter 2 & 1 & 2 & 5 & 3 & 3 & 5 & 1 & 1 & 2 & 1 & 1 & 0 & 3 & 4 & 6 & 3 & 4 & 3 \\
\hline$\%$ Growth & -66.67 & -33.33 & 0.00 & 200.00 & 200.00 & 150.00 & 0.00 & 0.00 & 200.00 & -66.67 & -75.00 & 100.00 & 0.00 & 0.00 & 100.00 & 300.00 & 400.00 & 300.00 \\
\hline July & 0 & 0 & 0 & 3 & 2 & 1 & 0 & 0 & 0 & 0 & 0 & 0 & 1 & 1 & 1 & 1 & 0 & 0 \\
\hline August & 0 & 0 & 0 & 1 & 0 & 6 & 0 & 0 & 0 & 0 & 0 & 0 & 0 & 1 & 0 & 1 & 0 & 0 \\
\hline September & 0 & 0 & 0 & 0 & 2 & 1 & 0 & 0 & 0 & 1 & 0 & 0 & 2 & 1 & 0 & 1 & 0 & 0 \\
\hline Quarter 3 & 0 & 0 & 0 & 4 & 4 & 8 & 0 & 0 & 0 & 1 & 0 & 0 & 3 & 3 & 1 & 3 & 0 & 0 \\
\hline$\%$ Growth & 100.00 & 100.00 & 100.00 & 400.00 & 400.00 & 800.00 & 100.00 & 0.00 & 0.00 & -66.67 & 100.00 & 100.00 & 0.00 & 300.00 & 100.00 & 300.00 & 0.00 & 0.00 \\
\hline October & 0 & 0 & 0 & 2 & 0 & 2 & 1 & 1 & 0 & 0 & 0 & 0 & 1 & 1 & 0 & 0 & 0 & 1 \\
\hline November & 0 & 0 & 0 & 0 & 0 & 1 & 0 & 0 & 1 & 0 & 0 & 0 & 1 & 1 & 0 & 0 & 0 & 2 \\
\hline December & 0 & 0 & 0 & 0 & 1 & 0 & 0 & 2 & 4 & 0 & 1 & 0 & 0 & 1 & 0 & 0 & 1 & 0 \\
\hline Quarter 4 & 0 & 0 & 0 & 2 & 1 & 3 & 1 & 3 & 5 & 0 & 1 & 0 & 2 & 3 & 0 & 0 & 1 & 3 \\
\hline$\%$ Growth & 100.00 & 100.00 & 100.00 & 100.00 & -66.67 & -40.00 & 100.00 & 200.00 & 500.00 & 100.00 & -66.67 & 0.00 & 200.00 & 200.00 & 100.00 & 0.00 & 100.00 & 300.00 \\
\hline Total & 10 & 11 & 11 & 12 & 11 & 16 & 3 & 4 & 8 & 4 & 3 & 1 & 9 & 10 & 8 & 7 & 6 & 7 \\
\hline$\%$ Growth & -16.67 & 0.00 & -31.25 & 300.00 & 175.00 & 100.00 & -25.00 & 33.33 & 700.00 & -55.56 & -70.00 & -87.50 & 28.57 & 66.67 & 14.29 & 700.00 & 600.00 & 700.00 \\
\hline
\end{tabular}

\section{Intercambios entrantes}

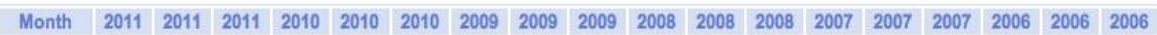
\begin{tabular}{|l|l|l|l|l|l|l|l|l|l|l|l|l|l|l|l|l|l|}
\hline $\mathrm{Re}$ & $\mathrm{Ma}$ & $\mathrm{Ra}$ & $\mathrm{Re}$ & $\mathrm{Ma}$ & $\mathrm{Ra}$ & $\mathrm{Re}$ & $\mathrm{Ma}$ & $\mathrm{Ra}$ & $\mathrm{Re}$ & $\mathrm{Ma}$ & $\mathrm{Ra}$ & $\mathrm{Re}$ & $\mathrm{Ma}$ & $\mathrm{Ra}$ & $\mathrm{Re}$ & $\mathrm{Ma}$ & $\mathrm{Ra}$ \\
\hline
\end{tabular}

\begin{tabular}{|c|c|c|c|c|c|c|c|c|c|c|c|c|c|c|c|c|c|c|}
\hline January & 2 & 2 & 0 & 0 & 0 & 0 & 0 & 0 & 0 & 0 & 0 & 0 & 1 & 0 & 0 & 0 & 0 & 1 \\
\hline February & 2 & 0 & 0 & 0 & 0 & 0 & 0 & 0 & 0 & 0 & 0 & 0 & 0 & 0 & 0 & 1 & 1 & 0 \\
\hline March & 0 & 0 & 2 & 0 & 0 & 1 & 0 & 1 & 0 & 0 & 0 & 1 & 1 & 1 & 0 & 1 & 2 & 2 \\
\hline Quarter 1 & 4 & 2 & 2 & 0 & 0 & 1 & 0 & 1 & 0 & 0 & 0 & 1 & 2 & 1 & 0 & 2 & 3 & 3 \\
\hline$\%$ Growth & 400.00 & 200.00 & 100.00 & 0.00 & 100.00 & 100.00 & 0.00 & 100.00 & 100.00 & 100.00 & 100.00 & 100.00 & 0.00 & -66.67 & 100.00 & 200.00 & 300.00 & 300.00 \\
\hline April & 0 & 0 & 5 & 0 & 0 & 1 & 1 & 0 & 0 & 0 & 0 & 0 & 0 & 2 & 1 & 3 & 1 & 0 \\
\hline May & 0 & 1 & 0 & 0 & 0 & 1 & 0 & 0 & 1 & 0 & 0 & 0 & 3 & 2 & 2 & 2 & 2 & 1 \\
\hline June & 0 & 0 & 0 & 1 & 1 & 0 & 1 & 1 & 0 & 0 & 1 & 1 & 1 & 0 & 0 & 0 & 0 & 2 \\
\hline Quarter 2 & 0 & 1 & 5 & 1 & 1 & 2 & 2 & 1 & 1 & 0 & 1 & 1 & 4 & 4 & 3 & 5 & 3 & 3 \\
\hline$\%$ Growth & 100.00 & 0.00 & 150.00 & -50.00 & 0.00 & 100.00 & 200.00 & 0.00 & 0.00 & 100.00 & -75.00 & -66.67 & -20.00 & 33.33 & 0.00 & 500.00 & 300.00 & 300.00 \\
\hline July & 0 & 0 & 0 & 0 & 2 & 2 & 0 & 0 & 0 & 2 & 1 & 0 & 0 & 1 & 0 & 0 & 1 & 1 \\
\hline August & 0 & 0 & 0 & 0 & 1 & 0 & 0 & 0 & 1 & 0 & 0 & 0 & 0 & 0 & 0 & 1 & 0 & 0 \\
\hline September & 0 & 0 & 0 & 3 & 0 & 0 & 1 & 1 & 0 & 0 & 0 & 0 & 0 & 0 & 0 & 0 & 0 & 0 \\
\hline Quarter 3 & 0 & 0 & 0 & 3 & 3 & 2 & 1 & 1 & 1 & 2 & 1 & 0 & 0 & 1 & 0 & 1 & 1 & 1 \\
\hline$\%$ Growth & 100.00 & 100.00 & 100.00 & 200.00 & 200.00 & 100.00 & -50.00 & 0.00 & 100.00 & 200.00 & 0.00 & 0.00 & 100.00 & $0^{0.00}$ & 100.00 & 100.00 & 100.00 & 100.00 \\
\hline October & 0 & 0 & 0 & 0 & 0 & 0 & 0 & 0 & 0 & 0 & 0 & 0 & 2 & 0 & 0 & 0 & 1 & 0 \\
\hline November & 0 & 0 & 0 & 1 & 2 & 3 & 0 & 0 & 0 & 0 & 0 & 0 & 0 & 0 & 0 & 0 & 0 & 0 \\
\hline December & 0 & 0 & 0 & 2 & 3 & 4 & 0 & 0 & 0 & 0 & 0 & 0 & 0 & 0 & 1 & 0 & 1 & 1 \\
\hline Quarter 4 & 0 & 0 & 0 & 3 & 5 & 7 & 0 & 0 & 0 & 0 & 0 & 0 & 2 & 0 & 1 & 0 & 2 & 1 \\
\hline$\%$ Growth & 100.00 & 100.00 & 100.00 & 300.00 & 500.00 & 700.00 & 0.00 & 0.00 & 0.00 & 100.00 & 0.00 & 100.00 & 200.00 & 100.00 & 0.00 & 0.00 & 200.00 & 100.00 \\
\hline & 4 & 3 & 7 & 7 & 9 & 12 & 3 & 3 & 2 & 2 & 2 & 2 & 8 & 6 & 4 & 8 & 9 & 8 \\
\hline
\end{tabular}

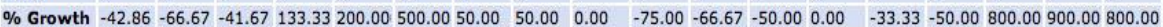

Fuente: Documentos internos Comité UNAM. 
